January 2021

"Labor leverage, coordination failures, and aggregate risk"

Matthieu Bouvard, Adolfo de Motta 


\title{
Labor leverage, coordination failures, and aggregate risk *
}

\author{
Matthieu Bouvard ${ }^{\mathrm{a}}$, Adolfo de Motta ${ }^{\mathrm{b}, *}$ \\ ${ }^{a}$ Toulouse School of Economics, Université Toulouse Capitole (TSM-Research), Toulouse 31000, France \\ ${ }^{b}$ Desautels Faculty of Management, McGill University, Montreal, QC H3A 1G5, Canada
}

\begin{abstract}
This paper studies an economy where demand spillovers make firms' production decisions strategic complements. Firms choose their operating leverage trading off higher fixed costs for lower variable costs. Operating leverage governs firms' exposures to an aggregate labor productivity shock. In equilibrium, firms exhibit excessive operating leverage as they do not internalize that an economy with higher aggregate operating leverage is more likely to fall into a recession following a negative productivity shock. Welfare losses coming from firms' failure to coordinate production are amplified by suboptimal risk-taking, which magnifies
\end{abstract} the impact of productivity shocks onto aggregate output.

Keywords: Operating leverage; Labor leverage; Coordination failure; Global games; Aggregate risk.

JEL classification: D24; D62; G01; E32

${ }^{\star}$ We thank Patrick Augustin, Laurent Barras, Bruno Biais, Mattia Girotti, Philipp Koenig, Thomas Rivera, Jean-Charles Rochet, and David Schumacher for their helpful input. We also thank participants to the 2018 Paris Finance conference, to the 2019 EFA conference, and to seminars at HEC Paris, McGill University, Oxford University, University of Bristol, University of Texas at Dallas, University of Exeter, INSEAD, Toulouse School of Economics, EPFL, and University of Minnesota for their helpful comments. We thank the Montreal Institute of Structured Finance and Derivatives for their financial support. The Montreal Institute of Structured Finance and Derivatives was not involved in the writing of the report or in the decision to submit the article for publication. Matthieu Bouvard acknowledges funding from ANR under grant ANR-17-EURE-0010 (Investissements d'Avenir program).

${ }^{*}$ Corresponding author. Tel.: +1 5143984029 E-mail address: adolfo.demotta@mcgill.ca. 


\section{Introduction}

Labor leverage is a first-order determinant of firms' risk as it creates a rigid cost structure that cannot be easily adjusted to demand shocks. For instance, Danthine and Donaldson (2002) note that the obligations originated by firms' labor force dwarf their financial obligations and provide evidence consistent with labor leverage generating undiversifiable risk. A subsequent stream of literature in asset pricing (e.g., Merz and Yashiv, 2007; Donangelo, Gourio, Kehrig, and Palacios, 2019; and Faviloukis, Lin, and Zhao, 2020) has shown that labor leverage has explanatory power in the pricing of equity and debt, both in the cross-section and in aggregate. In this paper, we endogenize firms' labor leverage decisions and study how these firm-level choices compound into aggregate risk. Specifically, labor leverage affects the likelihood that the economy falls into a Pareto-inferior equilibrium in which output is depressed and welfare is low. These episodes of coordination failure are interpreted as economic crises, in line with a long tradition in economics. While these crises are self-fulfilling in nature, the global games approach (e.g., Morris and Shin, 2000) suggests that their occurrence is anchored to fundamentals through firms' exposure to a common productivity shock. We illustrate how this transmission channel operates through labor leverage and evaluate its implications for the risk of recessions and more broadly for welfare.

We consider an imperfectly competitive economy with aggregate demand spillovers as in Murphy, Shleifer, and Vishny (1989). The economy is populated by consumers who supply labor to firms in different sectors. Labor is subject to a productivity shock, which is the only 
source of risk in this economy. Firms are collectively owned by consumers and use labor as their sole input to produce final goods. Each sector has a competitive fringe of firms with a constant returns to scale technology and a unique large firm with an increasing returns to scale technology. Increasing returns to scale generates strategic complementarities across sectors: higher profits in one firm trickle down to consumers and stimulate their demand for goods in other sectors. Higher demand, in turn, allows firms in other sectors to leverage their increasing returns to scale technologies and increase their own profits.

Importantly, we allow large firms to adjust their cost structure ex ante. For instance, in Chaney and Ossa (2013), firms organize production by choosing their division of labor, which trades off fixed versus marginal costs. A greater division of labor is associated to higher labor leverage. We interpret labor leverage as an enduring technological and organizational choice, consistent with the idea that adjustments to the size and structure of the labor force within a firm requires time and involves sizeable costs. More specifically, at the initial date, each firm chooses its labor leverage, trading off higher fixed labor costs for lower variable labor costs. Labor leverage determines the exposure of a firm's profits to the aggregate productivity shock. On the one hand, when demand is high, a firm benefits from higher leverage as it can produce at a lower average cost. On the other hand, higher leverage, by raising fixed labor costs, makes a firm more vulnerable to a drop in demand. At that final date, the productivity shock is realized and large firms set prices to maximize profits given the threat from the competitive fringe. A firm, however, retains the option to leave the market following a negative productivity shock if it expects demand to be insufficient 
to cover its fixed costs.

Finally, we assume that tasks in large firms are subject to moral hazard. This is consistent with the idea that in larger and more complex organizations, information frictions create room for opportunistic behavior. Similar to Murphy, Shleifer, and Vishny (1989), it is the combination of demand externalities and this labor friction that ultimately creates scope for coordination failures. Specifically, the presence of moral hazard requires large firms to pay a premium over the wage in the competitive fringe, and these firms fail to internalize the demand spillovers that higher wages have on the rest of the economy. As a result, in the final date, the economy can be trapped in an equilibrium in which large firms exit and output is inefficiently low.

The main contribution of the paper is to show that coordination failures at the production stage contaminate ex ante risk-taking decisions and generate excessive labor leverage in aggregate. We derive this result in two steps. First, we study production decisions at the final date and show that when labor productivity falls below a threshold, coordination motives generate a sharp transition from a Pareto-optimal production outcome in which large firms reap the benefits of increasing returns to scale, to a Pareto-inferior outcome in which large firms cease to operate. Importantly, we also show that this endogenous operating threshold is higher when firms' aggregate labor leverage increases, that is, an increase in labor leverage increases the likelihood of a coordination failure.

We then turn to ex ante labor leverage decisions. When setting their labor leverages, firms take into account their option to cease operations when demand is low. Because of 
this option, firms optimize leverage over the states in which they anticipate being active. Coordination problems make it less likely for large firms to survive a bad productivity shock, which tilts each firm's optimization program towards higher-productivity states. In these states, the return to labor leverage is higher, so that aggregate labor leverage rises when the production-stage coordination problem worsens. We show that the equilibrium labor leverage is constrained inefficient: a social planner that takes the production-stage equilibrium as given could increase welfare by forcing all firms to lower their labor leverage. The welfare loss caused by excess labor leverage occurs through a shift of the output distribution towards high-productivity states that comes at the cost of higher downside risk and lower expected output. Intuitively, each firm chooses its labor leverage taking the aggregate labor leverage as given. Hence, firms do not internalize that their collective decision to increase labor leverage raises the coordination threshold, making it more likely that the economy coordinates on a Pareto-inferior regime with depressed output.

The excessive labor leverage is inherently related to the existence of a coordination failure. To formally make this point, we also study a case without coordination failures, that is, a case in which we allow firms to coordinate on the Pareto-superior equilibrium at the production stage. As mentioned earlier, atomistic firms do not internalize that a collective decrease in leverage would widen the range of states in which production takes place. However, when firms coordinate on the Pareto-superior equilibrium, production decisions are optimal ex post and hence, the social value of producing in the marginal state (at the production threshold) is exactly zero. Therefore, a marginal decrease in aggregate labor leverage would 
extend production to a state where it brings no social value. In that case, the equilibrium leverage is constrained efficient. By contrast, when there is a coordination failure at the production stage, there exists a region just below the production threshold where the net value of all firms switching from inaction to production is strictly positive.

Our paper builds on a stream of literature in economics that grounds low aggregate output realizations into coordination failures. (See Diamond, 1982; Hart, 1982; and Weitzman, 1982, for early contributions.) Cooper and John (1988) provide a general framework to analyze economies in which agents' actions are strategic complements. In our paper, demand complementarities originate from a combination of imperfect competition and increasing returns to scale technologies as in Shleifer and Vishny (1988), Kiyotaki (1988) and Murphy, Shleifer, and Vishny (1989). Lamont (1995) shows that coordination failures arise with imperfect competition but constant returns to scale economy when firms can suffer from debt overhang. The common feature in these papers is the existence of multiple self-fulfilling equilibria that can be Pareto-ranked. While this illustrates how economies can be trapped into inferior low-output equilibria, equilibrium indeterminacy precludes a meaningful analysis of firms' ex ante risk-exposure decisions, the objective of our paper.

To overcome this problem, we take advantage of global games techniques. As shown in Carlsson and Van Damme (1993), introducing dispersed information in games of strategic complementarities can lead to a unique equilibrium prediction pinned down by the realization of an underlying economic fundamental. Chamley (1999) and Bebchuk and Goldstein (2011) use this insight to study economies in which agents' investment decisions exhibit a generic 
form of complementarity. Schaal and Taschereau-Dumouchel (2018) introduce global games in a dynamic model with demand complementarities and show how transitory shocks can trigger long-lasting periods of depressed investment and recession. Guimaraes and Morris (2008) show that risk-averse agents' exposures to an underlying source of risk affect the outcome of the coordination game they play. Our contribution to this body of literature is to endogenize risk-taking; that is, agents' exposures to the underlying common risk factor.

Our paper is also related to the literature on operating leverage and firms' risk initiated by Lev (1974). More specifically, a stream of papers in finance focuses on labor leverage, building on the premise that labor is the main fixed component of firms' cost structures. Danthine and Donaldson (2002) note that labor generates obligations for firms that are of an order of magnitude greater than their financial obligations, and that the labor share is countercyclical. These empirical observations motivate a general equilibrium model in which labor leverage creates nondiversifiable risk for equity holders. Subsequent papers have shown labor leverage to be positively related to CAPM beta, stock volatility, credit risk, and procyclicality of profits in a cross-section of firms. (See, for instance, Donangelo, Gourio, Kehrig, and Palacios, 2019 and Faviloukis, Lin, and Zhao, 2020.) Merz and Yashiv (2007) show that the shape and magnitude of labor adjustment costs effectively makes hiring conceptually similar to an investment. These empirical findings lend support to the mechanism at play in the model where operating leverage is driven by labor costs and constitutes a structural long-term choice that affects a firm's exposure to aggregate risk.

Finally, there is a large body of literature that studies the relation between financial 
frictions and economic crises. (See, for instance, Bernanke and Gertler, 1989; Kiyotaki and Moore, 1997; Lorenzoni, 2008; Gorton and Ordoñez, 2014; and He and Kondor, 2016.) This literature highlights the role of financial frictions (e.g., credit constraints arising from contract incompleteness) in generating and amplifying crises. While the role of financial leverage in economic crises has been extensively studied, the role of operating leverage has received less attention. This is despite the fact that financial distress is typically preceded by economic distress, and despite the importance of firms' non-financial obligations in comparison to their financial obligations. For instance, according to the Bureau of Economic Analysis, employee compensation for US non-financial corporations in 2018, $\$ 5,946$ billions, amounted to 17 times their net interest payments, $\$ 33$ billions. The nature of operating leverage and financial leverage are also markedly distinct: firms may change their capital structure by going to the capital market or through renegotiation, whereas operating leverage is a structural choice that cannot be adjusted in the short run. Moreover, firms can use financial markets to hedge against the costs associated to financial risk. In contrast, financial markets are of limited use in managing operating risk as hedging does not change the cost structure and therefore, whether firms create or destroy value. Our paper suggests that these fundamental technological and organizational choices at the firm level can have outsized aggregate effects in economies subject to coordination failures. 


\section{Model}

We consider a unit interval of identical consumers with a utility function $\exp \left[\int_{0}^{1} \ln x(q) d q\right]$ defined over a unit interval of goods indexed by $q$. Each consumer is endowed with $L$ units of labor that he supplies inelastically, so $L$ is also the total amount of labor in the economy. $L$ is drawn from a uniform distribution over $[0, \bar{L}]$, and the realization of $L$ is interpreted as an economy-wide labor productivity shock, the only source of risk in this economy. To ensure the existence of equilibria in which agents' optimization problems have interior solutions, we take the upper bound, $\bar{L}$, to be large enough, in a sense we make precise in the Appendix (for most results, $\bar{L}>2$ ).

Each good $q$ is produced by a sector, and each sector consists of two types of firms. A competitive fringe of firms with a constant returns to scale technology in which one unit of output requires one unit of labor, and a unique firm, a monopolist, with access to an increasing returns to scale technology. To produce, monopolist $q$ incurs a fixed cost of $F\left(s_{q}\right)=\frac{s_{q}}{\alpha-s_{q}}$ units of labor and a constant marginal cost of $\alpha-s_{q}$ units of labor per unit of output. We assume $\alpha<1$, and take $s_{q} \in[0, \alpha]$ to be a choice variable that captures operating leverage: by increasing $s_{q}$, monopolist $q$ reduces its marginal labor cost $\alpha-s_{q}$ at the expense of inflating its fixed labor cost $F\left(s_{q}\right) .{ }^{1}$ The model is closed by assuming that consumers own all the profits and that each firm maximizes expected profits where the

\footnotetext{
${ }^{1}$ The optimization problem with respect to operating leverage $s_{q}$, which we study below, is not convex so local conditions are not sufficient for global optimality. The convex function we choose for $F\left(s_{q}\right)$ provides the necessary analytical tractability for studying large deviations to determine existence. However, as Proposition 10 in Section 5.3 shows, the economic intuitions of the paper hold for any generic increasing and convex function.
} 
workers' wage per unit of labor is taken as the numeraire. ${ }^{2}$

Consistent with the literature on labor leverage surveyed in the introduction, we interpret leverage $s_{q}$ as a structural, long-term choice that regulates monopolist $q$ 's cost structure in future production periods. As originally illustrated by Adam Smith's famous pin factory example, a key decision in the organization of production is the division of labor, which he argued to be limited by the market size. Chaney and Ossa (2013) provide a formalization of Adam Smith's argument. In their model, firms choose their division of labor trading off fixed and marginal costs. Specifically, a greater number of teams, which would allow for a greater division of labor, is associated with higher fixed costs but lower marginal costs. (Each team bears a fixed cost but having more teams allows each team to perform a narrower range of tasks around a core competency.) As the expected size of the market increases, firms choose a greater division of labor, that is, a production technology with higher operating leverage.

To capture the enduring quality of these long-term technological and organizational choices and therefore, that firms cannot respond to a productivity shock by swiftly changing their production technologies, we assume that each monopolist $q$ chooses $s_{q}$ at $t=0$, before the realization of the productivity shock and the production decisions at $t=1$. At $t=1$, the final period, $L$, is realized, and all firms decide how much to produce and at which price to sell. Note that monopolist $q$ may decide not to produce upon learning $L$. In that case,

\footnotetext{
${ }^{2}$ Utility function $\exp \left[\int_{0}^{1} \ln x(q) d q\right]$ ensures that consumers' marginal utility of income is constant across states and hence, that consumers behave as risk-neutral vis-à-vis aggregate uncertainty. Consequently, maximizing expected profits is equivalent to maximizing firm value. We can also take the wage per unit of labor as the numeraire because, as will become clear below, the real wage is constant across realizations of the aggregate shock $L$.
} 
it saves the fixed cost $F\left(s_{q}\right)$, but abandons production in sector $q$ to the competitive fringe. Hence, labor cost $F\left(s_{q}\right)$ is fixed rather than sunk as, for instance, in Maskin and Tirole (1988): "Fixed costs (measured as a flow) persist only as long as production continues, but are, strictly speaking, independent of scale. Pure sunk costs . . . are incurred with or without production." Therefore, the irreversibility in the model is in the labor leverage choice, $s_{q}$, that is, in the firm's choice of its technology.

Finally, we assume that production by monopolists requires monitoring that needs to be incentivized. Specifically, a subset of the workers hired by each monopolist performs supervisory functions, where each supervisor is responsible for a share of the firm's production. If a supervisor exerts monitoring effort, each unit produced under his supervision is functional, but he incurs a personal cost $\beta$ per unit. ${ }^{3}$ If a supervisor does not exert effort, units are defective and worthless to consumers. Quality is contractible, and we assume that $\alpha+\beta<1$, so that the overall marginal cost is still lower when a monopolist produces than when the competitive fringe does. This specification is consistent with monopolists being larger, more sophisticated organizations in which division of labor and information frictions require supervisory tasks of a different nature than the tasks required in small fringe firms. For instance, Garicano and Van Zandt (2012) reviews a body of literature in which hierarchies and division of labor jointly emerge as a response to costly information processing. This monitoring friction is also isomorphic to the assumption in Murphy,

\footnotetext{
${ }^{3}$ Having a cost of effort proportional to production ensures that only aggregate effort within a firm, rather than the mass of supervisors or the scope of their assignments, matters.
} 
Shleifer, and Vishny (1989) who posit that workers experience a disutility when working for monopolist firms rather than for firms in the competitive fringe, as we discuss in Section 5.1. The disutility in Murphy, Shleifer, and Vishny (1989) is in the spirit of Rosenstein-Rodan (1943), capturing the idea that to bring farm laborers to work in a factory, a firm must pay them a wage premium. While their specification is tailored to developing economies where a "big push" can jump-start development, our specification has a more natural interpretation in developed economies where business cycles are amplified by coordination failures. As in Murphy, Shleifer, and Vishny (1989), the role of this assumption is to generate equilibrium multiplicity and the possibility of a coordination failure at the production stage. This allows us to study the relation between coordination failures in production at $t=1$ and risk-taking decisions at $t=0$, the objective of this paper. As will become clear below (Proposition 4), our results are not related to the monitoring friction per se, but to the possibility of a coordination failure.

Fig. 1 below illustrates the timing of events. Notice that production only takes place at $t=1$, after the realization of the productivity shock $L$. A setup in which firms produce both at $t=0$ and at $t=1$ would produce qualitatively similar results, provided that monopolists cannot change their chosen technologies between the two periods. (See the Online Appendix for such case.) In other words, what is important for our results is that monopolists cannot respond to the productivity shock by quickly changing their production technologies at $t=1$; that is, that firms' technological and organizational choices are long lasting. As we will show, this causes monopolists' choices of operating leverage ex ante $(t=0)$ to affect the 
probability of a coordination failure ex post $(t=1)$.

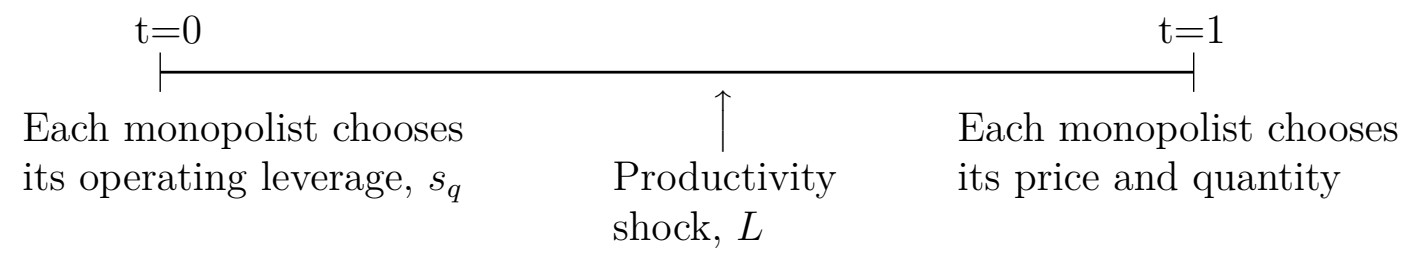

Fig. 1. Timing of events

\section{Coordination failures and excess operating leverage}

\subsection{Demand externalities and equilibrium multiplicity}

The analysis of the final period $(t=1)$ is analogous to the one in Murphy, Shleifer, and Vishny (1989). A reader familiar with their analysis could jump to Lemma 1 below, which summarizes a result equivalent to the one in their paper, and which we take as a building block.

Each consumer buys the consumption basket $\{x(q)\}_{q \in[0,1]}$ that maximizes his utility given prices $\{p(q)\}_{q \in[0,1]}$ and his available income $y$ :

$$
\max _{\{x(q)\}_{q \in[0,1]}} \exp \left[\int_{0}^{1} \ln x(q) d q\right] \text { s.t. } \int_{0}^{1} p(q) x(q)=y
$$

At optimum, consumers spend equally on each good, that is, they buy quantity $x(q)=\frac{y}{p(q)}$ of $\operatorname{good} q$. 
Monopolist $q$ sets price $p(q)$ to maximize profit given demand

$$
x(q)= \begin{cases}\frac{y}{p(q)} & \text { if } p(q) \leq 1, \\ 0 & \text { if } p(q)>1 .\end{cases}
$$

Note that the monopolist is priced out if it sets $p(q)>1$ : since the competitive fringe can produce one unit of good $q$ with one unit of labor whose wage is the numeraire, the price in the competitive fringe is equal to one. Given the demand function in Eq. (2), if monopolist $q$ is active, it sets the highest price that generates a positive demand, $p(q)=1$, and produces $x(q)=y$ units of output. Because monitoring requires effort, supervisors have to be paid a premium over the wage in the competitive fringe. Since quality is contractible, and since the probability of producing a functional unit without monitoring effort is zero, promising a bonus $\beta$ conditional on delivering a functioning unit is sufficient to incentivize monitoring, and only compensates the supervisor for his monitoring cost. The profit of an active monopolist, given that $p(q)=1$ and $x(q)=y$, is then

$$
\pi_{q}=\left(1-\beta-\alpha+s_{q}\right) y-F\left(s_{q}\right)
$$

Monopolist $q$ is active when $\pi_{q} \geq 0$. Consumption and production decisions endogenously determine aggregate income at $t=1$. Specifically, aggregate income, or equivalently, aggre- 
gate output, is the sum of corporate profits and labor income,

$$
y=\int_{q \in \mathcal{A}}\left[\left(1-\beta-\alpha+s_{q}\right) y-F\left(s_{q}\right)\right] d q+L+\int_{q \in \mathcal{A}} \beta y d q,
$$

where $\mathcal{A} \subset[0,1]$ is the set of sectors in which a monopolist is active at $t=1$. From Eq. (4), monitoring does not affect aggregate income $y$ for a given set of active monopolists $\mathcal{A}$ : monitoring reduces the profit of each active monopolist by $\beta y$ but increases labor income by the same amount. Rearranging Eq. (4) we obtain

$$
y=\frac{L-\int_{q \in \mathcal{A}} F\left(s_{q}\right) d q}{1-\int_{q \in \mathcal{A}}\left[1-\alpha+s_{q}\right] d q} .
$$

From Eq. (5), we can derive the marginal impact on output $y$ of monopolist $i$ joining the set of active monopolists $\mathcal{A}:^{4}$

$$
d y=\frac{\pi_{i}(y)+\beta y}{1-\int_{q \in \mathcal{A}}\left[1-\alpha+s_{q}\right] d q} d i
$$

This expression captures an important intuition for production decisions at $t=1$ : the contribution of the marginal active monopolist $i$ to output is that monopolist's profit $\pi_{i}(y)$ plus the paid wage premium $\beta y$ amplified by a multiplier $\left(1-\int_{q \in \mathcal{A}} 1-\alpha+s_{q} d q\right)^{-1}$, which is

\footnotetext{
${ }^{4}$ Assume a mass $n$ of monopolists with the same leverage $s_{i}$ become active, in addition to $\mathcal{A}$. Then Eq. (5) becomes $y(n) \equiv \frac{L-\int_{q \in \mathcal{A}} F\left(s_{q}\right) d q-n F\left(s_{i}\right)}{1-\int_{q \in \mathcal{A}} 1-\alpha+s_{q} d q-n\left(1-\alpha+s_{i}\right)}$, and Eq. (6) is just $y^{\prime}(0)$ where we use Eq. (4) to simplify the expression.
} 
strictly greater than one as long as the set of active monopolists $\mathcal{A}$ has a positive mass. This multiplier captures a demand externality: when $\pi_{i}(y)+\beta y$ is positive, the profit and the wage premium stimulates demand for other goods, which allows other active monopolists to take advantage of their increasing returns to scale technologies and increase their own profits.

Note that monopolist $i$, by becoming active, generates $\beta y$ as compensation for the supervisors' monitoring cost, in addition to profit $\pi_{i}(y)$. Factoring in this monitoring cost $\beta y$ in Eq. (6), the net impact of monopolist $i$ 's decision to become active on consumers' utility is

$$
\frac{\pi_{i}(y)+\beta y}{1-\int_{q \in \mathcal{A}}\left[1-\alpha+s_{q}\right] d q}-\beta y
$$

This expression shows how the demand multiplier $\left(1-\int_{q \in \mathcal{A}} 1-\alpha+s_{q} d q\right)^{-1}$ and the monitoring cost $\beta y$ combine to create a wedge between private and social incentives. The sign of a monopolist's profit $\pi_{i}(y)$ and the sign of its impact on welfare (i.e., the sign of Eq. (7)) coincide if there is no multiplier (i.e., $\mathcal{A}=\{\emptyset\}$ so $\left.\left(1-\int_{q \in \mathcal{A}} 1-\alpha+s_{q} d q\right)^{-1}=1\right)$ in which case Eq. (7) reduces to $\pi_{i}(y)$. The misalignment of private and social incentives arises when $\beta>0$ and a strictly positive mass of monopolists is active. In that case, monopolist $i$ internalizes the monitoring cost $\beta y$ through the wage premium it pays, but not the multiplier effect of that additional compensation on the demand to other active monopolists $\mathcal{A}$. Specifically, if $\pi_{i}(y)<0<\left(\pi_{i}(y)+\beta y\right)\left(1-\int_{q \in \mathcal{A}} 1-\alpha+s_{q} d q\right)^{-1}-\beta y$, it is individually optimal for monopolist $i$ to leave the market, yet its net effect on consumers' utility if it were to produce 
would be positive (i.e., Eq. (7) would be greater than zero).

This misalignment creates scope for coordination failures. Consider the case in which all monopolists choose the same operating leverage $s$ at $t=0$. Then, combining Eq. (3) and Eq. (4), a monopolist does not operate if no other monopolist operates (if $\mathcal{A}=\{\emptyset\}$ ) when

$$
L<\frac{F(s)}{1-\alpha-\beta+s} .
$$

Conversely, a monopolist operates if all other monopolists operate (if $\mathcal{A}=[0,1]$ ) when

$$
L>\frac{(1-\beta) F(s)}{1-\alpha-\beta+s}
$$

Therefore, if

$$
L \in\left(\frac{(1-\beta) F(s)}{1-\alpha-\beta+s}, \frac{F(s)}{1-\alpha-\beta+s}\right),
$$

a high-output equilibrium in which all monopolists are active coexists with a low-output equilibrium in which the fringe takes over production. That second equilibrium is Paretodominated and embodies a coordination failure: each monopolist does not internalize that its individual decision to produce and pay a wage premium increases demand and hence, the other monopolists' profits from producing. We summarize this discussion in the next lemma.

Lemma 1. If all monopolists choose the same operating leverage at $t=0$, then at $t=1:(i)$ if $L>\frac{F(s)}{1-\alpha-\beta+s}$, all monopolists operate; (ii) if $L<\frac{(1-\beta) F(s)}{1-\alpha-\beta+s}$, no monopolist operates; and (iii) if $L \in\left(\frac{(1-\beta) F(s)}{1-\alpha-\beta+s}, \frac{F(s)}{1-\alpha-\beta+s}\right)$, there is one equilibrium in which all monopolists operate 
and another Pareto-dominated equilibrium in which no monopolist operates.

\subsection{Global games and the production threshold}

While the presence of multiple equilibria captures the idea of a coordination failure, the indeterminacy at the production stage at $t=1$ precludes the analysis of the operating leverage decision at $t=0$. To resolve this indeterminacy, we now depart from Murphy, Shleifer, and Vishny (1989) and apply a global games treatment. This is done by introducing dispersed information: at $t=1$, each monopolist $q$ observes a noisy signal of $L, l_{q}=L+\xi_{q}$, where $\xi_{q}$ is independent across monopolists and uniformly distributed on $[-\varepsilon, \varepsilon]$. One can show there is no loss of generality in restricting attention to threshold strategies in which monopolist $q$ operates at $t=1$ if $l_{q}$ is above a threshold $l^{*}$. Then, for a given $L$, the mass of active monopolists is

$$
n(L) \equiv\left\{\begin{array}{ll}
1 & \text { if } L>l^{*}+\varepsilon \\
\frac{L+\varepsilon-l^{*}}{2 \varepsilon} & \text { if } L \in\left[l^{*}-\varepsilon, l^{*}+\varepsilon\right] \\
0 & \text { if } L<l^{*}-\varepsilon
\end{array} .\right.
$$

When observing $l_{q}=l^{*}$, monopolist $q$ must be indifferent between producing or not,

$$
\frac{1}{2 \varepsilon} \int_{l^{*}-\varepsilon}^{l^{*}+\varepsilon}(1-\alpha-\beta+s) \frac{L-n(L) F(s)}{1-n(L)(1-\alpha+s)}-F(s) d L=0,
$$


which uniquely pins down $l^{*}$. Finally, a well-known property of global games is that equilibrium uniqueness carries over to the asymptotic case in which the noise in the signals vanishes, $\varepsilon \rightarrow 0$, and the information structure becomes arbitrarily close to common knowledge. In that case, solving for $l^{*}$ in Eq. (12) delivers the threshold on the underlying state $L$ above which production takes place,

$$
L^{T}(s) \equiv \frac{F(s)}{1-\alpha+s}+\frac{\beta F(s)}{(1-\alpha-\beta+s) \ln \left(\frac{1}{\alpha-s}\right)} .
$$

Proposition 1. If all monopolists choose operating leverage $s$ at $t=0$ and $\varepsilon \rightarrow 0$, then all monopolists operate at $t=1$ if $L \geq L^{T}(s)$ and no monopolist operates at $t=1$ if $L<L^{T}(s)$.

The production equilibrium in Proposition 1 has two important features. First, the equilibrium bears an economically intuitive relation to fundamentals: monopolists are more likely to operate for higher realizations of the productivity shock $L$. Notice that the production threshold belongs to the region in which multiple equilibria previously coexisted: $L^{T}(s) \in\left(\frac{(1-\beta) F(s)}{1-\alpha-\beta+s}, \frac{F(s)}{1-\alpha-\beta+s}\right)$. Specifically, the global games treatment selects the Paretoinferior equilibrium for $L \in\left(\frac{(1-\beta) F(s)}{1-\alpha-\beta+s}, L^{T}(s)\right)$, that is, for the lower realizations of the productivity shock, thereby maintaining scope for coordination failures.

Second, the production threshold $L^{T}(s)$ is increasing in aggregate operating leverage $s$ : a more levered economy needs a higher productivity shock to coordinate on the production equilibrium at $t=1$; that is, operating leverage aggravates the coordination problem. Note also that, if monopolists were to choose zero operating leverage, there would no coordina- 
tion failures at $t=1$ as monopolists would always produce (i.e., $L^{T}(0)=0$ ). Therefore, coordination failures will endogenously arise in the model because of monopolists' incentives to take on operating leverage. Next, we build on Proposition 1 to analyze these incentives and to derive the equilibrium operating leverage at $t=0$.

\subsection{Equilibrium operating leverage}

The distinct feature in our model is to allow each monopolist $q$ to calibrate its exposure to the aggregate shock $L$ through the choice of operating leverage $s_{q}$; that is, we endogenize risk-taking. To build intuition on the relation between operating leverage and risk, we start with two simple observations.

First, monopolist $q$ only produces at $t=1$ if $\pi_{q} \geq 0$, which, from Eq. (3), requires demand to be high enough: $y \geq \frac{F\left(s_{q}\right)}{1-\alpha-\beta+s_{q}}$. This income threshold, $\frac{F\left(s_{q}\right)}{1-\alpha-\beta+s_{q}}$, increases with $s_{q}$ : a monopolist with higher operating leverage needs higher demand to cover its fixed cost $F\left(s_{q}\right)$, and hence is more likely to exit the market at $t=1$. The adverse effect of operating leverage on profits can extend to states in which demand is high enough to allow the monopolist to operate (i.e., $\pi_{q} \geq 0$ ) yet too low for the lower marginal costs to outweigh the higher fixed costs: $\frac{\partial \pi_{q}}{\partial s_{q}}<0$ if $y<\frac{\alpha}{\left(\alpha-s_{q}\right)^{2}}$. However, as demand increases further, higher leverage becomes beneficial: $\frac{\partial \pi_{q}}{\partial s_{q}}>0$ if $y>\frac{\alpha}{\left(\alpha-s_{q}\right)^{2}}$. Intuitively, operating leverage magnifies the impact of demand shocks on profits, $\frac{\partial \pi_{q}}{\partial y}=s_{q}$, and therefore is more valuable when demand is high. Second, shocks to demand $y$ are driven by shocks to labor productivity $L$, as is apparent in Eq. (5). Operating leverage affects the relation between monopolists' profits and this 
fundamental risk through two channels: $\frac{\partial \pi_{q}}{\partial L}=\frac{\partial \pi_{q}}{\partial y} \cdot \frac{\partial y}{\partial L}$. The first one, $\frac{\partial \pi_{q}}{\partial y}=s_{q}$, is the direct exposure of profits $\pi_{q}$ to demand $y$, as discussed in the previous paragraph. The second one, $\frac{\partial y}{\partial L}=\left(1-\int_{i \in \mathcal{A}} 1-\alpha+s_{i} d i\right)^{-1}$, captures that shocks to $L$ are amplified by the demand multiplier, which itself depends on all active monopolists' leverages, $\left\{s_{i}\right\}_{i \in \mathcal{A}}$. Hence, through demand externalities, a monopolist's leverage affects the transmission of productivity shock $L$ to aggregate demand $y$, and therefore, the sensitivity of all other monopolists' profits to this productivity shock. Via this demand externality channel, firms' leverage decisions become interdependent and jointly determine aggregate risk.

We analyze operating leverage decisions, focusing on symmetric equilibria. Specifically, suppose all monopolists choose non-cooperatively the same operating leverage $s$ at $t=0$. From Proposition 1, aggregate income is then given by

$$
y(s, L) \equiv\left\{\begin{array}{ll}
\frac{L-F(s)}{\alpha-s} & \text { if } L \geq L^{T}(s) \\
L & \text { if } L<L^{T}(s)
\end{array} .\right.
$$

If monopolist $q$ were to choose operating leverage $s_{q}$ while all other monopolists choose $s$, monopolist $q$ would make a profit, and hence, produce when

$$
\left(1-\alpha-\beta+s_{q}\right) y(s, L)-F\left(s_{q}\right) \geq 0,
$$


or equivalently, when

$$
L \geq \hat{L}\left(s_{q}, s\right) \equiv \begin{cases}\max \left\{(\alpha-s) \frac{F\left(s_{q}\right)}{1-\alpha-\beta+s_{q}}+F(s), L^{T}(s)\right\} & \text { if } s_{q} \geq s, \\ \min \left\{\frac{F\left(s_{q}\right)}{1-\alpha-\beta+s_{q}}, L^{T}(s)\right\} & \text { if } s_{q}<s .\end{cases}
$$

Then $s^{*}$ is an equilibrium if and only if

$$
s^{*} \in \underset{s_{q}}{\operatorname{argmax}} \int_{\min \left\{\hat{L}\left(s_{q}, s^{*}\right), \bar{L}\right\}}^{\bar{L}}\left(1-\alpha-\beta+s_{q}\right) y\left(s^{*}, L\right)-F\left(s_{q}\right) d L .
$$

The next proposition follows from this condition.

Proposition 2. There exists a unique symmetric equilibrium $s^{*}$ defined by

$$
\mathbb{E}\left[y \mid L \geq L^{T}\left(s^{*}\right)\right]-F^{\prime}\left(s^{*}\right)=0
$$

To understand the condition in Eq. (18), note that, from Eq. (17), operating leverage $s_{q}$ affects monopolist q's profit through two margins. The first one is an extensive margin: changing $s_{q}$ affects monopolist $q$ 's production threshold $\hat{L}\left(s_{q}, s^{*}\right)$ at $t=1$, namely, the lower bound of the integral in Eq. (17). The extensive margin, $\hat{L}\left(s_{q}, s^{*}\right)$, does not enter the monopolist's first order condition in Eq. (18). Intuitively, at $\hat{L}\left(s^{*}, s^{*}\right)=L^{T}\left(s^{*}\right)$, monopolist $q$ 's profit is strictly positive only because other monopolists also produce. As $L$ falls below $L^{T}\left(s^{*}\right)$ and other monopolists stop producing, monopolist $q$ 's profit from producing turns 
strictly negative, and the monopolist is better off stopping production as well. This holds when $s_{q}=s^{*}$, but also, by continuity, for a range of values of $s_{q}$ below $s^{*}$. Conversely, monopolist $q$ is better off producing at $L^{T}\left(s^{*}\right)$ for a range of values of $s_{q}$ above $s^{*}$. The rigidity of $\hat{L}\left(s_{q}, s^{*}\right)$ with respect to $s_{q}$ around $s^{*}$ reflects the strength of strategic complementarities around the production threshold, which underlines the coordination failure. Consequently, the only relevant margin is an intensive one: changing $s_{q}$ affects monopolist $q$ 's profit taking the states in which it produces (i.e., the bounds of the integral in Eq. (17)) as fixed. The condition in Eq. (18) states that there are no marginal gains in terms of profits along that intensive margin when monopolist $q$ chooses $s^{*}$ and produces for $L$ above $L^{T}\left(s^{*}\right)=\hat{L}\left(s^{*}, s^{*}\right)$. Note that this marginal reasoning only provides a necessary condition for optimality. Specifically, gains along the extensive margin become non-negligible as $s_{q}$ moves further away from $s^{*}$. The proof of Proposition 2 in the Appendix shows that these large deviations can also be ruled out.

A key aspect in the above analysis is that the coordination failure at $t=1$ is unaffected by a unilateral change in leverage; that is, the leverage and production decisions of a single monopolist have a negligible effect on the aggregate income and therefore, on the production decisions of all the other monopolists at $t=1$. We now ask whether welfare could improve if a social planner were to choose all monopolists' leverage. Specifically, we define the optimal leverage $s^{\text {opt }}$ as the one maximizing consumers' expected utility at $t=0$ given that monopolists behave at $t=1$ as per Proposition 1. Our social optimum is therefore constrained efficient: the social planner chooses leverage at $t=0$ but cannot avoid coordination failures 
at $t=1$. Note finally that the extra labor income $\beta y$ earned by supervisors in states in which monopolists are active merely compensates them for their effort cost and, therefore, labor income net of monitoring disutility always sums up to $L$. Consequently, maximizing consumers' expected utility amounts to maximizing their expected income from corporate profits:

$$
s^{\text {opt }} \in \underset{s}{\operatorname{argmax}} \int_{\min \left\{L^{T}(s), \bar{L}\right\}}^{\bar{L}}(1-\alpha-\beta+s) y(s, L)-F(s) d L .
$$

Proposition 3. In the symmetric equilibrium, there is excessive operating leverage: $s^{*}>$ $s^{\text {opt }}$.

To understand why equilibrium leverage is excessive, consider the first order derivative of the social planner objective function in Eq. (19) with respect to $s,{ }^{5}$

$$
\begin{aligned}
& \int_{L^{T}(s)}^{\bar{L}} y(s, L)-F^{\prime}(s) d L+\int_{L^{T}(s)}^{\bar{L}}(1-\alpha-\beta+s) \frac{\partial y}{\partial s}(s, L) d L \\
& -\frac{\partial L^{T}(s)}{\partial s}\left[(1-\alpha-\beta+s) y\left(s, L^{T}(s)\right)-F(s)\right] .
\end{aligned}
$$

This derivative has three terms. The first one corresponds to the impact of leverage on each monopolist's profit, given that a monopolist produces for $L \geq L^{T}(s)$. From Eq. (18), this term is zero at $s=s^{*}$ : each monopolist optimizes along the intensive margin in equilibrium. The second term captures the demand externality that each monopolist exerts by stimulating demand $y$ for other active monopolists when $L \geq L^{T}(s)$. From Eq. (7), the equilibrium

\footnotetext{
${ }^{5}$ This is assuming that $s$ is such that $L^{T}(s)<\bar{L}$, which holds both in equilibrium and at the social optimum: it is neither individually nor socially optimal to choose $s$ at $t=0$ such that monopolists never operate at $t=1$.
} 
impact of monopolist $q$ on $y$ is $\pi_{q}+\beta y$ times a demand multiplier $\left(\alpha-s^{*}\right)^{-1}$. (The equilibrium demand multiplier is $\left(\alpha-s^{*}\right)^{-1}$ for $L \geq L^{T}(s)$ and 1 for $L<L^{T}(s)$.) The monopolist does not internalize that the demand multiplier, $\left(\alpha-s^{*}\right)^{-1}$, amplifies the contribution of its profit to output. However, because the equilibrium demand multiplier is constant for $L \geq L^{T}\left(s^{*}\right)$, monopolist $q$, when choosing $s_{q}$ to maximize its expected profit $\pi_{q}$ along the intensive margin, also maximizes the expected externality it exerts on other monopolists across all states $L \geq L^{T}\left(s^{*}\right)$. As a result, the second term in Eq. (20) also cancels out when evaluated at the equilibrium leverage: $\int_{L^{T}\left(s^{*}\right)}^{\bar{L}} \frac{\partial y}{\partial s}\left(s^{*}, L\right) d L=0$.

The equilibrium inefficiency goes through the impact of leverage on the lower bound of the monopolists' production region $L^{T}(s)$, which is captured by the third term in Eq. (20). As discussed earlier, if a monopolist were to unilaterally lower its leverage marginally, it would not produce in the neighborhood below $L^{T}\left(s^{*}\right)$ at $t=1$, as it anticipates all other monopolists will remain inactive. However, if a social planner constrains all monopolists to lower their operating leverage, coordination in production at $t=1$ changes: $\frac{\partial L^{T}(s)}{\partial s}>0$. Specifically, at the equilibrium leverage $s^{*}$, a marginal decrease in the leverage of all monopolists lead them to switch from inactivity to production just below $L^{T}\left(s^{*}\right)$. Because $L^{T}\left(s^{*}\right)$ belongs to the region in which monopolists being inactive is Pareto-dominated, inducing all of them to produce in that marginal state improves welfare by the corresponding aggregate profit $\left(1-\alpha-\beta+s^{*}\right) y\left(s, L^{T}\left(s^{*}\right)\right)-F\left(s^{*}\right)>0$. In other words, if monopolists could collectively commit to lowering their leverage at $t=0$, they would increase their expected profits and raise welfare by expanding the range of states in which they coordinate on the Pareto- 
superior production decision at $t=1$. They, however, have no unilateral incentive to do so.

It follows from the above discussion, that the excessive leverage result in Proposition 3 is inherently related to the monopolists' failure to coordinate production below $L^{T}(s)$ at $t=1$. In fact, our model establishes a direct relationship between the possibility of coordination failures at $t=1$ and the efficiency of the risk-taking decision at $t=0$. To see this, consider the equilibrium in Lemma 1 and instead of applying a global games treatment, suppose monopolists always coordinate on the Pareto-superior production equilibrium; that is, assuming that for any common leverage $s$, firms produce at $t=1$ if and only if $L \geq \frac{(1-\beta) F(s)}{1-\alpha-\beta+s}$.

Proposition 4. If firms coordinate on the Pareto-superior production equilibrium at $t=1$ and a symmetric operating leverage equilibrium exists, it is unique and socially optimal.

Proposition 4 highlights that constrained inefficiency in Proposition 3 is not related to the monitoring friction per se: equilibrium leverage is socially optimal with $\beta>0$ as long as monopolists coordinate on the Pareto-superior equilibrium at $t=1$. Hence, the possibility of coordination failures at $t=1$, rather than their origin in itself, is what really matters for the excessive leverage result. In other words, the role in the model of the monitoring cost $\beta$ is to create scope for these inefficient production outcomes at $t=1$, but other sources of coordination failures can lead to the same result. Intuitively, absent coordination failures, the net social value of monopolists producing in the marginal state, that is, at $L=\frac{(1-\beta) F(s)}{1-\alpha-\beta+s}$, is equal to zero. By contrast, the net social value of monopolists producing at $L^{T}\left(s^{*}\right)$ is strictly positive, which reflects the coordination failure. This strictly positive value at 
$L^{T}\left(s^{*}\right)$ creates the social benefit of lowering aggregate leverage to extend production below $L^{T}\left(s^{*}\right)$, which monopolists fail to internalize.

The inefficiency in Proposition 3 is a statement on the first moment of the output distribution: excessive operating leverage causes expected output to be lower in equilibrium than in the constrained optimum. Our model also shows that this loss in expected output compounds differential effects across states: output is actually higher than in the social optimum for high realizations of the productivity shock, but lower for low realizations. In addition, the transition from a Pareto-superior equilibrium with high production to the Pareto-inferior one with low production occurs through a larger drop in output in equilibrium than in the constrained optimum. This result is the combination of two forces: first, the economy is more levered in equilibrium than in the social optimum, $s^{*}>s^{\text {opt}}$; and second, the drop into a low-production regime occurs for a higher realization of the productivity shock, $L^{T}\left(s^{*}\right)>L^{T}\left(s^{\text {opt }}\right)$. Summing up, the welfare loss caused by excess leverage occurs through a shift of the output distribution towards high-productivity states that comes at the cost of higher downside risk and lower expected output.

\subsection{Evidence and empirical implications}

In the model, strategic complementarities are associated with demand spillovers, which is in line with the Keynesian narrative that attributes the bulk of business cycles to shifts in aggregate demand. Blanchard and Quah (1989) use structural VARs to provide evidence in support of the idea that business cycles are driven by shifts in aggregate demand. The 
same idea is corroborated by recent work that exploits the regional variation in business cycles, such as Mian and Sufi (2014) and Beraja, Hurst, and Ospina (2019). Low aggregate demand is also considered to be an important force behind the Great Recession and the slow recovery from it. (See, for instance, Hall, 2011; Eggertsson and Krugman, 2012; and Mian, Rao, and Sufi, 2013.)

The particular way in which firms gain exposure to aggregate shocks in the model, namely through increasing labor leverage, has the empirical advantage of being more directly observable when in general, risk-taking by firms is notoriously difficult to identify and may only be indirectly inferred from the variability of profit measures. Moreover, as we discuss below, the literature has identified labor leverage as a first-order determinant of firm risk. The starting points are two simple observations (see the discussion in Danthine and Donaldson, 2002): (i) labor costs are typically the main component of firms' cost structures; and (ii) labor costs are in large part fixed costs and consequently tend to vary less than income. For example, Donangelo, Gourio, Kehrig, and Palacios (2019) show that on average, a $1 \%$ reduction in sales leads to a $0.99 \%$ reduction in non-labor costs, but only to a $0.69 \%$ reduction in labor costs. Our model captures these two features by focusing on labor as a production factor and by assuming that firms' organizational and technological choices generate costs that cannot be readily adjusted to demand shocks. At the same time, it is important for our results that labor leverage be a decision variable that can be calibrated in the long run. Holzhacker, Krishnan, and Mahlendorf (2015) and Aboody, Levi, and Weiss (2018) provide empirical evidence consistent with managers having the ability to rebalance 
operating leverage in response to changes in the regulatory environment. Merz and Yashiv (2007) present a structural model in which firms' decisions to adjust their labor force are subject to a convex adjustment cost. Consistent with our setup, in their model, labor cost structures are both rigid in the short term and structural decision variables in the long term. Merz and Yashiv (2007) show that this framework helps to explain the volatility of firm values.

The link between labor leverage and firm risk is an empirically well-documented relation that provides support for the transmission channel of the aggregate shock in our model. Beyond the previously discussed papers Danthine and Donaldson (2002) and Merz and Yashiv (2007), a growing literature in asset pricing and macro-finance seeks to explain asset prices through the magnifying impact of labor leverage. Donangelo, Gourio, Kehrig, and Palacios (2019) show that firms with higher labor leverage are more sensitive to aggregate shocks, and therefore have stocks with higher expected return. In fact, they argue that half of the value premium can be explained through labor leverage. While we do not model capital structure, the risk induced by labor leverage should be embedded into any claim that is junior to labor obligations, which includes not only equity, but also debt. Consistent with this idea, Faviloukis, Lin, and Zhao (2020) show that labor leverage forecasts credit spreads as well as credit risk in the cross-section of firms. The literature has also used structural breaks to assess the causal relation between labor leverage and firm risk. For instance, Simintzi, Vig, and Volpin (2015) find that firms tend to reduce financial leverage when employment protection rises; and Serfling (2016) finds that labor protection laws that make 
workers more costly to dismiss cause firms operating profits to be more volatile. Overall, there is consistent and widespread evidence of the importance of labor leverage for firm risk. This evidence lends support to the mechanism at play in our model and suggests that distortions to labor leverage are likely to have a material impact on output and, ultimately, welfare.

In the paper, the distortion of operating leverage from a constrained optimum is tied to the possibility of coordination failures across firms. On the positive side, this leads to novel predictions. First, operating leverage is higher when demand spillovers are more important. In the model, the monitoring $\operatorname{cost} \beta$ and the compensation associated with it calibrates the magnitude of demand spillovers when monopolies start producing, and operating leverage is increasing in $\beta$. Identifying these spillovers is then a key empirical challenge. One possibility is to exploit firms' geographical locations. For instance, Dougal, Parsons, and Titman (2014) show that firms' investments are sensitive to investment by firms located in the same area even if those firms are in different industries. They argue this is suggestive of spillovers that could be rooted in consumption externalities between residents, like those at play in our model. Therefore, variations in geographical location could be used to proxy for the intensity of these spillover effects, with the caveat that location is in part endogenous. (See also Tuzel and Zhang, 2017.) Second, the effect of operating leverage is particularly pervasive when coordination failures are more likely to arise. Testing this prediction requires measures of firms' ability to coordinate production and investment. For instance, common ownership can serve as a coordination device by 
inducing shareholders to internalize the demand externality. Weinstein and Yafeh (1995) show that Japanese firms that belong to a Keiretsu behave differently from those that do not. Their results suggest that the pattern of cross-ownership that characterizes these large multiindustry corporate groups induce them to produce at a higher level than those maximizing individual firms' profits, consistent with coordination motives. Recent studies on common ownership (e.g., Azar, Schmalz, and Tecu, 2018) argue that large institutional investors play a coordinating role within and across industries. Interestingly, this literature also identifies plausibly exogenous shocks to common ownership -mergers between asset managers- that could help with identification. Finally, government intervention and a strong public sector can also have a role in preventing economic crises by reducing the likelihood of a coordination failure. For instance, a countercyclical public policy of stimulating the economy in the low productivity states can have a stabilizing effect by means of coordinating production. The role of public policy is explored in detail in Section 4 below.

On the normative side, our model predicts that in the presence of demand externalities, operating leverage is inefficiently high in that expected output is too low. The model also predicts that this depressed output is related to an excessive exposure of the economy to recession risk. Taking this prediction to the data would likely require a structural approach, where one could run counterfactuals and obtain an estimate of the output loss. One step in that direction are quantitative models of business cycles that embed coordination problems such as Schaal and Taschereau-Dumouchel (2018, 2019). These models can quantitatively account for the slow recovery that follows large aggregate shocks as agents coordinate on 
inefficient low-output equilibria. Incorporating a labor leverage decision would be the next step. Nonetheless, there is evidence supporting the idea that volatility is harmful in terms of economic growth, particularly in developing economies. For instance, Hnatkovska and Loayza (2005) show that the volatility due to crises has outsized effects on the growth of developing countries relative to the volatility due to normal fluctuations. More generally, the relation between recession risk and growth is consistent with a stream of papers initiated by the finding in Ramey and Ramey (1995) that output volatility and output growth are negatively correlated.

\section{Public policy}

This section analyzes the role of public policy: how government intervention at the production stage feeds back into firms' production and operating leverage decisions. Specifically, we assume the government can intervene at $t=1$ to coordinate production among an $m$ mass of monopolists where $m \in[0,1)$. The rest of the monopolists, of mass $(1-m)$, are as in the baseline model. The $m$-mass of monopolists differ from the other $(1-m)$-mass of monopolists in the economy in two ways. First, the $m$-mass of monopolists can share their private signals $l_{q}=L+\varepsilon_{q}$ with the government which, therefore, learns $L$ perfectly. Second, the government can commit to having the $m$-mass of monopolists produce in a given set of states -realizations of $L$ - even if producing in some of these states yields negative profits. In that case, the government could finance these losses through a lump-sum tax. 
Natural interpretations of the $m$-mass of monopolists are the size of the public sector, the number of government-controlled firms, or the number of sectors in which the government has the capacity to influence production decisions, possibly through subsidies or investment tax credits. Note that this extension nests the baseline model, which corresponds to the case with $m=0$. As in the baseline model, we use global games techniques to pin down the production strategy of the $m$-mass of monopolists not controlled by the government, and we focus on the case in which the noise in the private signals about $L$ vanishes: $\varepsilon \rightarrow 0$. The following proposition characterizes the resulting equilibrium of the production game at $t=1$

Proposition 5. Suppose all monopolists choose operating leverage $s$ at $t=0$. There exists a government strategy such that when $\varepsilon \rightarrow 0$, all monopolists produce if

$$
L \geq \frac{F(s)}{1-\alpha+s}+\frac{\beta(1-m) F(s)}{(1-\alpha-\beta+s) \ln \left(\frac{1-m(1-\alpha+s)}{\alpha-s}\right)} \equiv L^{T}(s, m),
$$

and no monopolist produces if $L<L^{T}(s, m)$. The threshold $L^{T}(s, m)$ is strictly decreasing in $m$ from $L^{T}(s, 0)=L^{T}(s)$, the production threshold in the baseline model in Eq. (13), to $L^{T}(s, 1)=\frac{(1-\beta) F(s)}{1-\alpha-\beta+s}$, the Pareto-optimal production threshold.

The main insight of Proposition 5 is that government control over the production of a fraction $m$ of monopolists alleviates the coordination problem at $t=1$ for all monopolists. Indeed, the government's commitment to have an $m$-mass of monopolists produce for $L \geq L^{T}(s, m)$ creates a positive demand externality on the other $(1-m)$-mass of monopolists, which induces them to produce as well. Specifically, for $L \in\left[L^{T}(s, m), L^{T}(s, 0)\right)$, the government's commitment shifts the economy from an equilibrium in which no monopolist produces to 
a Pareto-improving equilibrium in which all monopolists produce and are making strictly positive profits.

Proposition 5 also shows that if $m<1$, the government's strategy alleviates the coordination problem but does not eliminate it completely: for $L \in\left(\frac{(1-\beta) F(s)}{1-\alpha-\beta+s}, L^{T}(s, m)\right)$ monopolists are still not producing, which is Pareto-dominated by all monopolists producing. However, the equilibrium in Proposition 5 is the best government can do at $t=1$ to coordinate production.

Corollary 1. Suppose all monopolists choose operating leverage $s$ at $t=0$. When $\varepsilon \rightarrow 0$, monopolists producing if and only if $L \geq L^{T}(s, m)$ is constrained efficient at $t=1$.

Intuitively, while the government can coordinate production among an $m$-mass of monopolists, the other $(1-m)$-mass of monopolists still face a coordination problem. Because of this coordination problem, the $(1-m)$-mass of monopolists do not produce below $L^{T}(s, m)$, even if they expect the $m$-mass of government-controlled monopolists to produce. Then, given that the $(1-m)$-mass of monopolists never produce below $L^{T}(s, m)$, it is Pareto-optimal for the government to have the $m$-mass of monopolists also abstain from producing below $L^{T}(s, m)$ : their producing in that region would generate losses that decrease welfare with no effect on the behavior of the other $(1-m)$-mass of monopolists. Note finally that in this constrained optimum, no monopolist ever makes losses when it operates, including the $m$-mass controlled by the government, and hence no taxation is required in equilibrium. In that sense, while the government's commitment to production by the $m$-mass of monopolists is useful in shifting the behavior of the $(1-m)$-mass of monopolists, it does not generate costs for the former monopolists or the government. 
We now turn to the choice of operating leverage at $t=0$. Monopolists choose their operating leverage to maximize expected profits. Since all monopolists produce if and only if $L \geq$ $L^{T}(s, m)$ at $t=1$, they all face the same optimization problem at $t=0$, which is equivalent to the one in Eq. (17) except for the fact that now $\hat{L}\left(s_{q}, s^{*}\right)$ depends on threshold $L^{T}(s, m)$. The following proposition characterizes the equilibrium operating leverage at $t=0$ :

Proposition 6. There is a unique equilibrium operating leverage $s^{*}(m)$ which is the solution to

$$
\mathbb{E}\left[y \mid L \geq L^{T}\left(s^{*}(m), m\right)\right]-F^{\prime}\left(s^{*}(m)\right)=0
$$

This equilibrium $s^{*}(m)$ is strictly decreasing in $m$.

Proposition 6 is equivalent to Proposition 2 in the main model and has the same interpretation. More specifically, similar to condition in Eq. (18), condition in Eq. (22) states that there are no marginal gains in terms of profits along that intensive margin when monopolist $q$ chooses $s^{*}(m)$ and produces for $L$ above $L^{T}\left(s^{*}(m), m\right)$. Proposition 6 , however, has the additional implication that $s^{*}(m)$ is decreasing in $m$. Therefore, the government's commitment to inducing production above $L^{T}(s, m)$ at $t=1$ has two effects: (i) improving coordination at $t=1$ for a given operating leverage $s$ (i.e., from Proposition $5, L^{T}(s, m)<L^{T}(s, 0)$ for $m>0$ ); and (ii) reducing operating leverage at $t=0$ (i.e., Proposition $6, s^{*}(m)<s^{*}(0)$ for $m>0)$. As we show next, these two effects increase welfare.

Since maximizing welfare is akin to maximizing corporate profits (see Eq. (19)), let $W(s, m)$ be the welfare function for an economy with operating leverage $s$ and an $m$-mass of 
government-controlled monopolists:

$$
W(s, m) \equiv \int_{\min \left\{L^{T}(s, m), \bar{L}\right\}}^{\bar{L}}(1-\alpha-\beta+s) \frac{L-F(s)}{\alpha-s}-F(s) d L .
$$

Proposition 7 below shows that welfare increases in $m$.

Proposition 7. $W\left(s^{*}(m), m\right)$ is strictly increasing in $m$. When $m \rightarrow 1$, operating leverage and production decisions tend to the first-best optimal.

The intuition for Proposition 7 is directly related to the two above-mentioned effects. First, the government's intervention prevents coordination failures in production at $t=1$ for a given $s$ (i.e., $\frac{\partial W(s, m)}{\partial m}>0$ ). Second, the government's intervention that mitigates the coordination problem at $t=1$ has the additional benefit of curbing excessive operating leverage at $t=0$ (i.e., $\frac{\partial W(s, m)}{\partial s} \frac{\partial s}{\partial m}>0$ ). Therefore, a government that can credibly commit to stimulating the economy in low productivity states has a stabilizing effect by both avoiding abrupt transitions between high- and low-production regimes ex post and inducing lower leverage ex ante. Importantly, government intervention at $t=1$ can only be fully effective if it is anticipated at $t=0$ and, therefore, if it has the effect of reducing the equilibrium operating leverage at $t=0$. In other words, a lack of credibility to intervene in the future generates excess operating leverage ex ante, which in turn, magnifies the need for government intervention ex post. Note also that Proposition 7 is a statement on expected profits, but the increase in welfare compounds differential effects across states: there is a decrease in downside risk at the cost of a worse economic performance in high productivity states. 
Overall, our results indicate that public policy can be an efficient instrument to curb risktaking and prevent crises. Rodrik (1998) provides evidence consistent with the idea that government spending plays a risk-reducing role in economies exposed to a significant amount of external risk.

Finally, note that we have allowed for the government to intervene at $t=1$ to coordinate production but not at $t=0$ to lower operating leverage. (The lower operating leverage at $t=0$ when goverment can coordinate production among an $m$-mass of monopolists at $t=1$, i.e., $s^{*}(m)<s^{*}(0)$, is the byproduct of monopolists anticipating a lower production threshold at $t=1$.) In doing so, this section highlights the stabilizing effect that a policy of stimulating the economy in low-productivity states has by means of coordinating production. Naturally, however, the excessive leverage result we focus on in the baseline model generalizes to this extension: lowering all monopolists' operating leverage from the equilibrium level in Proposition 7 can also raise welfare. This suggests that another lever for government intervention would be to directly induce the $m$-mass of monopolists to lower their operating leverage to below the equilibrium level in Proposition 7.

\section{Discussion}

\subsection{Sources of coordination failure}

As previously discussed, the role of the monitoring friction is to generate equilibrium multiplicity and the possibility of a coordination failure at the production stage. Our assumption 
is isomorphic to one in Murphy, Shleifer, and Vishny (1989) but it also lends itself to a natural extension in which workers perceive a rent. ${ }^{6}$ Suppose that when supervisors do not exert effort, there is now a small but strictly positive probability $p$ that the product is functional. In that case, if supervisors are protected by limited liability, incentivizing monitoring requires leaving each supervisor with a pay equal to $\beta /(1-p)>\beta$ per unit, which is strictly higher than the supervisor's monitoring cost. The severity of the moral hazard friction (i.e., the magnitude of this rent) aggravates equilibrium inefficiencies through two channels. First, a higher rent makes monopolists more likely to coordinate on the non-productive equilibrium at $t=1$. This is because monopolists internalize the rent as a real cost, while it merely is a redistribution of surplus from shareholders to workers. The higher incidence of coordination failures at $t=1$ lowers consumers' expected utility, keeping operating leverage constant. Second, the incremental production inefficiency at $t=1$ induces monopolists to increase their operating leverage at $t=0$. Intuitively, more frequent coordination failures make all monopolists less likely to survive a bad shock, which increases the weight of high-productivity states in each monopolist's leverage optimization problem. As a result, equilibrium operating leverage moves further away from the social optimum, amplifying the ex post production inefficiency and depressing welfare. The following proposition formalizes this discussion.

Proposition 8. In any symmetric equilibrium, there is excessive operating leverage, and an

\footnotetext{
${ }^{6}$ In our setup, monopolist $q$ makes profit $\pi\left(x_{q}\right)=p_{q} x_{q}(1-\beta)-\left[\left(\alpha-s_{q}\right) x_{q}+F\left(s_{q}\right)\right]$. If we rewrite $\pi^{\prime}\left(x_{q}\right)=p_{q} x_{q}-\frac{1}{1-\beta}\left[\left(\alpha-s_{q}\right) x_{q}+F\left(s_{q}\right)\right], \frac{\beta}{1-\beta}\left(=\frac{1}{1-\beta}-1\right)$ would correspond to the wage premium in Murphy, Shleifer, and Vishny (1989).
} 
increase in p increases operating leverage and decreases welfare.

Proposition 8 establishes that rents increase operating leverage and decrease welfare by creating a misalignment between firms' objective functions and consumers' welfare. Note that this misalignment aggravates the inefficiency in risk-taking but is not necessary to generate it. As Proposition 3 shows, even when rents are absent $(p=0)$ and maximizing aggregate corporate profits coincide with maximizing consumers' welfare (see Eq. (19)), the coordination problem between firms persists, which makes production and operating leverage decisions suboptimal.

Finally, Murphy, Shleifer, and Vishny (1989) provide other mechanisms beyond moral hazard that lead to equilibrium multiplicity in the presence of demand externalities, for instance, when firms invest to generate future labor savings. Therefore, while our modelling choice is both technically convenient as well economically relevant -information frictions are pervasive in large organizations-, it is not the only way to generate a coordination failure in the context of the modelled economy. Moreover, as emphasized by Proposition 4, the excessive operating leverage at $t=0$ is caused by the coordination failure at $t=1$ in itself, rather than by the specific origin of the coordination failure.

\subsection{State-dependent multiplier}

In our model, the inefficiency operates through the impact that monopolists' leverage decisions have on the probability of a coordination failure, that is, it operates through the 
extensive margin. However, monopolists' leverage decisions also affect each other's profitability in every state $L \geq L^{T}\left(s^{*}\right)$ in which they produce, that is, it affects the intensive margin. So far, the incentives of monopolists and the social planner have been aligned along the intensive margin because the demand multiplier has been constant across all states in which monopolists produce. (See Eq. (20) and the discussion that follows.) Shleifer and Vishny (1988) show that a misalignment of public and private incentives to produce can arise along the intensive margin if the demand multiplier is not constant across states. By shutting down this channel, our model is designed to isolate the effect of ex post coordination failures on ex ante risk-taking (Proposition 3). We explore next how a misalignment along the intensive margin would affect operating leverage decisions.

As will become clear below, one way to endogenously make the demand multiplier statecontingent is to introduce heterogeneity among monopolists. ${ }^{7}$ Specifically, we assume that all monopolists have the same fixed cost, $F\left(s_{q}\right)=\frac{s_{q}}{\alpha-s_{q}}$, but a proportion $n_{i}$ of monopolists have marginal cost $\alpha+\Delta_{i}-s_{q}$, where $i=1,2, n_{i}+n_{j}=1, \alpha+\Delta_{i}<1$, and $\Delta_{1} \neq \Delta_{2}$. To isolate the effect of heterogeneity on operating leverage decisions, we rule out coordination failures at the production stage by assuming that $\beta=0$. The next proposition characterizes the efficiency of the equilibrium operating leverage at $t=0$.

Proposition 9. Any symmetric equilibrium in which type-i monopolists choose $s_{i}^{*}$ is constrained inefficient: the equilibrium features insufficient operating leverage in that increasing

\footnotetext{
${ }^{7}$ The effect of firm heterogeneity on the demand multiplier is as in Shleifer and Vishny (1988). However, their model studies inefficiencies at the production stage and relies on firms making production decisions before the productivity shock $L$ is realized. In our model, $L$ is known when firms make production decisions, but unknown when firms choose operating leverage.
} 
operating leverage for the monopolists with the lowest production threshold increases welfare.

To understand the intuition behind Proposition 9, note first that, since there are no coordination failures at $t=1(\beta=0)$, production is ex post efficient. As a result, monopolists' and social planer's incentives to take on operating leverage are aligned along the extensive margin. However, private and public incentives no longer align along the intensive margin. While in the main model all monopolists have the same operating threshold, here, the production threshold depends on the monopolist's type. Assume without loss of generality that type- $i$ monopolists have a lower production threshold $L_{i}^{T}$ than type- $j$ monopolists $L_{j}^{T}$, that is, for $L \in\left[L_{i}^{T}, L_{j}^{T}\right)$ only type- $i$ monopolists operate while for $L \in\left[L_{j}^{T}, \bar{L}\right]$ both types operate. This implies that the demand multiplier is no longer constant across states in which a monopolist is active: it is equal to $\left(1-n_{i}\left(1-\alpha-\Delta_{i}+s_{i}^{*}\right)\right)^{-1}$ for $L \in\left[L_{i}^{T}, L_{j}^{T}\right)$ and $\left(1-n_{i}\left(1-\alpha-\Delta_{i}+s_{i}^{*}\right)-n_{j}\left(1-\alpha-\Delta_{j}+s_{j}^{*}\right)\right)^{-1}$ for $L \in\left[L_{j}^{T}, \bar{L}\right]$. Since $\left(1-n_{i}\left(1-\alpha-\Delta_{i}+s_{i}^{*}\right)-n_{j}\left(1-\alpha-\Delta_{j}+s_{j}^{*}\right)\right)^{-1}>\left(1-n_{i}\left(1-\alpha-\Delta_{i}+s_{i}^{*}\right)\right)^{-1}$, a marginal unit of profit has a higher welfare impact when $L \in\left[L_{j}^{T}, \bar{L}\right]$ than when $L \in\left[L_{i}^{T}, L_{j}^{T}\right)$. As a result, maximizing expected profit is no longer equivalent to maximizing expected welfare. Relative to a monopolist, a social planner has a higher willingness to shift profits from $\left[L_{i}^{T}, L_{j}^{T}\right)$ to $\left[L_{j}^{T}, \bar{L}\right]$ because the welfare impact per unit of profit is higher in $\left[L_{j}^{T}, \bar{L}\right]$ than in $\left[L_{i}^{T}, L_{j}^{T}\right)$. This is exactly what higher operating leverage achieves. ${ }^{8}$

\footnotetext{
${ }^{8}$ While Proposition 9 shows that increasing $s_{i}^{*}$ (the operating leverage of the monopolists with the lower production threshold) given $s_{j}^{*}$ (the operating leverage of the monopolists with the higher production threshold) increases welfare, $s_{j}^{*}$ is optimal given $s_{i}^{*}$. The reason is that the equilibrium demand multiplier is constant across all states in which type- $j$ monopolists are active (i.e., the demand multiplier is $\left(1-n_{i}(1-\right.$ $\left.\left.\alpha-\Delta_{i}+s_{i}^{*}\right)-n_{j}\left(1-\alpha-\Delta_{j}+s_{j}^{*}\right)\right)^{-1}$ for all $\left.L \in\left[L_{j}^{T}, \bar{L}\right]\right)$. Therefore, type- $j$ monopolists, maximizing expected profit in $L \in\left[L_{j}^{T}, \bar{L}\right]$ is equivalent to maximizing expected welfare.
} 
Overall, contrasting the insufficient leverage result in Proposition 9 with our main result of excessive leverage in Proposition 3 stresses that coordination failures have a distinct directional effect on ex ante risk-taking decisions. While the analysis in the current section suggests that risk-taking decisions can be distorted in more than one way, the importance of the excessive leverage result of Proposition 3 is commensurate to the role that coordination failures play in explaining crises and recessions, as discussed at the end of Section 3. In that sense, the inefficiencies in Proposition 3 and Proposition 9 speak to different concerns about the distribution of output across states of the economy. In Proposition 9, insufficient leverage prevents the economy from fully exploiting demand spillovers after a positive productivity shock, while in Proposition 3, excessive leverage makes the economy too exposed to a negative productivity shock. To the extent that recessions and crises inflict material and long-lasting damages, that second channel ought to be of particular significance.

\subsection{Operating leverage specification}

In the paper, firms decide their cost structure by trading off higher fixed labor costs for lower variable costs. Specifically, monopolist $q$ incurs a fixed cost of $F\left(s_{q}\right)=\frac{s_{q}}{\alpha-s_{q}}$ units of labor and a constant marginal cost of $\alpha-s_{q}$ units of labor per unit of output, where $s_{q} \in[0, \alpha]$ is choice variable that captures operating leverage. The function $F\left(s_{q}\right)$ is increasing, convex, and tends to infinity as $s_{q} \rightarrow \alpha$, which guarantees that the equilibrium operating leverage $s^{*}$ is smaller than $\alpha$ (and hence, that variable costs are positive).

Because the monopolist's optimization problem with respect to $s_{q}$ in Eq. (17) is not convex, 
local optimality conditions are not sufficient for global optimality, and large deviations also need to be ruled out. The function we chose for $F\left(s_{q}\right), \frac{s_{q}}{\alpha-s_{q}}$, provides the necessary analytical tractability for studying large deviations to determine existence. (See the proof of Proposition 2 in the Appendix.) However, the local necessary condition that characterizes the equilibrium in Proposition 2 holds for a generic increasing and convex function. Moreover, around this local equilibrium condition, there is excessive operating leverage, as in Proposition 3. The logic is also identical to the one previously discussed for Proposition 3: at the equilibrium leverage $s^{*}$, a marginal decrease in the leverage of all monopolists lead them to switch from inactivity to production just below $L^{T}\left(s^{*}\right)$ (i.e., $\frac{\partial L^{T}\left(s^{*}\right)}{\partial s}>0$ ), which improves welfare. This highlights once again that the excessive leverage result is driven by the monopolists' failure to coordinate production below $L^{T}\left(s^{*}\right)$ at $t=1$, and not by the chosen functional form for the fixed cost. The following proposition formalizes this discussion.

Proposition 10. Consider a generic increasing and convex function $F($.$) , any symmetric$ interior equilibrium $s^{*}$ at $t=1$ satisfies condition in Eq. (18) in Proposition 2, and a collective marginal decrease in operating leverage around $s^{*}$ increases welfare.

\section{Conclusion}

Coordination failures are often invoked to explain periods of recession and crises in which economies appear to be trapped in down-cycles of low output, trading, and investment. In essence, the literature views economies as interdependent systems in which agents need to coordinate their investment and consumption decisions. We show that these economies 
feature excessive operating leverage as firms do not internalize the effect that their risk choices have on the probability of the economy suffering a coordination failure. The excessive operating leverage increases downside risk and causes expected output to be lower than in the social optimum. The loss in expected output compounds differential effects across states: There is a shift in output towards high-productivity states that comes at the cost of more frequent and severe economic crises. The analysis has implications for public policy: a countercyclical policy that stimulates the economy in low productivity states has a stabilizing effect by both, avoiding coordination failures ex post and curving excessive risk ex ante.

While our model emphasizes the role of demand externalities because of its economic importance, strategic complementarities across economic agents have been shown to arise through a broad variety of channels (e.g., thick market externalities, technological complementarities, and imperfect information). These other sources of strategic complementarities can also generate multiple equilibria and create scope for coordination failures. In general, we expect the same economic forces to apply in setups with these alternative sources. Indeed, as long as risk increases the probability of a coordination failure and agents do not internalize this effect, agents will tend to engage in excessive risk-taking.

Strategic complementarities are notably important in the financial system as illustrated by recurrent financial crises. Specifically, the liquidity transformation role of financial institutions combined with the fact that these institutions form a highly interconnected network makes financial systems particularly vulnerable to coordination failures. Our analysis suggests that a concentrated financial system is more stable in that financial institutions 
internalize, to a larger extent, the effect that their risk choices have on the probability of a systemic financial crisis. Alternatively, it also suggests that a more disperse financial system requires stricter regulation to curve excessive risk-taking. The analysis of these effects in the specific context of an economy with a financial system is an interesting avenue for future research.

\section{References}

Aboody, D., Levi, S., Weiss, G., 2018. Managerial incentives, options, and cost-structure choices. Review of Accounting Studies 23, pp. 422-451.

Azar, J., Schmalz, M., Tecu, I., 2018. Anticompetitive effects of common ownership. Journal of Finance 73, pp. 1513-1565.

Bebchuk, L., Goldstein, I., 2011. Self-fulfilling credit market freezes. Review of Financial Studies 24, pp. 3519-3555.

Beraja, M., Hurst, E., Ospina, J., 2019. The aggregate implications of regional business cycles. Econometrica 87, pp. 1789-1833

Bernanke, B., Gertler, M., 1989. Agency costs, net worth, and business fluctuations. American Economic Review 79, pp. 14-31.

Blanchard, O., Quah, D., 1989. The dynamic effects of aggregate demand and supply disturbances. American Economic Review 79, pp. 655-673.

Carlsson, H., Van Damme, E., 1993. Global payoff uncertainty and risk dominance. Econo- 
metrica 61, pp. 989-1018.

Chamley, C., 1999. Regime switches. Quarterly Journal of Economics 114, pp. 869-905.

Chaney, T., Ossa, R., 2013. Market size, division of labor, and firm productivity. Journal of International Economics 90, pp. 177-180.

Cooper, R., John, A., 1988. Coordinating coordination failures in keynesian models. Quarterly Journal of Economics 103, pp. 441-463.

Danthine, J., Donaldson, J., 2002. Labour relations and asset returns. Review of Economic Studies 69, pp. 41-64.

Diamond, P., 1982. Aggregate demand management in search equilibrium. Journal of Political Economy 91, pp. 401-409.

Donangelo, A., Gourio, F., Kehrig, M., Palacios, M., 2019. The cross-section of labor leverage and equity returns. Journal of Financial Economics 132, pp. 497-518.

Dougal, C., Parsons, C., Titman, S., 2014. Urban vibrancy and corporate growth. Journal of Finance 70, pp. 163-210.

Eggertsson, G., Krugman, P., 2012. Debt, deleveraging, and the liquidity trap: a FisherMinsky-Koo approach. Quarterly Journal of Economics 127, pp. 1469-1513.

Faviloukis, J., Lin, X., Zhao, X., 2020. The elephant in the room: the impact of labor obligations on credit risk. American Economic Review 110, pp. 1673-1712.

Garicano, L., Van Zandt, T., 2012. Hierarchies and the division of labor. In: Handbook of Organizational Economics, edited by R. Gibbons and J. Roberts, Princeton University Press. 
Gorton, G., Ordoñez, G., 2014. Collateral crises. American Economic Review 104, pp. 343378.

Guimaraes, B., Morris, S., 2008. Risk and wealth in a model of self-fulfilling currency attacks. Journal of Monetary Economics 54, pp. 2205-2230.

Hall, R., 2011. The long slump. American Economic Review 101, pp. 431-469.

Hart, O., 1982. A model of imperfect competition with Keynesian features. Quarterly Journal of Economics 97, pp. 109-138.

He, Z., Kondor, P., 2016. Inefficient investment waves. Econometrica 84, pp. 735-780.

Hnatkovska, V., Loayza, N., 2005. Volatility and growth. In: Managing Economic Volatility and Crises, edited by J. Aizenmann and B. Pinto, Cambridge University Press.

Holzhacker, M., Krishnan. R., Mahlendorf, M., 2015. The impact of changes in regulation on cost behavior. Contemporary Accounting Research, 32, pp. 534-566.

Kiyotaki, N., 1988. Multiple expectations equilibria under monopolistic competition. Quarterly Journal of Economics 103, pp, 695-714.

Kiyotaki, N., Moore, J., 1997, Credit cycles, Journal of Political Economy 105, pp, 211-248.

Lamont, O., 1995. Corporate-debt overhang and macroeconomic expectations. American Economic Review 85, pp. 1106-1117.

Lev, B., 1974. On the association between operating leverage and risk. Journal of Financial and Quantitative Analysis 9, pp. 627-641.

Lorenzoni, G., 2008. Inefficient credit booms. Review of Economic Studies 75, pp. 809-833.

Maskin, E., Tirole, J., 1988. A theory of dynamic oligopoly, I: overview and quantity com- 
petition with large fixed costs. Econometrica 56, pp. 549-569.

Merz, M., Yashiv, E., 2007. Labor and the market value of the firm. American Economic Review 97, pp. 1419-1431.

Mian, A., Rao, K., Sufi, A., 2013. Household balance sheets, consumption, and the economic slump. Quarterly Journal of Economics 128, pp.1687-1726.

Mian, A., Sufi, A., 2014. What explains high unemployment? The aggregate demand channel. Econometrica 82, pp. 2197-2223.

Morris, S., Shin, H., 2000. Rethinking multiple equilibria in macroeconomics. NBER Macroeconomics Annual 2000, MIT Press.

Morris, S., Shin, H., 2003. Global games: theory and applications. In: Advances in Economics and Econometrics (Proceedings of the Eighth World Congress of the Econometric Society), edited by M. Dewatripont, L. Hansen, S. Turnovsky, Cambridge University Press. Murphy, K., Shleifer, A., Vishny, R., 1989. Industrialization and the big push. Journal of Political Economy 97, pp. 1003-1026.

Ramey, G., Ramey, V., 1995. Cross-country evidence on the link between volatility and growth. American Economic Review 85, pp. 1138-1151.

Rodrik, D., 1998. Why do more open economies have bigger governments? Journal of Political Economy 106, pp. 997-1032.

Rosenstein-Rodan, P., 1943. Problems of industrialisation of Eastern and South-Eastern Europe. The Economic Journal 53, pp. 202-211.

Schaal, E., Taschereau-Dumouchel, M., 2018. Coordinating business cycles. Unpublished 
working paper. Cornell University.

Schaal, E., Taschereau-Dumouchel, M., 2019. Aggregate demand and the dynamics of unemployment. Unpublished working paper. Cornell University.

Serfling, M., 2016. Firing costs and capital structure decisions. Journal of Finance 71, pp. $2239-2286$.

Shleifer, A., Vishny, R., 1988. The efficiency of investment in the presence of aggregate demand spillovers. Journal of Political Economy 96, pp. 1221-1231.

Simintzi, E., Vig, V., Volpin, P., 2015. Labor protection and leverage. Review of Financial Studies 28, pp. 561-591.

Tuzel, S., Zhang, M., 2017. Local risk, local factors, and asset prices. Journal of Finance 72, pp. $325-370$.

Weinstein, D., Yafeh, Y., 1995. Japan's corporate groups: collusion or competitive? An empirical investigation of Keiretsu behavior. Journal of Industrial Economics 43, issue 4, p. 359-76.

Weitzman, M., 1982. Increasing returns and the foundations of unemployment theory. Economic Journal 92, pp. 787-804. 


\section{Appendix}

To ensure the existence of equilibria in which agents' optimization problems have interior solutions, we assume throughout this Appendix that the upper bound $\bar{L}$ is large enough, in a sense we make precise in the proofs below. For most of our results, this assumption boils down to $\bar{L}>2$.

\section{Proof of Proposition 1}

Suppose all firms choose $s$, and firm $q$ observes a noisy signal of $L$ : a signal $l_{q}=L+\xi_{q}$ where $\xi_{q}$ is uniform on $[-\varepsilon, \varepsilon]$. Suppose firm $q$ produces iff $l_{q}>l^{*}$. Then, for a given realization of $L$, the number of firms that produce is

$$
n(L) \equiv \begin{cases}1 & \text { if } L>l^{*}+\varepsilon \\ \frac{L+\varepsilon-l^{*}}{2 \varepsilon} & \text { if } L \in\left[l^{*}-\varepsilon, l^{*}+\varepsilon\right] \\ 0 & \text { if } L<l^{*}-\varepsilon\end{cases}
$$

The firm with signal $l^{*}$ must be indifferent:

$$
\frac{1}{2 \varepsilon} \int_{l^{*}-\varepsilon}^{l^{*}+\varepsilon}(1-\alpha-\beta+s) \frac{L-n(L) F}{1-n(L)(1-\alpha+s)}-F d L=0
$$


Consider the following change of variable: $z=\frac{L+\varepsilon-l^{*}}{2 \varepsilon} \Leftrightarrow L=2 \varepsilon z+l^{*}-\varepsilon$. Eq. (A.2) becomes

$$
\begin{aligned}
& \frac{1}{2 \varepsilon} \int_{0}^{1}\left\{(1-\alpha-\beta+s) \frac{2 \varepsilon z+l^{*}-\varepsilon-n\left(2 \varepsilon z+l^{*}-\varepsilon\right) F}{1-n\left(2 \varepsilon z+l^{*}-\varepsilon\right)(1-\alpha+s)}-F\right\} 2 \varepsilon d z=0 \\
& \Leftrightarrow \int_{0}^{1}(1-\alpha-\beta+s) \frac{2 \varepsilon z+l^{*}-\varepsilon-z F}{1-z(1-\alpha+s)}-F d z=0 .
\end{aligned}
$$

Taking the limit when $\varepsilon \rightarrow 0$ and defining $L^{T}(s)$ as the limit of $l^{*}$ when $\varepsilon \rightarrow 0$, Eq. (A.4) writes

$$
\begin{aligned}
& \int_{0}^{1}(1-\alpha-\beta+s) \frac{L^{T}(s)-z F}{1-z(1-\alpha+s)}-F d z=0 \\
& \Leftrightarrow \frac{1-\alpha-\beta+s}{1-\alpha+s} \int_{0}^{1} \frac{(1-\alpha+s) L^{T}(s)-z(1-\alpha+s) F}{1-z(1-\alpha+s)} d z-F=0 \\
& \Leftrightarrow \frac{1-\alpha-\beta+s}{1-\alpha+s} \int_{0}^{1} \frac{(1-\alpha+s) L^{T}(s)-F}{1-z(1-\alpha+s)} d z-\frac{\beta}{1-\alpha+s} F=0 \\
& \Leftrightarrow-\frac{1-\alpha-\beta+s}{(1-\alpha+s)^{2}}\left[(1-\alpha+s) L^{T}(s)-F\right] \ln (\alpha-s)-\frac{\beta}{1-\alpha+s} F=0 .
\end{aligned}
$$

Therefore

$$
L^{T}(s)=\frac{F}{1-\alpha+s}+\frac{\beta F}{(1-\alpha-\beta+s) \ln \left(\frac{1}{\alpha-s}\right)}
$$

It is apparent that the RHS of Eq. (A.4) is increasing in $l^{*}$, which guarantees the uniqueness of an equilibrium in threshold strategies for any $\varepsilon$. Now, iterated deletion of strictly dominated strategies ensure global uniqueness in a setting with global strategic complementarities (see, e.g., Morris and Shin, 2003). One potential concern here is that monopolists' actions are not complement if $L$ is small enough. Specifically, letting $n$ be the fraction of 
monopolists who produce,

$$
\frac{\partial \pi}{\partial n} \geq 0 \Leftrightarrow L \geq \frac{F(s)}{1-\alpha+s}
$$

Note however, that

$$
\frac{F(s)}{1-\alpha+s}<\frac{(1-\beta) F(s)}{1-\alpha-\beta+s}
$$

i.e., the region where the firms' actions are not strategic complement is strictly smaller than the upper bound of the lower-dominance region. Therefore if

$$
2 \varepsilon<\frac{(1-\beta) F(s)}{1-\alpha-\beta+s}-\frac{F(s)}{1-\alpha+s},
$$

a private signal $l_{q}$ consistent with $L \geq \frac{(1-\beta) F(s)}{1-\alpha-\beta+s}$ rules out $L<\frac{F(s)}{1-\alpha+s}$ (i.e., ensures that $L$ is in the region where actions are complement). This, in turn, allows to apply the standard iterated deletion of strictly dominated strategies. It follows that the threshold equilibrium derived in Eq. (A.4) is the unique equilibrium for $\varepsilon$ small enough, hence when $\varepsilon \rightarrow 0$. Q.E.D.

Proof of Proposition 2

Part I. Proof of Proposition 2: Local Conditions.

Suppose monopolist $q$ chooses $s_{q}$ and all other monopolists choose $s^{*} \in(0, \alpha)$. 
(a) If no other monopolist operate, monopolist $q$ operates if

$$
L>L_{-}\left(s_{q}\right) \equiv \frac{F\left(s_{q}\right)}{1-\alpha-\beta+s_{q}} .
$$

Since (i) $\alpha+\beta<1, L_{-}^{\prime}\left(s_{q}\right)>0$; (ii) $\beta>0, L_{-}\left(s^{*}\right)>L^{T}\left(s^{*}\right)$ (from Eq. (A.9)); and (iii) $L_{-}(0)=0<L^{T}\left(s^{*}\right)$, there is a unique $s_{-}$such that $L_{-}\left(s_{-}\right)=L^{T}\left(s^{*}\right)$ and $s_{-}<s^{*}$. If $L<L^{T}\left(s^{*}\right)$ and $s_{q}<s_{-}, q$ operates iff $L>L_{-}\left(s_{q}\right)$. If $L<L^{T}\left(s^{*}\right)$ and $s_{q}>s_{-}, q$ never operates.

(b) If all other monopolist operate, monopolist $q$ operates if

$$
L>L_{+}\left(s_{q}\right) \equiv\left(\alpha-s^{*}\right) \frac{F\left(s_{q}\right)}{1-\alpha-\beta+s_{q}}+F\left(s^{*}\right),
$$

Since (i) $L_{+}^{\prime}\left(s_{q}\right)>0$; (ii) $\beta>0, L_{+}\left(s^{*}\right)<L^{T}\left(s^{*}\right)$ (from Eq. (A.9)); and $\lim _{s \rightarrow \alpha} L_{+}(s)=$ $+\infty$, there is a unique $s_{+}<\alpha$ such that $L_{+}\left(s_{+}\right)=L^{T}\left(s^{*}\right)$ and $s_{+}>s^{*}$. If $L>L^{T}\left(s^{*}\right)$ and $s_{q}>s_{+}, q$ operates iff $L>L_{+}\left(s_{q}\right)$. If $L>L^{T}\left(s^{*}\right)$ and $s_{q}<s_{+}, q$ always operates. 
(a) and (b) implies that

$$
L \geq \hat{L}\left(s_{q}, s^{*}\right) \equiv \begin{cases}\left(\alpha-s^{*}\right) \frac{F\left(s_{q}\right)}{1-\alpha-\beta+s_{q}}+F\left(s^{*}\right) & \text { if } s_{q} \geq s_{+}, \\ L^{T}\left(s^{*}\right) & \text { if } s_{q} \in\left(s^{*}, s_{+}\right), \\ L^{T}\left(s^{*}\right) & \text { if } s_{q} \in\left(s_{-}, s^{*}\right), \\ \frac{F\left(s_{q}\right)}{1-\alpha-\beta+s_{q}} & \text { if } s_{q} \leq s_{-} .\end{cases}
$$

The monopolist optimization problem writes (see Eq. (17))

$$
\max _{s_{q}} \int_{\min \left\{\hat{L}\left(s_{q}, s^{*}\right), \bar{L}\right\}}^{\bar{L}}\left(1-\alpha-\beta+s_{q}\right) y\left(s^{*}, L\right)-F\left(s_{q}\right) d L
$$

and therefore, since the optimal $s_{q}$ is such that $\hat{L}\left(s_{q}, s^{*}\right)<\bar{L}$, and since Eq. (A.15) implies that $\left|\frac{\partial \hat{L}\left(s_{q}, s^{*}\right)}{\partial s_{q}}\right|_{s_{q}=s^{*}}=0$, the first-order condition for an interior solution to the monopolist optimization problem writes

$$
\begin{aligned}
& E\left[y \mid L \geq L^{T}\left(s^{*}\right)\right]-F^{\prime}\left(s^{*}\right)=0 \\
& \Leftrightarrow\left(\frac{\bar{L}+L^{T}\left(s^{*}\right)}{2}-F\left(s^{*}\right)\right) \frac{1}{\alpha-s^{*}}-F^{\prime}\left(s^{*}\right)=0 \\
& \Leftrightarrow \bar{L}=\frac{1}{\alpha-s^{*}}\left[2\left(\alpha+s^{*}\right)-\frac{s^{*}}{1-\alpha+s^{*}}-\frac{\beta s^{*}}{\left(1-\alpha-\beta+s^{*}\right) \ln \left(\frac{1}{\alpha-s^{*}}\right)}\right]
\end{aligned}
$$


If $s^{*}=0$, the RHS of Eq. (A.19)) is equal to 2. If $s^{*} \rightarrow \alpha$, the RHS of Eq. (A.19) tends to $+\infty$. It follows that if $\bar{L}>2$, Eq. (A.19) has at least one solution. Rewrite, Eq. (A.19) as

$$
\alpha \bar{L}=2 \alpha+s^{*} \underbrace{\left(2+\bar{L}-\frac{1}{1-\alpha+s^{*}}-\frac{\beta}{\left(1-\alpha-\beta+s^{*}\right) \ln \left(\frac{1}{\alpha-s^{*}}\right)}\right)}_{\equiv f\left(s^{*}\right)}
$$

Since $f^{\prime}()>$.0 and $\lim _{s \rightarrow \alpha} f(s)=1+\bar{L}>0$ implies there exists $\hat{s}$ (possibly equal to 0 ) such that $f(s)>0$ iff $s>\hat{s} . \bar{L}>2$ implies that at $s=0$, the RHS is lower than $2 \alpha$ and therefore, $s \in[0, \hat{s})$ cannot be a solution to Eq. (A.20) since for $s \in[0, \hat{s})$, the RHS is also lower than $2 \alpha$. If $s>\hat{s}$, then $f(s)>0$ and $f^{\prime}(s)>0$ imply that the RHS of Eq. (A.20) is strictly increasing. Therefore, Eq. (A.20) has a unique solution. Hence, if there exists a symmetric equilibrium, this equilibrium is unique, interior (i.e., $\left.s^{*} \in(0, \alpha)\right)$ and defined by the f.o.c. in Eq. (A.17).

The first-order condition in Eq. (A.17) gives a necessary condition for a symmetric equilibrium to exists as otherwise firm $q$ would have incentive to deviate locally from $s^{*}$. Next we analyze the possibility of non-local deviations from $s^{*}$ by firm $q$.

\section{Part II. Proof of Proposition 2: Large Deviations}

*Consider first a deviation to $s_{q}<s^{*}$.

Reminder: let $s_{-} \in\left(0, s^{*}\right]$ be the unique solution to $L_{-}\left(s_{-}\right)=L^{T}\left(s^{*}\right)$, where $L_{-}($.$) is defined$ in Eq. (A.13). If $\beta>0$ then $s_{-}<s^{*}$, and 
- if $s_{q} \leq s_{-}$, then $q$ invests iff $L \geq L_{-}\left(s_{q}\right)=\frac{F\left(s_{q}\right)}{1-\alpha-\beta+s_{q}}$,

- if $s_{q}>s_{-}$, then $q$ invests iff $L \geq L^{T}\left(s^{*}\right)$.

Monopolist $q$ chooses $s_{q}$ to maximize profits

$$
\begin{aligned}
\pi\left(s_{q}\right)= & \int_{L^{T}\left(s^{*}\right)}^{\bar{L}}\left(1-\alpha-\beta+s_{q}\right) \frac{L-F\left(s^{*}\right)}{\alpha-s^{*}}-F\left(s_{q}\right) d L \\
& +\int_{\min \left\{L_{-}\left(s_{q}\right), L^{T}\left(s^{*}\right)\right\}}^{L^{T}\left(s^{*}\right)}\left(1-\alpha-\beta+s_{q}\right) L-F\left(s_{q}\right) d L .
\end{aligned}
$$

The first derivative with respect to $s_{q}$ is

$$
\frac{\partial \pi\left(s_{q}\right)}{\partial s_{q}}=\int_{L^{T}\left(s^{*}\right)}^{\bar{L}} \frac{L-F\left(s^{*}\right)}{\alpha-s^{*}}-F^{\prime}\left(s_{q}\right) d L+\int_{\min \left\{L_{-}\left(s_{q}\right), L^{T}\left(s^{*}\right)\right\}}^{L^{T}\left(s^{*}\right)} L-F^{\prime}\left(s_{q}\right) d L .
$$

Two observations:

1. If $s_{q} \in\left[s_{-}, s^{*}\right), \pi^{\prime}\left(s_{q}\right)$ simplifies to

$$
\int_{L^{T}\left(s^{*}\right)}^{\bar{L}} \frac{L-F\left(s^{*}\right)}{\alpha-s^{*}}-F^{\prime}\left(s_{q}\right) d L>0
$$

since $F^{\prime \prime}>0$. Therefore, monopolist $q$ does not deviate an $s_{q} \in\left[s_{-}, s^{*}\right)$.

2. $\pi^{\prime}($.$) is continuous (though not differentiable at s_{-}$), which implies that when $s_{q} \rightarrow s_{-}$ from below, $\pi^{\prime}\left(s_{q}\right)>0$.

Suppose now $s_{q}<s_{-}$. 


$$
\begin{aligned}
\pi^{\prime \prime}\left(s_{q}\right) & =-\int_{L_{-}\left(s_{q}\right)}^{\bar{L}} F^{\prime \prime}\left(s_{q}\right) d L-\left[L_{-}\left(s_{q}\right)-F^{\prime}\left(s_{q}\right)\right] L_{-}^{\prime}\left(s_{q}\right) \\
& =-\left[\bar{L}-L_{-}\left(s_{q}\right)\right] F^{\prime \prime}\left(s_{q}\right)+\frac{\left[F^{\prime}\left(s_{q}\right)-L_{-}\left(s_{q}\right)\right]^{2}}{1-\alpha-\beta+s_{q}}
\end{aligned}
$$

where we are using (and will use repeatedly) that

$$
L_{-}^{\prime}\left(s_{q}\right)=\frac{\left(1-\alpha-\beta+s_{q}\right) F^{\prime}\left(s_{q}\right)-F\left(s_{q}\right)}{\left(1-\alpha-\beta+s_{q}\right)^{2}}=\frac{F^{\prime}\left(s_{q}\right)-L_{-}\left(s_{q}\right)}{1-\alpha-\beta+s_{q}} .
$$

Next, we calculate the sign of the second derivative $\pi^{\prime \prime}(s)$ in Eq. (A.25). Since $F^{\prime \prime}\left(s_{q}\right)>0$, $\operatorname{sign}\left(\pi^{\prime \prime}\left(s_{q}\right)\right)=\operatorname{sign}\left(\pi^{\prime \prime}\left(s_{q}\right) / F^{\prime \prime}\left(s_{q}\right)\right)$

$$
\frac{\pi^{\prime \prime}\left(s_{q}\right)}{F^{\prime \prime}\left(s_{q}\right)}=-\bar{L}+\underbrace{L_{-}\left(s_{q}\right)+\frac{\left[F^{\prime}\left(s_{q}\right)-L_{-}\left(s_{q}\right)\right]^{2}}{\left(1-\alpha-\beta+s_{q}\right) F^{\prime \prime}\left(s_{q}\right)}}_{\equiv G\left(s_{q}\right)}
$$

$$
\begin{aligned}
G^{\prime}\left(s_{q}\right)= & \frac{F^{\prime}\left(s_{q}\right)-L_{-}\left(s_{q}\right)}{1-\alpha-\beta+s_{q}} \\
& +\frac{2\left[F^{\prime}\left(s_{q}\right)-L_{-}\left(s_{q}\right)\right]\left[F^{\prime \prime}\left(s_{q}\right)-L_{-}^{\prime}\left(s_{q}\right)\right]\left(1-\alpha-\beta+s_{q}\right) F^{\prime \prime}\left(s_{q}\right)}{\left[F^{\prime \prime}\left(s_{q}\right)\left(1-\alpha-\beta+s_{q}\right)\right]^{2}} \\
& -\frac{\left[F^{\prime}\left(s_{q}\right)-L_{-}\left(s_{q}\right)\right]^{2}\left[F^{\prime \prime \prime}\left(s_{q}\right)\left(1-\alpha-\beta+s_{q}\right)+F^{\prime \prime}\left(s_{q}\right)\right]}{\left[F^{\prime \prime}\left(s_{q}\right)\left(1-\alpha-\beta+s_{q}\right)\right]^{2}} .
\end{aligned}
$$


Since $F^{\prime}\left(s_{q}\right)>L_{-}\left(s_{q}\right), G^{\prime}\left(s_{q}\right)$ has the sign of

$$
\begin{aligned}
& {\left[F^{\prime \prime}\left(s_{q}\right)\right]^{2}\left(1-\alpha-\beta+s_{q}\right) } \\
& +2\left[F^{\prime \prime}\left(s_{q}\right)-L_{-}^{\prime}\left(s_{q}\right)\right]\left(1-\alpha-\beta+s_{q}\right) F^{\prime \prime}\left(s_{q}\right) \\
& -\left[F^{\prime}\left(s_{q}\right)-L_{-}\left(s_{q}\right)\right]\left[F^{\prime \prime \prime}\left(s_{q}\right)\left(1-\alpha+s_{q}\right)+F^{\prime \prime}\left(s_{q}\right)\right] \\
= & 3\left[F^{\prime \prime}\left(s_{q}\right)\right]^{2}\left(1-\alpha-\beta+s_{q}\right)-2\left[F^{\prime}\left(s_{q}\right)-L_{-}\left(s_{q}\right)\right] F^{\prime \prime}\left(s_{q}\right) \\
& -\left[F^{\prime}\left(s_{q}\right)-L_{-}\left(s_{q}\right)\right]\left[F^{\prime \prime \prime}\left(s_{q}\right)\left(1-\alpha-\beta+s_{q}\right)+F^{\prime \prime}\left(s_{q}\right)\right] \\
= & 3\left[F^{\prime \prime}\left(s_{q}\right)\right]^{2}\left(1-\alpha-\beta+s_{q}\right) \\
& -\left[F^{\prime}\left(s_{q}\right)-L_{-}\left(s_{q}\right)\right]\left[F^{\prime \prime \prime}\left(s_{q}\right)\left(1-\alpha-\beta+s_{q}\right)+3 F^{\prime \prime}\left(s_{q}\right)\right] \\
= & \frac{12 \alpha^{2}}{\left(\alpha-s_{q}\right)^{6}}\left(1-\alpha-\beta+s_{q}\right)-\frac{6 \alpha^{2}}{\left(\alpha-s_{q}\right)^{6}}\left(1-\alpha-\beta+s_{q}\right) \\
& +\frac{6 \alpha s_{q}}{\left(\alpha-s_{q}\right)^{5}}-\frac{6 \alpha^{2}}{\left(\alpha-s_{q}\right)^{5}}+\frac{6 \alpha s}{(\alpha-s)^{4}\left(1-\alpha-\beta+s_{q}\right)},
\end{aligned}
$$

which, in turn has the sign of

$$
g\left(s_{q}\right) \equiv \alpha\left(1-\alpha-\beta+s_{q}\right)^{2}-(1-\alpha-\beta)\left(\alpha-s_{q}\right)^{2}
$$

There are two possible cases:

(I) $2 \alpha+\beta-1 \leq 0$

Then $g($.$) is concave, g(\alpha)>0$ and $g(0) \geq 0$, therefore, $g()>$.0 for $s_{q} \in\left(0, s_{-}\right)$. It follows that $\pi^{\prime \prime}$ is increasing for $s_{q}=0$ and is strictly increasing for $s \in\left(0, s_{-}\right)$. 
(II) $2 \alpha+\beta-1>0$ Then $g($.$) is convex, g(\alpha)>0$ and $g(0)<0$. It follows that $\pi^{\prime \prime}($.$) is$ first decreasing, then increasing on $[0, \alpha)$.

N.B.: $\pi^{\prime}(0)>0$ and $\pi^{\prime \prime}\left(s_{-}\right)<0$ is then sufficient to rule out the deviation.

Indeed, in (I), $\pi^{\prime \prime}\left(s_{-}\right)<0$ and $\pi^{\prime \prime}$ increasing imply $\pi^{\prime \prime}()<$.0 on $\left[0, s_{-}\right)$. Then since $\pi^{\prime}\left(s_{-}\right)>$ $0, \pi^{\prime}()>$.0 on $\left[0, s_{-}\right)$

In (II), $\pi^{\prime \prime}\left(s_{-}\right)<0$ implies either $\pi^{\prime \prime}()<$.0 on $\left[0, s_{-}\right)$(then back to previous case), or $\pi^{\prime \prime}($. is first positive and then negative. Then since $\pi^{\prime}(0)>0$ and $\pi^{\prime}\left(s_{-}\right)>0, \pi^{\prime}()>$.0 on $\left[0, s_{-}\right)$.

Sufficient conditions for $\pi^{\prime}(0)>0$ and $\pi^{\prime \prime}\left(s_{-}\right)<0$ :

i) $\pi^{\prime}(0)>0$ is true if $\bar{L}$ is large enough, for instance $\bar{L}>\frac{2}{\alpha}$ is sufficient.

ii) $\pi^{\prime \prime}\left(s_{-}\right)<0$ :

From Eq. (A.19), if $\bar{L} \rightarrow+\infty$ then $s^{*} \rightarrow \alpha$, and $\bar{L}\left(\alpha-s^{*}\right) \rightarrow 3 \alpha$. In addition, if $\bar{L} \rightarrow+\infty$ then $L^{T}\left(s^{*}\right) \rightarrow+\infty$ which implies $L_{-}\left(s_{-}\right) \rightarrow+\infty$, which implies $s_{-} \rightarrow \alpha$. Finally, by definition, $L_{-}\left(s_{-}\right)=L^{T}\left(s^{*}\right)$ :

$$
\begin{aligned}
& L_{-}\left(s_{-}\right)\left(\alpha-s^{*}\right)=\frac{s_{-}}{\left(\alpha-s_{-}\right)\left(1-\alpha-\beta+s_{-}\right)}\left(\alpha-s^{*}\right)=L^{T}\left(s^{*}\right)\left(\alpha-s^{*}\right) \\
\Leftrightarrow & \frac{s_{-}}{1-\alpha-\beta+s_{-}} \bar{L}\left(\alpha-s^{*}\right)=L^{T}\left(s^{*}\right)\left(\alpha-s^{*}\right) \bar{L}\left(\alpha-s_{-}\right)
\end{aligned}
$$


Using, $\lim _{\bar{L} \rightarrow+\infty} L^{T}\left(s^{*}\right)\left(\alpha-s^{*}\right)=\alpha, \lim _{\bar{L} \rightarrow+\infty} \bar{L}\left(\alpha-s^{*}\right)=3 \alpha$ and $\lim _{\bar{L} \rightarrow+\infty} s_{-}=\alpha$ yields

$$
\lim _{\bar{L} \rightarrow+\infty} \bar{L}\left(\alpha-s_{-}\right)=\frac{3 \alpha}{1-\beta}
$$

Next, from Eq. (A.25):

$$
\begin{aligned}
\pi^{\prime \prime}\left(s_{-}\right)= & -\left[\bar{L}-L_{-}\left(s_{-}\right)\right] F^{\prime \prime}\left(s_{-}\right)+\frac{\left[F^{\prime}\left(s_{-}\right)-L_{-}\left(s_{-}\right)\right]^{2}}{1-\alpha-\beta+s_{-}} \\
= & -\left[\bar{L}-\frac{s_{-}}{\left(\alpha-s_{-}\right)\left(1-\alpha-\beta+s_{-}\right)}\right] \frac{2 \alpha}{\left(\alpha-s_{-}\right)^{3}} \\
& +\frac{1}{1-\alpha-\beta+s_{-}}\left[\frac{\alpha}{\left(\alpha-s_{-}\right)^{2}}-\frac{s_{-}}{\left(\alpha-s_{-}\right)\left(1-\alpha-\beta+s_{-}\right)}\right]^{2},
\end{aligned}
$$

which has the sign of

$$
-2 \alpha\left[\bar{L}\left(\alpha-s_{-}\right)-\frac{s_{-}}{\left(1-\alpha-\beta+s_{-}\right)}\right]+\frac{\left[\alpha-\frac{\left(\alpha-s_{-}\right) s_{-}}{\left(1-\alpha-\beta+s_{-}\right)}\right]^{2}}{1-\alpha-\beta+s_{-}},
$$

which tends to

$$
-2 \alpha\left(3 \frac{\alpha}{1-\beta}-\frac{\alpha}{1-\beta}\right)+\frac{\alpha^{2}}{1-\beta}=-\frac{3 \alpha^{2}}{1-\beta}<0
$$

when $\bar{L} \rightarrow+\infty$. Therefore there exists $\hat{L}$ such that if $L>\hat{L}, \pi^{\prime \prime}\left(s_{-}\right)<0$.

This concludes the proof that monopolist $q$ does not deviate to $s_{q} \in\left[0, s_{-}\right)$.

* Consider now a deviation to $s_{q}>s^{*}$.

Monopolist $q$ continues if $L \geq \max \left\{\left(\alpha-s^{*}\right) \frac{F\left(s_{q}\right)}{1-\alpha-\beta+s_{q}}+F\left(s^{*}\right), L^{T}\left(s^{*}\right)\right\}$. The monopolist will not deviate to a $s_{q}>s^{*}$ such that $\left(\alpha-s^{*}\right) \frac{F\left(s_{q}\right)}{1-\alpha-\beta+s_{q}}+F\left(s^{*}\right) \leq L^{T}\left(s^{*}\right)$ as Eq. (A.17) implies 
that

$$
s^{*}=\arg \max _{s_{q}} \int_{L^{T}\left(s^{*}\right)}^{\bar{L}} \frac{L-F\left(s^{*}\right)}{\alpha-s^{*}}\left(1-\alpha-\beta+s_{q}\right)-F\left(s_{q}\right) d L=0 .
$$

Consider a large deviation such that $\left(\alpha-s^{*}\right) \frac{F\left(s_{q}\right)}{1-\alpha-\beta+s_{q}}+F\left(s^{*}\right)>L^{T}\left(s^{*}\right)$ The firm would solve

$$
\max _{s_{q}} \frac{1}{\bar{L}} \int_{\left(\alpha-s^{*}\right) \frac{F\left(s_{q}\right)}{1-\alpha-\beta+s_{q}}+F\left(s^{*}\right)}^{\bar{L}} \frac{L-F\left(s^{*}\right)}{\alpha-s^{*}}\left(1-\alpha-\beta+s_{q}\right)-F\left(s_{q}\right) d L,
$$

which yields the following first derivative

$$
\overline{\bar{L}} \int_{\left(\alpha-s^{*}\right) \frac{F\left(s_{q}\right)}{1-\alpha-\beta+s_{q}}+F\left(s^{*}\right)}^{\bar{L}} \frac{L-F\left(s^{*}\right)}{\alpha-s^{*}}-F^{\prime}\left(s_{q}\right) d L,
$$

which also writes as

$$
\frac{\bar{L}-\left(\alpha-s^{*}\right) \frac{F\left(s_{q}\right)}{1-\alpha-\beta+s_{q}}-F\left(s^{*}\right)}{\bar{L}}[\frac{1}{2} \frac{\bar{L}-F\left(s^{*}\right)}{\alpha-s^{*}}+\underbrace{\frac{1}{2} \frac{F\left(s_{q}\right)}{1-\alpha-\beta+s_{q}}-F^{\prime}\left(s_{q}\right)}_{\equiv \Psi\left(s_{q}\right)}] .
$$

Therefore since $\bar{L}>\left(\alpha-s^{*}\right) \frac{F\left(s_{q}\right)}{1-\alpha-\beta+s_{q}}-F\left(s^{*}\right)$ (i.e., monopolist will never deviate to a $s_{q}$ where never produces):

$$
\operatorname{sign}(\text { first derivative })=\operatorname{sign}\left\{\frac{1}{2} \frac{\bar{L}-F\left(s^{*}\right)}{\alpha-s^{*}}+\Psi\left(s_{q}\right)\right\} .
$$


Since $L^{T}\left(s^{*}\right)>\left(\alpha-s^{*}\right) \frac{F\left(s^{*}\right)}{1-\alpha-\beta+s^{*}}+F\left(s^{*}\right)$ and, from Eq. (A.17),

$$
\frac{1}{2} \frac{\bar{L}-F\left(s^{*}\right)}{\alpha-s^{*}}+\frac{1}{2} \frac{L^{T}\left(s^{*}\right)-F\left(s^{*}\right)}{\alpha-s^{*}}-F^{\prime}\left(s^{*}\right)=0
$$

then

$$
\frac{1}{2} \frac{\bar{L}-F\left(s^{*}\right)}{\alpha-s^{*}}+\Psi\left(s^{*}\right)<0
$$

Also

$$
\frac{1}{2} \frac{\bar{L}-F\left(s^{*}\right)}{\alpha-s^{*}}+\Psi(0)=\frac{1}{2} \frac{\bar{L}-F\left(s^{*}\right)}{\alpha-s^{*}}-\frac{1}{\alpha}>\frac{1}{2 \alpha}(\bar{L}-2)>0
$$

where the first inequality follows from

$$
\frac{\bar{L}-F\left(s^{*}\right)}{\alpha-s^{*}}>\frac{\bar{L}}{\alpha} \Rightarrow \alpha F\left(s^{*}\right)<s^{*} \bar{L} \Rightarrow \frac{\alpha}{\alpha-s^{*}}<\bar{L}
$$

which holds since at $\bar{L}$ monopolists make a profit (i.e., $y\left(s^{*}, \bar{L}\right)=\frac{\bar{L}-F\left(s^{*}\right)}{\alpha-s^{*}}>\frac{\bar{L}}{\alpha}=y(0, \bar{L})$ ) and from Eq. (A.17),

$$
\frac{1}{2} \bar{L}+\frac{1}{2} L^{T}\left(s^{*}\right)=\frac{\alpha+s^{*}}{\alpha-s^{*}} \Rightarrow \bar{L}>\frac{\alpha+s^{*}}{\alpha-s^{*}}>\frac{\alpha}{\alpha-s^{*}}
$$

From Eq. (A.47) and Eq. (A.48), $\Psi(0)>\Psi\left(s^{*}\right)$, and therefore, $\Psi^{\prime}(\widehat{s})<0$ for some $\widehat{s}<s^{*}$. 
Notice also that

$$
\begin{aligned}
\frac{\partial \Psi\left(s_{q}\right)}{\partial s_{q}} & =\frac{1}{2} \frac{s_{q}^{2}+\alpha(1-\beta-\alpha)}{\left(1-\alpha-\beta+s_{q}\right)^{2}\left(\alpha-s_{q}\right)^{2}}-\frac{2 \alpha}{\left(\alpha-s_{q}\right)^{3}} \\
& =\frac{\left(s_{q}^{2}+\alpha(1-\beta-\alpha)\right)\left(\alpha-s_{q}\right)-4 \alpha\left(1-\alpha-\beta+s_{q}\right)^{2}}{2\left(1-\alpha-\beta+s_{q}\right)^{2}\left(\alpha-s_{q}\right)^{2}} \\
& =\frac{-s_{q}^{3}-3 \alpha s_{q}^{2}-9 \alpha(1-\beta-\alpha) s_{q}+9 \alpha^{2}(1-\beta)-4 \alpha(1-\beta)^{2}-5 \alpha^{3}}{2\left(1-\alpha-\beta+s_{q}\right)^{2}\left(\alpha-s_{q}\right)^{2}}
\end{aligned}
$$

which implies that if $\Psi^{\prime}(\widehat{s})<0$ then $\Psi^{\prime}\left(s_{q}\right)<0$ for all $s_{q}>\widehat{s}$, and therefore, that $\Psi\left(s^{*}\right)>$ $\Psi\left(s_{q}\right)$ for all $s_{q}>s^{*}$. Since $\Psi\left(s^{*}\right)>\Psi\left(s_{q}\right)$ for all $s_{q}>s^{*}$, from Eq. (A.47), it follows that

$$
\operatorname{sign}\left(\text { first derivative }=\operatorname{sign}\left\{\frac{1}{2} \frac{\bar{L}-F\left(s^{*}\right)}{\alpha-s^{*}}+\Psi\left(s_{q}\right)\right\}<0 \text { for all } s_{q}>s^{*},\right.
$$

and therefore, there are no incentives to deviate to an $s_{q}>s^{*}$ such that $\left(\alpha-s^{*}\right) \frac{F\left(s_{q}\right)}{1-\alpha-\beta+s_{q}}+$ $F\left(s^{*}\right)>L^{T}\left(s^{*}\right)$. Q.E.D.

\section{Proof of Proposition 3}

The social planner maximizes over

$$
s^{o p t} \in \underset{s}{\operatorname{argmax}} \int_{\left.\min \left\{L^{T}(s), \bar{L}\right\}\right)}^{\bar{L}}(1-\alpha-\beta+s) \frac{L-F(s)}{\alpha-s}-F(s) d L
$$


Since at the optimum $L^{T}(s)<\bar{L}$, the first-order derivative writes

$$
\begin{aligned}
& \int_{L^{T}(s)}^{\bar{L}} \frac{L-F(s)}{\alpha-s}-F^{\prime}(s) d L+(1-\alpha-\beta+s) \int_{L^{T}(s)}^{\bar{L}} \frac{\partial}{\partial s}\left(\frac{L-F(s)}{\alpha-s}\right) d L \\
& -\left[(1-\alpha-\beta+s) \frac{L^{T}(s)-F(s)}{\alpha-s}-F(s)\right] \frac{\partial L^{T}(s)}{\partial s}
\end{aligned}
$$

Consider the three above terms in turn

- We have shown in the proof of Proposition 2 (local conditions) that $\int_{L^{T}(s)}^{\bar{L}} \frac{L-F(s)}{\alpha-s}-F^{\prime}(s)$ is 0 at $s^{*}$ and strictly negative for $s>s^{*}$.

- Next,

$$
\int_{L^{T}(s)}^{\bar{L}} \frac{\partial}{\partial s}\left(\frac{L-F(s)}{\alpha-s}\right)=\frac{1}{\alpha-s} \int_{L^{T}(s)}^{\bar{L}} \frac{L-F(s)}{\alpha-s}-F^{\prime}(s)
$$

which, as above, is 0 at $s^{*}$ and strictly negative for $s>s^{*}$.

- Finally, $\frac{\partial L^{T}(s)}{\partial s}>0$ and, at the operating threshold (i.e., at $L=L^{T}(s)$ ) firms make a strictly positive profit:

$$
(1-\alpha-\beta+s) \frac{L^{T}(s)-F(s)}{\alpha-s}-F(s)>0
$$

for any $s$.

It follows, that first-order derivative in Eq. (A.56) is negative for any $s \geq s^{*}$, that is, in equilibrium there is excessive risk-taking. Q.E.D. 


\section{Proof of Proposition 4}

Assume that for any (common) leverage $s$, monopolists coordinate on the Pareto-superior equilibrium in the production game, that is, from Eq. (9) monopolists produce at $t=1$ if and only if

$$
L \geq L^{+}(s) \equiv(1-\beta) \frac{F(s)}{1-\alpha-\beta+s} .
$$

Consider a deviation by monopolist $q$ : monopolist $q$ chooses $s_{q}$ when all other monopolists choose leverage $s$. Monopolist $q$ produces if and only if

$$
L \geq L^{+}\left(s_{q}, s\right) \equiv\left\{\begin{array}{l}
\min \left\{\frac{F\left(s_{q}\right)}{1-\alpha-\beta+s_{q}}, L^{+}(s)\right\} \quad \text { if } s_{q}<s \\
(\alpha-s) \frac{F\left(s_{q}\right)}{1-\alpha-\beta+s_{q}}+F(s) \text { if } s_{q} \geq s
\end{array}\right.
$$

The f.o.c. of $s_{q}$ when all other monopolists choose $s^{*}$ writes:

$$
\frac{\partial}{\partial s_{q}} \int_{L^{+}\left(s_{q}, s^{*}\right)}^{\bar{L}} \frac{L-F\left(s^{*}\right)}{\alpha-s^{*}}\left(1-\alpha-\beta+s_{q}\right)-\left.F\left(s_{q}\right) d L\right|_{s_{q}=s^{*}}=0
$$

Since $L^{+}(s, s)=L^{+}(s)$, and for any $s$,

$$
\frac{L^{+}(s)-F(s)}{\alpha-s}(1-\alpha-\beta+s)-F(s)=0
$$

a marginal change in $s_{q}$ around $s^{*}$ only affects the integral in Eq. (A.61) through its inte- 
grand. Therefore, Eq. (A.61) writes:

$$
\begin{aligned}
& \int_{L^{+}\left(s^{*}\right)}^{\bar{L}} \frac{L-F\left(s^{*}\right)}{\alpha-s^{*}}-F^{\prime}\left(s^{*}\right) d L=0 . \\
\Leftrightarrow & \left(\frac{\bar{L}+L^{+}\left(s^{*}\right)}{2}-F\left(s^{*}\right)\right) \frac{1}{\alpha-s^{*}}-F^{\prime}\left(s^{*}\right)=0 \\
\Leftrightarrow & \bar{L}=2\left(\alpha-s^{*}\right) F^{\prime}\left(s^{*}\right)+\left(2-\frac{1-\beta}{1-\alpha-\beta+s^{*}}\right) F\left(s^{*}\right)
\end{aligned}
$$

If $s^{*}=0$, the RHS of Eq. (A.65) is equal to 2. If $s^{*} \rightarrow \alpha$, the RHS of Eq. (A.65) tends to $+\infty$. It follows that if $\bar{L}>2$, Eq. (A.65) has at least one solution. Rewrite Eq. (A.65) as

$$
\bar{L} \alpha=2 \alpha+s^{*} \underbrace{\left(\bar{L}+2-\frac{1-\beta}{1-\alpha-\beta+s^{*}}\right)}_{\equiv h\left(s^{*}\right)}
$$

Since $h^{\prime}()>$.0 and $\lim _{s \rightarrow \alpha} h(s)=\bar{L}+1>0$, there exists $\hat{s}$ (possibly equal to 0 ) such that $h(s)>0$ iff $s>\hat{s} . \bar{L}>2$ implies that at $s=0$, the RHS is lower than $2 \alpha$ and therefore, $s \in[0, \hat{s})$ cannot be a solution to Eq. (A.66) since for $s \in[0, \hat{s})$, the RHS is also lower than $2 \alpha$. If $s>\hat{s}$, then $h(s)>0$ and $h^{\prime}(s)>0$ imply that the RHS of Eq. (A.66) is strictly increasing. Therefore, Eq. (A.66) has a unique solution. Hence, if there exists a symmetric equilibrium, this equilibrium is unique, interior (i.e., $s^{*} \in(0, \alpha)$ ) and defined by the f.o.c. in Eq. (A.63).

As explained in the main text, maximizing consumers' expected utility amounts to maximizing their expected income from corporate profits. Therefore, the social planner's problem 
maximizes

$$
\max _{s} \frac{1}{\bar{L}} \int_{\min \left\{L^{+}(s), \bar{L}\right\}}^{\bar{L}} y(s, L)(1-\alpha-\beta+s)-F(s) d L,
$$

where, as earlier, $y(s, L)=\frac{L-F(s)}{\alpha-s}$. Since at the social optimum $s^{* *}, L^{+}\left(s^{* *}\right)<\bar{L}$, and using Eq. (A.62) again, the f.o.c of the problem in Eq. (A.67) writes

$$
\begin{aligned}
& \frac{1}{\bar{L}} \int_{L^{+}\left(s^{* *}\right)}^{\bar{L}} \frac{\partial y\left(s^{* *}, L\right)}{\partial s}\left(1-\alpha-\beta+s^{* *}\right)+y\left(s^{* *}, L\right)-F^{\prime}\left(s^{* *}\right) d L=0 \\
\Leftrightarrow & \int_{L^{+}\left(s^{* *}\right)}^{\bar{L}} \frac{-F^{\prime}\left(s^{* *}\right)+y\left(s^{* *}, L\right)}{\left(\alpha-s^{* *}\right)}\left(1-\alpha-\beta+s^{* *}\right)+y\left(s^{* *}, L\right)-F^{\prime}\left(s^{* *}\right) d L=0 \\
\Leftrightarrow & \int_{L^{+}\left(s^{* *}\right)}^{\bar{L}} y\left(s^{* *}, L\right)-F^{\prime}\left(s^{* *}\right) d L=0
\end{aligned}
$$

Therefore, Eq. (A.70) holds at $s^{* *}=s^{*}$ (i.e., the equilibrium leverage satisfies the first-order condition of the social planner). Notice also that (i) as $s \rightarrow \alpha$ then $L^{+}(s) \rightarrow+\infty$ and the objective function in Eq. (A.67) $\rightarrow 0$; and (ii) if $\bar{L}>2$, the first derivative (see Eq. (A.70)) evaluated at $s^{* *}=0$ is positive:

$$
\operatorname{sign}\left\{\int_{L^{+}(0)}^{\bar{L}} y(0, L)-F^{\prime}(0) d L\right\}=\operatorname{sign}\left\{\int_{0}^{\bar{L}} \frac{L}{\alpha}-\frac{1}{\alpha} d L\right\}=\operatorname{sign}\left\{\frac{\bar{L}}{2}-1\right\}>0,
$$

then there is at interior optimum $s^{* *} \in(0, \alpha)$, which needs to satisfy f.o.c. in Eq. (A.70). Since Eq. (A.63) and Eq. (A.70) coincide, and since we showed above that there is a unique interior solution, $s^{*}$, to Eq. (A.63), it follows that $s^{* *}=s^{*}$. In words, if there is a symmetric equilibrium, it is unique and maximizes welfare. Q.E.D. 


\section{Proof of Proposition 5}

Consider first the case where the government commits to have the $m$-mass of monopolists produce for $L \geq \frac{(1-\beta) F(s)}{1-\alpha-\beta+s}$, that is, whenever it is Pareto-optimal for all monopolists to produce. (It would never be optimal to commit to produce below $\frac{(1-\beta) F(s)}{1-\alpha-\beta+s}$ as in such case, the $m$-mass of monopolists would exert a negative demand externality on the rest of the economy: when $L<\frac{(1-\beta) F(s)}{1-\alpha-\beta+s}$, monopolists would be making a loss with probability one.) Turn to the other $(1-m)$-mass of monopolist. As in Proposition 1, assume that monopolist $q$ produces if and only if $l_{q}>l^{*}$. Then for a given $L$ and for $\varepsilon$ small enough, the mass of active monopolists is

$$
n(L) \equiv \begin{cases}1 & \text { if } L>l^{*}+\varepsilon \\ m+(1-m) \frac{L+\varepsilon-l^{*}}{2 \varepsilon} & \text { if } L \in\left[l^{*}-\varepsilon, l^{*}+\varepsilon\right] \\ 0 & \text { if } L<l^{*}-\varepsilon\end{cases}
$$

A monopolist with signal $l^{*}$ must be indifferent between producing and not producing:

$$
\frac{1}{2 \varepsilon} \int_{l^{*}-\varepsilon}^{l^{*}+\varepsilon}(1-\alpha-\beta+s) \frac{L-n(L) F}{1-n(L)(1-\alpha+s)}-F d L=0
$$

Eq. (A.73) implicitly defines a unique $l^{*}(\varepsilon)$, which is strictly greater than $\frac{(1-\beta) F(s)}{1-\alpha-\beta+s}$ for $m \in$ $[0,1)$. (For $\varepsilon$ small enough, $l^{*}(\varepsilon)-\varepsilon$ is also strictly greater than $\frac{(1-\beta) F(s)}{1-\alpha-\beta+s}$.) Note that under 
the government's proposed strategy (i.e., to coordinate production among the $m$-mass of monopolists when $\left.L \geq \frac{(1-\beta) F(s)}{1-\alpha-\beta+s}\right)$, improved coordination comes at the cost of losses for $L$ close enough to $\frac{(1-\beta) F(s)}{1-\alpha-\beta+s}$ from above: in the absence of positive demand externalities from the $(1-m)$-mass of monopolists, production by the $m$-mass of monopolists for $L$ close to $\frac{(1-\beta) F(s)}{1-\alpha-\beta+s}$ carries a loss. To mitigate this problem, suppose that instead of producing for $L \geq \frac{(1-\beta) F(s)}{1-\alpha-\beta+s}$, government commits to produce for $L \geq l^{*}(\varepsilon)-\varepsilon$ where $l^{*}(\varepsilon)$ is still defined by Eq. (A.73). Note that investing if and only if $l_{q}>l^{*}(\varepsilon)$ still is the unique equilibrium of the production game among the $(1-m)$-mass of monopolists. Next we characterized $l^{*}(\varepsilon)$ as $\varepsilon \rightarrow 0$. Start from Eq. (A.73) and consider the following change of variable: $z=\frac{L+\varepsilon-l^{*}}{2 \varepsilon} \Leftrightarrow L=2 \varepsilon z+l^{*}-\varepsilon$. Eq. (A.73) becomes

$$
\int_{0}^{1}(1-\alpha-\beta+s) \frac{2 \varepsilon z+l^{*}-\varepsilon-(m+(1-m) z) F}{1-(m+(1-m) z)(1-\alpha+s)}-F d z=0
$$


Taking the limit when $\varepsilon \rightarrow 0$ and defining $L^{T}$ as the limit of $l^{*}$ when $\varepsilon \rightarrow 0$, Eq. (A.73) writes

$$
\begin{aligned}
& \int_{0}^{1}(1-\alpha-\beta+s) \frac{L^{T}-(m+(1-m) z) F}{1-(m+(1-m) z)(1-\alpha+s)}-F d z=0 \\
\Leftrightarrow & \frac{1-\alpha-\beta+s}{1-\alpha+s} \int_{0}^{1} \frac{(1-\alpha+s) L^{T}-(m+(1-m) z)(1-\alpha+s) F}{1-(m+(1-m) z)(1-\alpha+s)} d z-F=0 \\
\Leftrightarrow & \frac{1-\alpha-\beta+s}{1-\alpha+s} \int_{0}^{1} \frac{(1-\alpha+s) L^{T}-F}{1-(m+(1-m) z)(1-\alpha+s)} d z-\frac{\beta}{1-\alpha+s} F=0 \\
\Leftrightarrow & -\frac{1-\alpha-\beta+s}{(1-m)(1-\alpha+s)^{2}}\left[(1-\alpha+s) L^{T}-F\right][\ln (\alpha-s)-\ln (1-m(1-\alpha+s)] \\
& -\frac{\beta}{1-\alpha+s} F=0 \\
\Leftrightarrow & \frac{1-\alpha-\beta+s}{(1-m)(1-\alpha+s)}\left[(1-\alpha+s) L^{T}-F\right] \ln \left(\frac{1-m(1-\alpha+s)}{\alpha-s}\right)-\beta F=0
\end{aligned}
$$

This in turn implies

$$
L^{T}(s, m)=\frac{F}{1-\alpha+s}+\frac{\beta(1-m) F}{(1-\alpha-\beta+s) \ln \left(\frac{1-m(1-\alpha+s)}{\alpha-s}\right)}
$$

Note that $\frac{\partial L^{T}(s, m)}{\partial m}$ has the sign of

$$
\begin{aligned}
& -\ln \left[\frac{1-m(1-\alpha+s)}{\alpha-s}\right]+(1-m) \frac{1-\alpha+s}{1-m(1-\alpha+s)} \\
= & 1+\ln \left[\frac{\alpha-s}{1-m(1-\alpha+s)}\right]-\frac{\alpha-s}{1-m(1-\alpha+s)}<0
\end{aligned}
$$

since $1-m(1-\alpha+s)>\alpha-s>0$ and $1+\ln (x)-x<0$ for $x \in(0,1)$. 
Note that

$$
\lim _{m \rightarrow 1} \frac{1-m}{\ln \left(\frac{1-m(1-\alpha+s)}{\alpha-s}\right)}=\frac{\alpha-s}{1-\alpha+s}
$$

which, plugged into the expression of $L^{T}(s, m)$ yields $\lim _{m \rightarrow 1} L^{T}(s, m)=\frac{(1-\beta) F(s)}{1-\alpha-\beta+s}$.

Finally note that as $\varepsilon \rightarrow 0$, the production threshold of the $m$-mass of government-controlled firms $l^{*}(\varepsilon)-\varepsilon$ tends to the $(1-m)$-mass of monopolists' production threshold $L^{T}(s, m)$. This implies at the limit where $\varepsilon \rightarrow 0$, the profits of the $m$-mass of monopolists are positive almost certainly when they produce. Q.E.D.

\section{Proof of Corollary 1}

Recall that the production threshold $L^{T}(s, m)$ of the $(1-m)$-mass of monopolists is derived in the proof of Proposition 5 from the limit when $\varepsilon \rightarrow 0$ of the indifference condition in Eq. (A.73). That indifference condition states that the marginal independent monopolist should be indifferent between producing and not producing given the strategy of the other independent monopolists (mass $1-m$ ) and assuming that all government-controlled monopolist (mass $m$ ) produce. It follows that $L^{T}(s, m)$ is the smallest realization of $L$ above which the $(1-m)$-mass of monopolists produce for any strategy followed by the $m$-mass of monopolists.

Consider next the condition that implicitly defines $L^{T}(s, m)$ in Eq. (A.79):

$$
\int_{0}^{1}(1-\alpha-\beta+s) \frac{L^{T}(s, m)-(m+(1-m) z) F}{1-(m+(1-m) z)(1-\alpha+s)}-F d z=0
$$


The function $\frac{L-x F}{1-x(1-\alpha+s)}$ is strictly increasing in $x$ for $L>\frac{F}{1-\alpha+s}$ and $L^{T}(s, m)>\frac{F}{1-\alpha+s}$. Therefore, Eq. (A.84) implies

$$
\int_{0}^{1}(1-\alpha-\beta+s) \frac{L^{T}(s, m)-m F}{1-m(1-\alpha+s)}-F d z=(1-\alpha-\beta+s) \frac{L^{T}(s, m)-m F}{1-m(1-\alpha+s)}-F<0
$$

That is, at $L^{T}(s, m)$ and a fortiori for $L<L^{T}(s, m)$, the $m$-mass of monopolists make strictly negative profits if they produce and the $(1-m)$-mass of independent monopolists do not. Therefore, the optimal government strategy for $L<L^{T}(s, m)$ is for the $m$-mass of monopolists not to produce. It follows that all monopolists producing if and only if $L \geq L^{T}(s, m)$ is the highest output the government can induce for any production strategy of the $m$-mass of monopolists it controls. Q.E.D.

\section{Proof of Proposition 6}

The proof of Proposition 6 follows the same line as the proof of Proposition 2 of the baseline model. We just show here the comparative statics with respect to $m$. Eq. (A.19) in the proof of Proposition 2 is equivalent to

$$
\alpha \bar{L}=2 \alpha+s^{*} \underbrace{\left(2+\bar{L}-\frac{1}{1-\alpha+s^{*}}-\frac{(1-m) \beta}{\left(1-\alpha-\beta+s^{*}\right) \ln \left(\frac{1-m\left(1-\alpha+s^{*}\right)}{\alpha-s^{*}}\right)}\right)}_{\equiv f\left(s^{*}, m\right)}
$$

As in the baseline model, if $\bar{L}>2$, Eq. (A.86)) has a unique solution. Furthermore, $f\left(s^{*}, m\right)>0, f_{1}(s, m)>0$ and $f_{2}(s, m)>0$. Total differentiation of Eq. (A.86) with 
respect to $m$ yields

$$
\begin{aligned}
& \frac{\partial s^{*}(m)}{\partial m} f\left(s^{*}, m\right)+s^{*}\left[f_{1}\left(s^{*}, m\right) \frac{\partial s^{*}(m)}{\partial m}+f_{2}\left(s^{*}, m\right)\right]=0 \\
\Leftrightarrow & \frac{\partial s^{*}(m)}{\partial m}=-\frac{f_{2}\left(s^{*}, m\right)}{f\left(s^{*}, m\right)+s^{*} f_{1}\left(s^{*}, m\right)}<0 .
\end{aligned}
$$

Q.E.D.

\section{Proof of Proposition 7}

The first derivative of the $W(s, m)$ in Eq. (23) writes

$$
\frac{d W\left(s^{*}(m), m\right)}{d m}=\frac{\partial}{\partial s} W\left(s^{*}, m\right) \frac{\partial}{\partial m} s^{*}(m)+\frac{\partial}{\partial m} W\left(s^{*}, m\right)
$$

$L^{T}\left(s^{*}(m), m\right)>\frac{(1-\beta) F(s)}{1-\alpha-\beta+s}$ implies that monopolists make positive profits at the threshold $L^{T}\left(s^{*}(m), m\right)$, which, as in the baseline model (see Proposition 3) implies $\frac{\partial}{\partial s} W\left(s^{*}, m\right)<0$. From Proposition 6, $\frac{\partial s^{*}(m)}{\partial m}<0$ so the first term in Eq. (A.89) is positive. From Proposition 5, a higher $m$ induces monopolists to coordinate more often on the Pareto-superior production action (i.e., $L^{T}(s, m)$ is increasing in $\left.m \in[0,1)\right)$, which implies that $\frac{\partial}{\partial m} W\left(s^{*}, m\right)>0$ (i.e., that the second term in Eq. (A.89) is strictly positive) and therefore, that $\frac{d W\left(s^{*}(m), m\right)}{d m}>0$. From Proposition 5, production is optimal for a given $s$ when $m \rightarrow 1$, from Proposition 6 there is a unique symmetric operating leverage equilibrium at $t=0$, and from Proposition 4 , if firms coordinate on the Pareto-optimal production plan at $t=1$, the symmetric operating 
leverage equilibrium at $t=0$ is socially optimal. Q.E.D.

Proof of Proposition 8

Define $\beta^{\prime} \equiv \frac{\beta}{1-p}$. Monopolist $q$ profits are

$$
\pi_{q}=\left(1-\beta^{\prime}-\alpha+s_{q}\right) y-F\left(s_{q}\right) .
$$

Given a set $\mathcal{A} \subset[0,1]$ of active monopolists, aggregate income at $t=1$ is the sum of profits and labor income,

$$
y=\int_{q \in \mathcal{A}}\left(1-\beta^{\prime}-\alpha+s_{q}\right) y-F\left(s_{q}\right) d q+L+\int_{q \in \mathcal{A}} \beta^{\prime} y d q .
$$

From Eq. (A.91), monitoring does not affect aggregate income $y$ for a given set of active monopolists $\mathcal{A}$ : monitoring reduces the profit of each active monopolist by $\beta^{\prime} y$ but increases labor income by the same amount. Hence, the expression for $y$ obtained from Eq. (A.91) is as in Eq. (4),

$$
y=\frac{L-\int_{q \in \mathcal{A}} F\left(s_{q}\right) d q}{1-\int_{q \in \mathcal{A}} 1-\alpha+s_{q} d q} .
$$

Consider the case in which all monopolists choose the same operating leverage $s$ at $t=0$.

Then combining Eq. (A.90) and Eq. (A.91), a monopolist does not operate if no other 
monopolist operates (if $\mathcal{A}=\{\emptyset\}$ ) when

$$
L<\frac{F(s)}{1-\alpha-\beta^{\prime}+s} .
$$

Conversely, a monopolist operates if all other monopolists operate (if $\mathcal{A}=[0,1]$ ) when

$$
L>\frac{\left(1-\beta^{\prime}\right) F(s)}{1-\alpha-\beta^{\prime}+s}
$$

Therefore, if

$$
L \in\left(\frac{\left(1-\beta^{\prime}\right) F(s)}{1-\alpha-\beta^{\prime}+s}, \frac{F(s)}{1-\alpha-\beta^{\prime}+s}\right)
$$

Notice that Eq. (3), Eq. (8), Eq. (9), and Eq. (10) are identical to Eq. (A.90), Eq. (A.93), Eq. (A.94), and Eq. (A.95) except that the first four equations depend on parameter $\beta$ and the last four depend on parameter $\beta^{\prime}$. Therefore, an equivalent to Proposition 1 still holds, that is, if monopolists choose $s$, they operate at $t=1$ if $L \geq L_{\beta^{\prime}}^{T}(s)$ where

$$
L_{\beta^{\prime}}^{T}(s) \equiv \frac{F(s)}{1-\alpha+s}+\frac{\beta^{\prime} F(s)}{\left(1-\alpha-\beta^{\prime}+s\right) \ln \left(\frac{1}{\alpha-s}\right)} .
$$

Therefore, aggregate income is then given by

$$
y_{\beta^{\prime}}(s, L) \equiv\left\{\begin{array}{ll}
\frac{L-F(s)}{\alpha-s} & \text { if } L \geq L_{\beta^{\prime}}^{T}(s) \\
L & \text { if } L<L_{\beta^{\prime}}^{T}(s)
\end{array} .\right.
$$


Suppose monopolist $q$ chooses operating leverage $s_{q}$ while all other monopolists choose $s$. Monopolist $q$ produces when it makes a profit, that is, when

$$
\left(1-\alpha-\beta^{\prime}+s_{q}\right) y_{\beta^{\prime}}(s, L)-F\left(s_{q}\right) \geq 0
$$

or equivalently, when

$$
L \geq \hat{L}_{\beta^{\prime}}\left(s_{q}, s\right) \equiv \begin{cases}\max \left\{(\alpha-s) \frac{F\left(s_{q}\right)}{1-\alpha-\beta^{\prime}+s_{q}}+F(s), L_{\beta^{\prime}}^{T}(s)\right\} & \text { if } s_{q} \geq s, \\ \min \left\{\frac{F\left(s_{q}\right)}{1-\alpha-\beta^{\prime}+s_{q}}, L_{\beta^{\prime}}^{T}(s)\right\} & \text { if } s_{q}<s .\end{cases}
$$

Then $s_{\beta^{\prime}}^{*}$ is an equilibrium if and only if

$$
s_{\beta^{\prime}}^{*} \in \underset{s_{q}}{\operatorname{argmax}} \int_{\min \left\{\hat{L}_{\beta^{\prime}}\left(s_{q}, s_{\beta^{\prime}}^{*}\right), \bar{L}\right\}}^{\bar{L}}\left(1-\alpha-\beta+s_{q}\right) y_{\beta^{\prime}}\left(s_{\beta^{\prime}}^{*}, L\right)-F\left(s_{q}\right) d L .
$$

Notice that Eq. (17) and Eq. (A.100) identical except that the first equation depends on parameter $\beta$ and the second equation depends on parameter $\beta^{\prime}$. Therefore, one can show that an equivalent to Proposition 2 holds: there exists a unique symmetric equilibrium $s_{\beta^{\prime}}^{*}$ defined by

$$
\mathbb{E}\left[y \mid L \geq L_{\beta^{\prime}}^{T}\left(s_{\beta^{\prime}}^{*}\right)\right]-F^{\prime}\left(s_{\beta^{\prime}}^{*}\right)=0 .
$$


The social planer chooses leverage at $t=0$ but cannot avoid coordination failures at $t=1$. Hence, the constrained social optimum is

$$
\begin{aligned}
s_{\beta^{\prime}}^{\text {opt }} \in \underset{s}{\operatorname{argmax}} & \int_{\min \left\{L_{\beta^{\prime}}^{T}(s), \bar{L}\right\}}^{\bar{L}}\left(1-\alpha-\beta^{\prime}+s\right) y_{\beta^{\prime}}(s, L)-F(s) d L+ \\
& +\int_{\min \left\{L_{\beta^{\prime}}^{T}(s), \bar{L}\right\}}^{\bar{L}}\left(\beta^{\prime}-\beta\right) y_{\beta^{\prime}}(s, L) d L .
\end{aligned}
$$

Notice that the social planer's optimization problem in Eq. (A.102) is different from the problem in Eq. (19). In Eq. (19), the extra labor income $\beta y$ earned by supervisors in states in which monopolists are active merely compensates them for their effort cost and therefore, labor income net of monitoring disutility always sums up to $L$. Consequently, in Eq. (19) maximizing consumers' expected utility amounts to maximizing their expected income from corporate profits. However, in Eq. (A.102) the extra labor income $\beta^{\prime} y$ earned by supervisors in states in which monopolists are active more than compensates them for their effort cost $\beta y$. Consequently, in Eq. (A.102) maximizing consumers' expected utility amounts to maximizing the sum of the expected income from corporate profits plus the expected supervisors' rent. Since at the optimum $L_{\beta^{\prime}}^{T}(s)<\bar{L}$, the first-order derivative of 
the problem in Eq. (A.102) writes

$$
\begin{aligned}
& \int_{L_{\beta^{\prime}}^{T}(s)}^{\bar{L}} \frac{L-F(s)}{\alpha-s}-F^{\prime}(s) d L+\left(1-\alpha-\beta^{\prime}+s\right) \int_{L_{\beta^{\prime}}^{T}(s)}^{\bar{L}} \frac{\partial}{\partial s}\left(\frac{L-F(s)}{\alpha-s}\right) d L \\
& -\left[\left(1-\alpha-\beta^{\prime}+s\right) \frac{L_{\beta^{\prime}}^{T}(s)-F(s)}{\alpha-s}-F(s)\right] \frac{\partial L_{\beta^{\prime}}^{T}(s)}{\partial s} \\
& +\left(\beta-\beta^{\prime}\right) \int_{L_{\beta^{\prime}}^{T}(s)}^{\bar{L}} \frac{\partial}{\partial s}\left(\frac{L-F(s)}{\alpha-s}\right) d L \\
& \left.-\left[\left(\beta-\beta^{\prime}\right) \frac{L_{\beta^{\prime}}^{T}(s)-F(s)}{\alpha-s}\right)\right] \frac{\partial L_{\beta^{\prime}}^{T}(s)}{\partial s}
\end{aligned}
$$

which can be rewritten as

$$
\begin{aligned}
& \int_{L_{\beta^{\prime}}^{T}(s)}^{\bar{L}} \frac{L-F(s)}{\alpha-s}-F^{\prime}(s) d L+(1-\alpha-\beta+s) \int_{L_{\beta^{\prime}}^{T}(s)}^{\bar{L}} \frac{\partial}{\partial s}\left(\frac{L-F(s)}{\alpha-s}\right) d L \\
& -\left[(1-\alpha-\beta+s) \frac{L_{\beta^{\prime}}^{T}(s)-F(s)}{\alpha-s}-F(s)\right] \frac{\partial L_{\beta^{\prime}}^{T}(s)}{\partial s}
\end{aligned}
$$

Consider the above three terms in turn:

- Similarly to what we showed in the proof of Proposition 2, one can show that $\int_{L_{\beta^{\prime}}^{T}(s)}^{\bar{L}} \frac{L-F(s)}{\alpha-s}-F^{\prime}(s)$ is 0 at $s_{\beta^{\prime}}^{*}$ and strictly negative for $s>s_{\beta^{\prime}}^{*}$.

- Next,

$$
\int_{L_{\beta^{\prime}}^{T}(s)}^{\bar{L}} \frac{\partial}{\partial s}\left(\frac{L-F(s)}{\alpha-s}\right)=\frac{1}{\alpha-s} \int_{L_{\beta^{\prime}}^{T}(s)}^{\bar{L}} \frac{L-F(s)}{\alpha-s}-F^{\prime}(s),
$$

which, as above, is 0 at $s_{\beta^{\prime}}^{*}$ and strictly negative for $s>s_{\beta^{\prime}}^{*}$.

- Finally, $\frac{\partial L_{\beta^{\prime}}^{T}(s)}{\partial s}>0$ and, at the operating threshold (i.e., at $\left.L=L_{\beta^{\prime}}^{T}(s)\right)$ firms make a 
strictly positive profit:

$$
(1-\alpha-\beta+s) \frac{L_{\beta^{\prime}}^{T}(s)-F(s)}{\alpha-s}>\left(1-\alpha-\beta^{\prime}+s\right) \frac{L_{\beta^{\prime}}^{T}(s)-F(s)}{\alpha-s}-F(s)>0
$$

for any $s$.

It follows, that first-order derivative in Eq. (A.104) is negative for any $s \geq s_{\beta^{\prime}}^{*}$, that is, in equilibrium there is excessive risk-taking.

Similarly to Eq. (A.20), which defines $s^{*}$, the following equation defines $s_{\beta^{\prime}}^{*}$ :

$$
\alpha \bar{L}=2 \alpha+s_{\beta^{\prime}}^{*} \underbrace{\left(2+\bar{L}-\frac{1}{1-\alpha+s_{\beta^{\prime}}^{*}}-\frac{\beta^{\prime}}{\left(1-\alpha-\beta^{\prime}+s_{\beta^{\prime}}^{*}\right) \ln \left(\frac{1}{\alpha-s_{\beta^{\prime}}^{*}}\right)}\right)}_{\equiv f\left(s_{\beta^{\prime}}^{*}\right)}
$$

Since, $\frac{\beta^{\prime}}{1-\alpha-\beta^{\prime}+s}$ is increasing in $\beta^{\prime}$ for $1-\alpha+s$ and since $\beta^{\prime}$ is increasing in $p$, then the RHS is decreasing in $p$ given $s_{\beta^{\prime}}^{*}$. Since $f^{\prime}()>$.0 the RHS is increasing in $s_{\beta^{\prime}}^{*}$ given $\beta^{\prime}$ (i.e., given $p)$. Therefore, $s_{\beta^{\prime}}^{*}$ is increasing in $p$.

Let $W(s, p)$ be the welfare function where

$$
W(s, p) \equiv \int_{\min \left\{L_{\beta^{\prime}}^{T}(s), \bar{L}\right\}}^{\bar{L}}(1-\alpha-\beta+s) y_{\beta^{\prime}}(s, L)-F(s) d L
$$

(See Eq. (A.102).) Since $L_{\beta^{\prime}}^{T}(s)$ depends on $\beta^{\prime}$ for any $s$ (see Eq. (A.96)) and since $s_{\beta^{\prime}}^{*}$ depends 
on $\beta^{\prime}$ (see Eq. (A.107)) then:

$$
\begin{aligned}
\frac{d W\left(s_{\beta^{\prime}}^{*}, p\right)}{d p}= & \frac{\partial W\left(s_{\beta^{\prime}}^{*}, p\right)}{\partial s_{\beta^{\prime}}^{*}} \frac{\partial s_{\beta^{\prime}}^{*}}{\partial p}+\frac{\partial W\left(s_{\beta^{\prime}}^{*}, p\right)}{\partial p} \\
= & \frac{\partial W\left(s_{\beta^{\prime}}^{*}, p\right)}{\partial s_{\beta^{\prime}}^{*}} \frac{\partial s_{\beta^{\prime}}^{*}}{\partial p} \\
& -\left.\left[\left(1-\alpha-\beta+s_{\beta^{\prime}}^{*}\right) y_{\beta^{\prime}}\left(s_{\beta^{\prime}}^{*}, L_{\beta^{\prime}}^{T}\left(s_{\beta^{\prime}}^{*}\right)\right)-F\left(s_{\beta^{\prime}}^{*}\right)\right] \frac{\partial L_{\beta^{\prime}}^{T}(s)}{\partial p}\right|_{s=s_{\beta^{\prime}}^{*}}
\end{aligned}
$$

where we have used the fact that $\min \left\{L_{\beta^{\prime}}^{T}\left(s_{\beta^{\prime}}^{*}\right), \bar{L}\right\}=L_{\beta^{\prime}}^{T}\left(s_{\beta^{\prime}}^{*}\right)$, that is, monopolists will not choose an operating leverage that never allows them to produce.

Note that (i) we have proved that $\left.\frac{\partial W^{\prime}(s, p)}{\partial s}\right|_{s=s_{\beta^{\prime}}^{*}}<0$ (i.e., the first-order derivative in Eq. (A.104) is negative for any $s \geq s_{\beta}^{*}$ ) and that $s_{\beta^{\prime}}^{*}$ is increasing in $p$, therefore, the first term in the RHS of Eq. (A.110) is negative; (ii) at the threshold, $L_{\beta^{\prime}}^{T}\left(s_{\beta^{\prime}}^{*}\right)$, monopolists make a profit and since $\beta<\beta^{\prime}$, this means that

$$
\left(1-\alpha-\beta+s_{\beta^{\prime}}^{*}\right) y_{\beta^{\prime}}\left(s_{\beta^{\prime}}^{*}, L_{\beta^{\prime}}^{T}\left(s_{\beta^{\prime}}^{*}\right)\right)-F\left(s_{\beta^{\prime}}^{*}\right)>0 ;
$$

and (iii) for $1-\alpha+s>0, L_{\beta^{\prime}}^{T}($.$) is increasing in p$ given $s$ (i.e., $\frac{\beta^{\prime}}{1-\alpha-\beta^{\prime}+s}$ is increasing in $p$ ). (i), (ii), and (iii) imply that

$$
\frac{d W\left(s_{\beta^{\prime}}^{*}, p\right)}{d p}<0
$$

that is, welfare decreases in $p$. Q.E.D 


\section{Proof of Proposition 9}

Assume without loss of generality throughout the proof that in equilibrium $L_{1}^{T}<L_{2}^{T}$, that is, for $L \in\left[L_{1}^{T}\left(s_{1}^{*}\right), L_{2}^{T}\left(s_{1}^{*}, s_{2}^{*}\right)\right)$ only type-1 monopolists operate while for $L \in\left[L_{2}^{T}\left(s_{1}^{*}, s_{2}^{*}\right), \bar{L}\right]$ both types operate. (See the NOTE at the end of the proof.)

- If both types of monopolists operate, the aggregate income is

$$
y\left(s_{1}, s_{2}, L\right) \equiv \frac{L-n_{1} F\left(s_{1}\right)-n_{2} F\left(s_{2}\right)}{1-n_{1}\left(1-\alpha-\Delta_{1}+s_{1}\right)-n_{2}\left(1-\alpha-\Delta_{2}+s_{2}\right)},
$$

and the profit of a type- $i$ firm is

$$
\pi_{i}\left(s_{1}, s_{2}, L\right) \equiv y\left(s_{1}, s_{2}, L\right)\left(1-\alpha-\Delta_{i}+s_{i}\right)-F\left(s_{i}\right)
$$

The operating threshold for type-2 monopolists if type- 1 monopolists operate, $L_{2}^{T}\left(s_{1}, s_{2}\right)$, satisfies:

$$
\pi_{2}\left(s_{1}, s_{2}, L_{2}^{T}\left(s_{1}, s_{2}\right)\right)=0
$$

- If only type-1 monopolists operate, the aggregate income is

$$
y\left(s_{1}, L\right) \equiv \frac{L-n_{1} F\left(s_{1}\right)}{1-n_{1}\left(1-\alpha-\Delta_{1}+s_{1}\right)},
$$


and the profit of a type- $i$ firm is

$$
\pi_{i}\left(s_{1}, L\right)=\frac{L-n_{1} F\left(s_{1}\right)}{1-n_{1}\left(1-\alpha-\Delta_{1}+s_{1}\right)}\left(1-\alpha-\Delta_{i}+s_{i}\right)-F\left(s_{i}\right)
$$

The operating threshold for type-1 monopolists if type- 2 monopolists do not operate, $L_{1}^{T}\left(s_{1}\right)$, satisfies:

$$
\pi_{1}\left(s_{1}, L_{1}^{T}\left(s_{1}\right)\right)=0
$$

Claim 1. Let $\left(s_{1}^{*}, s_{2}^{*}\right)$ be a symmetric equilibrium in which all type-1 monopolists choose $s_{1}^{*}$ and all type-2 monopolists choose $s_{2}^{*}$ then

$$
\begin{aligned}
& E\left[y \mid L>L_{1}^{T}\left(s_{1}^{*}\right)\right]-F^{\prime}\left(s_{1}^{*}\right)=0 \\
& E\left[y \mid L>L_{2}^{T}\left(s_{1}^{*}, s_{2}^{*}\right)\right]-F^{\prime}\left(s_{2}^{*}\right)=0 .
\end{aligned}
$$

Proof of Claim 1. Consider the local incentives to deviate of a type-1 monopolist $q$ taking the operating leverage of all the other monopolists as given.

- Consider first, the local incentives to deviate to $s_{q}<s_{1}^{*}$. The profit for type-1 monopolist $q$ writes:

$$
\begin{aligned}
& \int_{L_{2}^{T}\left(s_{1}^{*}, s_{2}^{*}\right)}^{\bar{L}} y\left(s_{1}^{*}, s_{2}^{*}, L\right)\left(1-\alpha-\Delta_{1}+s_{q}\right)-F\left(s_{q}\right) d L \\
& +\int_{L_{1}^{T}\left(s_{1}^{*}\right)}^{L_{2}^{T}\left(s_{1}^{*}, s_{2}^{*}\right)} y\left(s_{1}^{*}, L\right)\left(1-\alpha-\Delta_{1}+s_{q}\right)-F\left(s_{q}\right) d L \\
& +\int_{\frac{F\left(s_{q}\right)}{L_{1}^{T}\left(s_{1}^{*}\right)} L\left(1-\alpha-\Delta_{1}+s_{q}\right)-F\left(s_{q}\right) d L .}
\end{aligned}
$$


The first derivative of Eq. (A.121) w.r.t. $s_{q}$ writes:

$$
\begin{aligned}
& \int_{L_{2}^{T}\left(s_{1}^{*}, s_{2}^{*}\right)}^{\bar{L}} y\left(s_{1}^{*}, s_{2}^{*}, L\right)-F^{\prime}\left(s_{q}\right) d L \\
& +\int_{L_{1}^{T}\left(s_{1}^{*}\right)}^{L_{2}^{T}\left(s_{1}^{*}, s_{2}^{*}\right)} y\left(s_{1}^{*}, L\right)-F^{\prime}\left(s_{q}\right) d L+\int_{\frac{F\left(s_{q}\right)}{1-\alpha-\Delta_{1}+s_{q}}}^{L_{1}^{T}\left(s_{*}^{*}\right)} L-F^{\prime}\left(s_{q}\right) d L
\end{aligned}
$$

For $s_{1}^{*}$ to be an equilibrium, it must hold that at $s_{q}=s_{1}^{*}$ the f.o.c. in Eq. (A.122) must be greater or equal to zero, that is, since $L_{1}^{T}\left(s_{1}^{*}\right)=\frac{F\left(s_{1}^{*}\right)}{1-\alpha-\Delta_{1}+s_{1}^{*}}$ :

$$
\begin{aligned}
& \int_{L_{2}^{T}\left(s_{1}^{*}, s_{2}^{*}\right)}^{\bar{L}} y\left(s_{1}^{*}, s_{2}^{*}, L\right)-F^{\prime}\left(s_{1}^{*}\right) d L+\int_{L_{1}^{T}\left(s_{1}^{*}\right)}^{L_{2}^{T}\left(s_{1}^{*}, s_{2}^{*}\right)} y\left(s_{1}^{*}, L\right)-F^{\prime}\left(s_{1}^{*}\right) d L \geq 0 \\
\Leftrightarrow & E\left[y \mid L \geq L_{1}^{T}\left(s_{1}^{*}\right)\right]-F^{\prime}\left(s_{1}^{*}\right) \geq 0 .
\end{aligned}
$$

- Consider now, the local incentives to deviate to $s_{q}>s_{1}^{*}$. The profit for type-1 monopolist $q$ writes:

$$
\begin{aligned}
& \int_{L_{2}^{T}\left(s_{1}^{*}, s_{2}^{*}\right)}^{\bar{L}} y\left(s_{1}^{*}, s_{2}^{*}, L\right)\left(1-\alpha-\Delta_{1}+s_{q}\right)-F\left(s_{q}\right) d L
\end{aligned}
$$

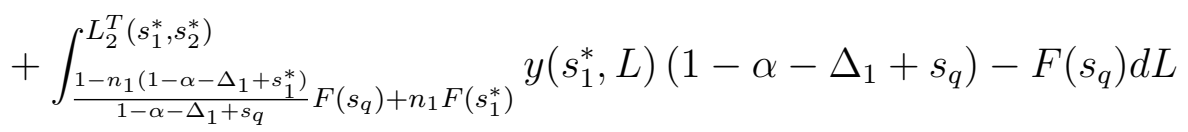

The first derivative of Eq. (A.125) w.r.t. $s_{q}$ writes:

$$
\int_{L_{2}^{T}\left(s_{1}^{*}, s_{2}^{*}\right)}^{\bar{L}} y\left(s_{1}^{*}, s_{2}^{*}, L\right)-F^{\prime}\left(s_{q}\right) d L+\int_{\frac{1-n_{1}\left(1-\alpha-\Delta_{1}+s_{1}^{*}\right)}{L_{2}^{T}\left(s_{1}^{*}, s_{1}^{*}\right)} F\left(s_{q}\right)+n_{1} F\left(s_{1}^{*}\right)} y\left(s_{1}^{*}, L\right)-F^{\prime}\left(s_{q}\right) d L
$$

For $s_{1}^{*}$ to be an equilibrium, it must hold that at $s_{q}=s_{1}^{*}$ the f.o.c. in Eq. (A.126) must 
be smaller or equal to zero, that is, since

$$
\frac{1-n_{1}\left(1-\alpha-\Delta_{1}+s_{1}^{*}\right)}{1-\alpha-\Delta_{1}+s_{q}} F\left(s_{q}\right)+\left.n_{1} F\left(s_{1}^{*}\right)\right|_{s_{q}=s_{1}^{*}}=L_{1}^{T}\left(s_{1}^{*}\right)=\frac{F\left(s_{1}^{*}\right)}{1-\alpha-\Delta_{1}+s_{1}^{*}}
$$

then,

$$
\begin{aligned}
& \int_{L_{2}^{T}\left(s_{1}^{*}, s_{2}^{*}\right)}^{\bar{L}} y\left(s_{1}^{*}, s_{2}^{*}, L\right)-F^{\prime}\left(s_{1}^{*}\right) d L+\int_{L_{1}^{T}\left(s_{1}^{*}\right)}^{L_{2}^{T}\left(s_{1}^{*}, s_{2}^{*}\right)} y\left(s_{1}^{*}, L\right)-F^{\prime}\left(s_{1}^{*}\right) d L \leq 0 \\
\Leftrightarrow & E\left[y \mid L \geq L_{1}^{T}\left(s_{1}^{*}\right)\right]-F^{\prime}\left(s_{1}^{*}\right) \leq 0
\end{aligned}
$$

Combining the two necessary conditions in Eq. (A.124) and Eq. (A.129):

$$
E\left[y \mid L>L_{1}^{T}\left(s_{1}^{*}\right)\right]-F^{\prime}\left(s_{1}^{*}\right)=0
$$

A similar argument yields the a necessary condition for a symmetric equilibrium for type- 2 monopolists:

$$
E\left[y \mid L>L_{2}^{T}\left(s_{1}^{*}, s_{2}^{*}\right)\right]-F^{\prime}\left(s_{2}^{*}\right)=0
$$

This completes the proof of Claim 1.

Assuming that $L_{1}^{T}\left(s_{1}\right)<L_{2}^{T}\left(s_{1}, s_{2}\right)$, the social planner chooses $s_{1}$ and $s_{2}$ to maximize ex- 
pected profits plus labor income, that is, to maximize $W\left(s_{1}, s_{2}\right)$ where

$$
\begin{aligned}
& W\left(s_{1}, s_{2}\right) \equiv n_{1} \int_{L_{2}^{T}\left(s_{1}, s_{2}\right)}^{\bar{L}} y\left(s_{1}, s_{2}\right)\left(1-\alpha-\Delta_{1}+s_{1}\right)-F\left(s_{1}\right) d L \\
& +n_{2} \int_{L_{2}^{T}\left(s_{1}, s_{2}\right)}^{\bar{L}} y\left(s_{1}, s_{2}\right)\left(1-\alpha-\Delta_{2}+s_{2}\right)-F\left(s_{2}\right) d L \\
& +n_{1} \int_{L_{1}^{T}\left(s_{1}\right)}^{L_{2}^{T}\left(s_{1}, s_{2}\right)} y\left(s_{1}\right)\left(1-\alpha-\Delta_{1}+s_{1}\right)-F\left(s_{1}\right) d L+\int_{0}^{\bar{L}} L d L
\end{aligned}
$$

The first derivatives of $W\left(s_{1}, s_{2}\right)$ write:

$$
\begin{aligned}
\frac{\partial W\left(s_{1}, s_{2}\right)}{\partial s_{1}}= & n_{1} \int_{L_{2}^{T}\left(s_{1}, s_{2}\right)}^{\bar{L}} y\left(s_{1}, s_{2}\right)-F^{\prime}\left(s_{1}\right) d L \\
& +\left[n_{1}\left(1-\alpha-\Delta_{1}+s_{1}\right)+n_{2}\left(1-\alpha-\Delta_{2}+s_{2}\right)\right] \int_{L_{2}^{T}\left(s_{1}, s_{2}\right)}^{\bar{L}} \frac{\partial y\left(s_{1}, s_{2}\right)}{\partial s_{1}} d L \\
& +n_{1} \int_{L_{1}^{T}\left(s_{1}\right)}^{L_{2}^{T}\left(s_{1}, s_{2}\right)} y\left(s_{1}\right)-F^{\prime}\left(s_{1}\right) d L \\
& +n_{1} \int_{L_{1}^{T}\left(s_{1}\right)}^{L_{2}^{T}\left(s_{1}, s_{2}\right)} \frac{\partial y\left(s_{1}\right)}{\partial s_{1}}\left(1-\alpha-\Delta_{1}+s_{1}\right) d L
\end{aligned}
$$

and

$$
\begin{aligned}
\frac{\partial W\left(s_{1}, s_{2}\right)}{\partial s_{1}}= & n_{2} \int_{L_{2}^{T}\left(s_{1}, s_{2}\right)}^{\bar{L}} y\left(s_{1}, s_{2}\right)-F^{\prime}\left(s_{2}\right) d L \\
& +\left[n_{1}\left(1-\alpha-\Delta_{1}+s_{1}\right)+n_{2}\left(1-\alpha-\Delta_{2}+s_{2}\right)\right] \int_{L_{2}^{T}\left(s_{1}, s_{2}\right)}^{\bar{L}} \frac{\partial y\left(s_{1}, s_{2}\right)}{\partial s_{2}} d L
\end{aligned}
$$


From Eq. (A.113),

$$
\frac{\partial y\left(s_{1}, s_{2}\right)}{\partial s_{i}}=\frac{n_{i}\left[y\left(s_{1}, s_{2}\right)-F^{\prime}\left(s_{i}\right)\right]}{1-n_{1}\left(1-\alpha-\Delta_{1}+s_{1}\right)-n_{2}\left(1-\alpha-\Delta_{2}+s_{2}\right)} \text { for } i=1,2
$$

and from Eq. (A.116),

$$
\frac{\partial y\left(s_{1}\right)}{\partial s_{1}}=\frac{n_{1}\left[y\left(s_{1}\right)-F^{\prime}\left(s_{1}\right)\right]}{1-n_{1}\left(1-\alpha-\Delta_{1}+s_{1}\right)} .
$$

Therefore, the first derivatives can be rewritten as

$$
\begin{aligned}
\frac{\partial W\left(s_{1}, s_{2}\right)}{\partial s_{1}}= & \frac{n_{1} \int_{L_{2}^{T}\left(s_{1}, s_{2}\right)}^{\bar{L}} y\left(s_{1}, s_{2}\right)-F^{\prime}\left(s_{1}\right) d L}{1-n_{1}\left(1-\alpha-\Delta_{1}+s_{1}\right)-n_{2}\left(1-\alpha-\Delta_{2}+s_{2}\right)} \\
& +\frac{n_{1} \int_{L_{1}^{T}\left(s_{1}\right)}^{L_{1}^{T}\left(s_{2}\right)} y\left(s_{1}\right)-F^{\prime}\left(s_{1}\right) d L}{1-n_{1}\left(1-\alpha-\Delta_{1}+s_{1}\right)}
\end{aligned}
$$

and

$$
\frac{\partial W\left(s_{1}, s_{2}\right)}{\partial s_{2}}=\frac{n_{2} \int_{L_{2}^{T}\left(s_{1}, s_{2}\right)}^{\bar{L}} y\left(s_{1}, s_{2}\right)-F^{\prime}\left(s_{2}\right) d L}{1-n_{1}\left(1-\alpha-\Delta_{1}+s_{1}\right)-n_{2}\left(1-\alpha-\Delta_{2}+s_{2}\right)}
$$

From Claim 1, at $\left(s_{1}, s_{2}\right)=\left(s_{1}^{*}, s_{2}^{*}\right)$,

$$
\int_{L_{2}^{T}\left(s_{1}^{*}, s_{2}^{*}\right)}^{\bar{L}} y\left(s_{1}^{*}, s_{2}^{*}\right)-F^{\prime}\left(s_{1}^{*}\right) d L+\int_{L_{1}^{T}\left(s_{1}^{*}\right)}^{L_{2}^{T}\left(s_{1}^{*}, s_{2}^{*}\right)} y\left(s_{1}^{*}\right)-F^{\prime}\left(s_{1}^{*}\right) d L=0,
$$

and using Eq. (A.137) and Eq. (A.139):

$$
\begin{aligned}
\left.\frac{\partial W\left(s_{1}, s_{2}\right)}{\partial s_{1}}\right|_{\left(s_{1}, s_{2}\right)=\left(s_{1}^{*}, s_{2}^{*}\right)}= & \frac{n_{1} \int_{L_{2}^{T}\left(s_{1}^{*}, s_{2}^{*}\right)}^{\bar{L}} y\left(s_{1}^{*}, s_{2}^{*}\right)-F^{\prime}\left(s_{1}^{*}\right) d L}{1-n_{1}\left(1-\alpha-\Delta_{1}+s_{1}\right)-n_{2}\left(1-\alpha-\Delta_{2}+s_{2}\right)} \\
& -\frac{n_{1} \int_{L_{2}^{T}\left(s_{1}^{*}, s_{2}^{*}\right)}^{L} y\left(s_{1}^{*}, s_{2}^{*}\right)-F^{\prime}\left(s_{1}^{*}\right) d L}{1-n_{1}\left(1-\alpha-\Delta_{1}+s_{1}\right)}>0
\end{aligned}
$$


In words, at $\left(s_{1}, s_{2}\right)=\left(s_{1}^{*}, s_{2}^{*}\right)$, increasing $s_{1}$ increases welfare.

From Claim 1, at $\left(s_{1}, s_{2}\right)=\left(s_{1}^{*}, s_{2}^{*}\right)$,

$$
\int_{L_{2}^{T}\left(s_{1}^{*}, s_{2}^{*}\right)}^{\bar{L}} y\left(s_{1}^{*}, s_{2}^{*}\right)-F^{\prime}\left(s_{2}^{*}\right) d L=0
$$

and using Eq. (A.137) and Eq. (A.139):

$$
\left.\frac{\partial W\left(s_{1}, s_{2}\right)}{\partial s_{2}}\right|_{\left(s_{1}, s_{2}\right)=\left(s_{1}^{*}, s_{2}^{*}\right)}=0
$$

In words, at $\left(s_{1}, s_{2}\right)=\left(s_{1}^{*}, s_{2}^{*}\right)$, a marginal change in $s_{2}$ does not change welfare.

NOTE: Since $\bar{L}>2 / \alpha, s_{i}^{*} \in(0, \alpha)$, which implies that $\left(s_{1}^{*}, s_{2}^{*}\right)$ are such that $L_{1}^{T}=L_{2}^{T}$ cannot be an equilibrium. Indeed, Any equilibrium requires

$$
\begin{aligned}
& E\left[y \mid L>L_{2}^{T}\right]-F^{\prime}\left(s_{2}^{*}\right)=0 \\
& E\left[y \mid L>L_{1}^{T}\right]-F^{\prime}\left(s_{1}^{*}\right)=0
\end{aligned}
$$

and, if $L_{1}^{T}=L_{2}^{T}$, Eq. (A.143) and Eq. (A.144) imply that $s_{1}^{*}=s_{2}^{*}\left(=s^{*}\right)$. However, since $\Delta_{1} \neq \Delta_{2}, L_{1}^{T}\left(s^{*}\right) \neq L_{2}^{T}\left(s^{*}\right)$, that is, one type of monopolists would have incentive to start producing for a lower threshold than the other type of monopolists. Q.E.D. 
Proof of Proposition 10

\section{Part I: Local Necessary Equilibrium Condition.}

Note first, that the proof of Proposition 1 does not make use of the specific functional form for $F\left(s_{q}\right)$ and therefore, the operating threshold $L^{T}(s)$ in Proposition 1 holds for a generic function $F\left(s_{q}\right)$.

Suppose monopolist $q$ chooses $s_{q}$ while all other monopolists choose $s^{*} \in(0, \alpha)$. If $s_{q}=s^{*}$ then, at $L=L^{T}\left(s^{*}\right)$ monopolist $q$ makes a strictly positive profit if all other monopolist operate and makes a strictly negative profit if no other monopolist operates. This implies that we can define an interval $\left[s^{*}-\tau, s^{*}+\tau\right]$ for some $\tau>0$ such that if $s_{q} \in\left[s^{*}-\tau, s^{*}+\tau\right]$ monopolist $q$ produces if and only if $L \geq L^{T}\left(s^{*}\right)$. Local optimality requires that

$$
s^{*} \in \underset{s_{q} \in\left[s^{*}-\tau, s^{*}+\tau\right]}{\operatorname{argmax}} \int_{L^{T}\left(s^{*}\right)}^{\bar{L}}\left(1-\alpha-\beta+s_{q}\right) y\left(s^{*}, L\right)-F\left(s_{q}\right) d L,
$$

and therefore, the local necessary condition for an interior solution to the monopolist optimization problem writes

$$
E\left[y \mid L \geq L^{T}\left(s^{*}\right)\right]-F^{\prime}\left(s^{*}\right)=0 .
$$

\section{Part II: Excessive Operating Leverage.}

The social planner maximizes over

$$
s^{o p t} \in \underset{s}{\operatorname{argmax}} \int_{\left.\min \left\{L^{T}(s), \bar{L}\right\}\right)}^{\bar{L}}(1-\alpha-\beta+s) \frac{L-F(s)}{\alpha-s}-F(s) d L
$$


Since at the optimum $L^{T}(s)<\bar{L}$, the first-order derivative writes

$$
\begin{aligned}
& \int_{L^{T}(s)}^{\bar{L}} \frac{L-F(s)}{\alpha-s}-F^{\prime}(s) d L+(1-\alpha-\beta+s) \int_{L^{T}(s)}^{\bar{L}} \frac{\partial}{\partial s}\left(\frac{L-F(s)}{\alpha-s}\right) d L \\
& -\left[(1-\alpha-\beta+s) \frac{L^{T}(s)-F(s)}{\alpha-s}-F(s)\right] \frac{\partial L^{T}(s)}{\partial s}
\end{aligned}
$$

Consider the three above terms in turn

- The local necessary condition in Eq. (A.146) implies that $\int_{L^{T}(s)}^{\bar{L}} \frac{L-F(s)}{\alpha-s}-F^{\prime}(s)$ is 0 at any interior symmetric equilibrium $s^{*}$.

- Next,

$$
\int_{L^{T}(s)}^{\bar{L}} \frac{\partial}{\partial s}\left(\frac{L-F(s)}{\alpha-s}\right)=\frac{1}{\alpha-s} \int_{L^{T}(s)}^{\bar{L}} \frac{L-F(s)}{\alpha-s}-F^{\prime}(s),
$$

which, as above, is 0 at $s^{*}$.

- Finally, at the operating threshold (i.e., at $L=L^{T}(s)$ ) firms make a strictly positive profit:

$$
(1-\alpha-\beta+s) \frac{L^{T}(s)-F(s)}{\alpha-s}-F(s)>0
$$

for any $s$. Therefore, if $\frac{\partial L^{T}\left(s^{*}\right)}{\partial s}>0$, the first-order derivative in Eq. (A.148) is strictly negative at $s=s^{*}$, that is, a marginal decrease in $s$ around $s^{*}$ increases welfare.

To complete the proof, we next show $\frac{\partial L^{T}\left(s^{*}\right)}{\partial s}>0$. 
The local necessary equilibrium condition in Eq. (A.146) writes,

$$
\frac{y\left(L^{T}\left(s^{*}\right), s^{*}\right)+y\left(\bar{L}, s^{*}\right)}{2}=F^{\prime}\left(s^{*}\right)
$$

Since $y\left(L, s^{*}\right)$ is increasing in $L$, it follows that

$$
y\left(L^{T}\left(s^{*}\right), s^{*}\right)<F^{\prime}\left(s^{*}\right)
$$

From Eq. (A.5), $L^{T}\left(s^{*}\right)$ is implicitly given by the indifference condition

$$
\int_{0}^{1}\left(1-\alpha-\beta+s^{*}\right) \hat{y}\left(L^{T}\left(s^{*}\right), s^{*}, z\right)-F\left(s^{*}\right) d z=0
$$

where

$$
\hat{y}(L, s, z) \equiv \frac{L-z F(s)}{1-z(1-\alpha+s)}
$$

$\frac{\partial \hat{y}(L, s, z)}{\partial z}\left(L^{T}\left(s^{*}\right), s^{*},.\right)$ has the sign of $\left(1-\alpha+s^{*}\right) L^{T}\left(s^{*}\right)-F\left(s^{*}\right)$ which, from Eq. (13) is strictly positive. It follows that for any $z \in(0,1)$,

$$
\hat{y}\left(L^{T}\left(s^{*}\right), s^{*}, z\right)<\hat{y}\left(L^{T}\left(s^{*}\right), s^{*}, 1\right)=y\left(L^{T}\left(s^{*}\right), s^{*}\right)<F^{\prime}\left(s^{*}\right)
$$

where the last inequality just repeats Eq. (A.152).

Next, for any $z \in(0,1), \frac{\partial \hat{y}(L, s, z)}{\partial s}\left(L^{T}\left(s^{*}\right), s^{*},.\right)$ has the sign of $y\left(L^{T}\left(s^{*}\right), s^{*}, z\right)-F^{\prime}\left(s^{*}\right)$ which, from Eq. (A.155), is strictly negative. 
Finally, total differentiation of the indifference condition in Eq. (A.153) with respect to $s^{*}$ yields

$$
\begin{aligned}
& \int_{0}^{1} \hat{y}\left(L^{T}\left(s^{*}\right), s^{*}, z\right)-F^{\prime}\left(s^{*}\right) d z \\
& +\int_{0}^{1}\left(1-\alpha-\beta+s^{*}\right) \frac{\partial \hat{y}(L, s, z)}{\partial s}\left(L^{T}\left(s^{*}\right), s^{*}, .\right) d z \\
& +\int_{0}^{1}\left(1-\alpha-\beta+s^{*}\right) \frac{\partial \hat{y}(L, s, z)}{\partial L}\left(L^{T}\left(s^{*}\right), s^{*}, .\right) \frac{\partial L^{T}\left(s^{*}\right)}{\partial s^{*}} d z=0 .
\end{aligned}
$$

Eq. (A.155) implies that the first line of Eq. (A.156) is strictly negative. We have shown $\frac{\partial \hat{y}(L, s, z)}{\partial s}\left(L^{T}\left(s^{*}\right), s^{*},.\right)<0$ for any $z \in(0,1)$, which implies that the second line of Eq. (A.156) is also negative. Finally $\frac{\partial \hat{y}(L, s, z)}{\partial L}\left(L^{T}\left(s^{*}\right), s^{*},.\right)>0$ for any $z \in(0,1)$ and, therefore, $\frac{\partial L^{T}\left(s^{*}\right)}{\partial s^{*}}>$ O. Q.E.D. 


\section{Online appendix: Production at $\mathrm{t}=0$ and at $\mathrm{t}=1$}

In the main model, monopolists choose their operating leverage at $t=0$, before uncertainty about $L$ is realized at $t=1$. This captures the idea that firms' technological and organizational choices are long lasting and therefore, that firms cannot respond to a productivity shock by swiftly changing their production technologies. In this section, we extend the model to show that our results remain unchanged when monopolists also produce at $t=0$ and can condition their choice of operating leverage to the current $(t=0)$ productivity level, provided that they cannot rapidly adjust their operating leverage to accommodate realizations of future $(t=1)$ productivity shocks. Formally, this requires the following changes to the main model. We assume that production also takes place $t=0$. That is, a productivity shock $L_{0}$ is realized at $t=0$. Then, knowing $L_{0}$, each monopolists makes an operating leverage decision, a production decision and the game moves on to $t=1$. At $t=1$, a new shock $L_{1}$ is realized and monopolists make a second production decision. Importantly, a monopolist cannot adjust its operating leverage between the two production decisions at $t=0$ and $t=1$. The productivity shocks $\left\{L_{0}, L_{1}\right\}$ are uniformly distributed over $[0, \bar{L}]$ and independent. Similar to the main model, the consumer's utility is given by

$$
U=\exp \left[\int_{0}^{1} \ln x_{1}(q) d q\right]+\theta \exp \left[\int_{0}^{1} \ln x_{2}(q) d q\right]
$$

where $x_{t}(q)$ is the consumption at $t$ defined over a unit interval of goods indexed by $q$ and $\theta \in(0,1]$ is a time discount factor. Everything else remains the same as in the main model: 
(i) Each good $q$ is produced by a sector, and each sector consists of two types of firms. A competitive fringe of firms with a constant returns to scale technology in which one unit of output requires one unit of labour, and a monopolist with access to an increasing returns to scale technology; (ii) In each period $t$, monopolist $q$ incurs a marginal cost of $\alpha-s_{q}$ and a fixed cost of $F\left(s_{q}\right)$ to produce, where $F\left(s_{q}\right)$ is increasing, convex, and tends to infinity as $s_{q} \rightarrow \alpha$; and (iii) Production by monopolists requires a monitoring effort $\beta$ per unit of output.

This extension poses a minor technical challenge. In the baseline model, the equilibrium of the production game is pinned down as the limit of a dispersed information game in which monopolists imperfectly observe $L$ after their choices of operating leverage but before their production decisions. (See Section 3.2.) However, the point of the current extension is to let monopolists observe $L_{0}$ before deciding their operating leverages at $t=0$, which precludes having dispersed information about $L_{0}$ when monopolists make their production decisions at $t=0$. To circumvent this problem while keeping the global games treatment of the production game identical to the baseline model, we assume that all monopolists perfectly observe $L_{t}$ at the beginning of each period $t$. However, in each period, the realization of the shock is altered to be $L_{t}+\mathcal{L}_{t}$, where $\mathcal{L}_{t}$ is normally distributed with mean 0 and variance $\sigma^{2}$. Furthermore, in each period, monopolist $q$ also observes a private noisy signal of $\mathcal{L}_{t}$, $l_{q, t}=\mathcal{L}_{t}+\xi_{q, t}$, where $\xi_{q, t}$ is normally distributed with mean 0 and variance $\sigma_{\xi}^{2}$. Importantly, at $t=0$, monopolist $q$ observes $l_{q, 0}$ after its operating leverage decision but before its production decision. This design has the appealing property that we can take the limit to 
0 of both $\sigma_{\xi}^{2}$ and $\sigma^{2}$ in a way that (i) maintains equilibrium uniqueness; (ii) leaves $L_{t}$ as the only shock at time $t$ (since $\sigma^{2} \rightarrow 0, \mathcal{L}_{t}$ is 0 almost surely); and (iii) has monopolists producing at $t$ if and only $L_{t} \geq L^{T}(s)$, where $L^{T}(s)$ is the same threshold as in the baseline model. Fig. OA1 illustrates the timing of events.

\begin{tabular}{|c|c|c|c|c|c|}
\hline & $\mathrm{t}=0$ & $\mathrm{t}=0$ & & & $\mathrm{t}=1$ \\
\hline $\begin{array}{l}\text { Productivity } \\
L_{0} \text { observed }\end{array}$ & $\begin{array}{l}\text { Monopolists } \\
\text { choose } s_{q}\end{array}$ & 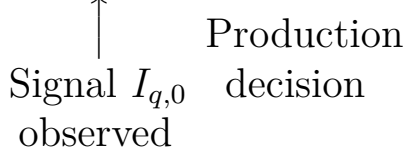 & $\begin{array}{l}\text { Productivity } \\
L_{1} \text { observed }\end{array}$ & $\begin{array}{l}\text { Signal } I_{q, 1} \\
\text { observed }\end{array}$ & $\begin{array}{l}\text { Production } \\
\text { decision }\end{array}$ \\
\hline
\end{tabular}

Fig. OA1. Timing of events.

Proposition OA.1 below formally states the result that the global games treatment that we consider in this section delivers the same prediction for the production game as the prediction of the baseline model. (For the proofs of Propositions OA.1 and OA.2 below, see at the end of this appendix.)

Proposition OA.1. Suppose all monopolists choose operating leverage $s$ at $t=0$, then if $\sigma \rightarrow 0$ and $\frac{\sigma_{\xi}}{\sigma^{2}} \rightarrow 0$, monopolists operate in period $t$ if and only if $L_{t} \geq L^{T}(s)$, where $L^{T}(s)$ is defined as in Eq. (13).

Next, we build on Proposition OA.1 to analyze the equilibrium operating leverage at $t=0$. Suppose monopolist $q$ chooses $s_{q}$ while all other monopolists choose $s^{*} \in(0, \alpha)$. If $s_{q}=s^{*}$ and $L=L^{T}\left(s^{*}\right)$, a monopolist $q$ makes a strictly positive profit at $t=1$ if all other monopolist operate and makes a strictly negative profit if no other monopolist operates. This implies that we can define an interval $\left[s^{*}-\tau, s^{*}+\tau\right]$ for some $\tau>0$ such that if $s_{q} \in\left[s^{*}-\tau, s^{*}+\tau\right]$ monopolist $q$ produces if and only if $L \geq L^{T}\left(s^{*}\right)$. Then, $s^{*}$ being an equilibrium requires OA.3 
that

$$
s^{*} \in \underset{s_{q} \in\left[s^{*}-\tau, s^{*}+\tau\right]}{\operatorname{argmax}}\left\{\begin{array}{c}
1_{\left\{L_{0} \geq L^{T}\left(s^{*}\right)\right\}}\left[\left(1-\alpha-\beta+s_{q}\right) y\left(s^{*}, L_{0}\right)-F\left(s_{q}\right)\right]+ \\
+\theta \int_{L^{T}\left(s^{*}\right)}^{\bar{L}}\left(1-\alpha-\beta+s_{q}\right) y\left(s^{*}, L_{1}\right)-F\left(s_{q}\right) d L_{1}
\end{array}\right\},
$$

where $\mathbf{1}_{\left\{L_{0} \geq L^{T}\left(s^{*}\right)\right\}}$ is an indicator function that takes a value of one when $L_{0} \geq L^{T}\left(s^{*}\right)$. From Eq. (0A.2), the local necessary first order condition for an interior solution writes

$$
\mathbf{1}_{\left\{L_{0} \geq L^{T}\left(s^{*}\right)\right\}}\left[y\left(s^{*}, L_{0}\right)-F^{\prime}\left(s^{*}\right)\right]+\theta \operatorname{Pr}\left(L_{1} \geq L^{T}\left(s^{*}\right)\right)\left[E\left[y \mid L_{1} \geq L^{T}\left(s^{*}\right)\right]-F^{\prime}\left(s^{*}\right)\right]=0 .
$$

The next proposition shows that around this local equilibrium condition, there is excessive operating leverage. The logic is identical to the one previously discussed for Proposition 3 and Proposition 10: at the equilibrium leverage $s^{*}$, a marginal decrease in the leverage of all monopolists lead them to switch from inactivity to production just below $L^{T}\left(s^{*}\right)$ (i.e., $\left.\frac{\partial L^{T}\left(s^{*}\right)}{\partial s}>0\right)$ which improves welfare.

Proposition OA.2. Consider a generic increasing and convex function $F($.$) any symmet-$ ric interior equilibrium $s^{*}$ at $t=1$ satisfies condition in Eq. (0A.3), and a collective marginal decrease in operating leverage below $s^{*}$ increases welfare.

\section{Proof of Proposition OA.1}

Suppose all monopolists choose $s$ at $t=0$ and monopolist $q$ with signal $l_{q, t}$ produces if and only if $l_{q, t}>l^{*}$ at time $t$, for $t=1,2$. Consider a monopolist who observes the signal $l^{*}$. Its 
posterior of $\mathcal{L}_{t}$ is normally distributed with mean $\frac{\sigma^{2}}{\sigma^{2}+\sigma_{\xi}^{2}} l^{*}$ and variance $\frac{\sigma^{2} \sigma_{\xi}^{2}}{\sigma^{2}+\sigma_{\xi}^{2}}$. Finally, for a given realization of $\mathcal{L}_{t}$, the mass of monopolists that produce at time $t$ is

$$
n\left(\mathcal{L}_{t}\right) \equiv 1-\Phi\left(\frac{l^{*}-\mathcal{L}_{t}}{\sigma_{\xi}}\right)
$$

where $\Phi($.$) is the cumulative distribution function of the normal distribution with mean 0$ and variance 1 . Since a monopolist with signal $l^{*}$ must be indifferent between producing and not producing:

$$
\int_{-\infty}^{+\infty}\left\{(1-\alpha-\beta+s) \frac{\mathcal{L}_{t}-n\left(\mathcal{L}_{t}\right) F}{1-n\left(\mathcal{L}_{t}\right)(1-\alpha+s)}-F\right\} \sqrt{\frac{\sigma^{2}+\sigma_{\xi}^{2}}{\sigma^{2} \sigma_{\xi}^{2}}} \varphi\left(\frac{\mathcal{L}_{t}-\frac{\sigma^{2}}{\sigma^{2}+\sigma_{\xi}^{2}}}{\sqrt{\frac{\sigma^{2} \sigma_{\xi}^{2}}{\sigma^{2}+\sigma_{\xi}^{2}}}}\right) d \mathcal{L}_{t}=0
$$

where $\varphi($.$) is the probability density function of the normal distribution with mean 0$ and variance 1 . Consider the following change of variable:

$$
x_{t}=\frac{\mathcal{L}_{t}-l^{*}}{\sigma_{\xi}}+\frac{\sigma_{\xi}}{\sigma^{2}+\sigma_{\xi}^{2}} l^{*} \Leftrightarrow \mathcal{L}_{t}=x_{t} \sigma_{\xi}+\frac{\sigma^{2}}{\sigma^{2}+\sigma_{\xi}^{2}} l^{*}
$$

then Eq. (0A.5) becomes

$$
(1-\alpha-\beta+s) \int_{-\infty}^{+\infty} \frac{x_{t} \sigma_{\xi}+\frac{\sigma^{2}}{\sigma^{2}+\sigma_{\xi}^{2}} l^{*}-\Phi\left(x_{t}-\frac{\sigma_{\xi}}{\sigma^{2}+\sigma_{\xi}^{2}} l^{*}\right) F}{1-\Phi\left(x_{t}-\frac{\sigma_{\xi}}{\sigma^{2}+\sigma_{\xi}^{2}} l *\right)(1-\alpha+s)} \sqrt{\frac{\sigma^{2}+\sigma_{\xi}^{2}}{\sigma^{2}}} \varphi\left(\sqrt{\frac{\sigma^{2}+\sigma_{\xi}^{2}}{\sigma^{2}}} x_{t}\right) d x_{t}=F
$$

where is $x_{t}$ is normally distributed with mean 0 and variance $\frac{\sigma^{2}}{\sigma^{2}+\sigma_{\xi}^{2}}$. 
Note

$$
\begin{aligned}
& \int_{0}^{+\infty} \frac{x_{t}}{1-\Phi\left(x_{t}-\frac{\sigma_{\xi}}{\sigma^{2}+\sigma_{\xi}^{2}} l^{*}\right)(1-\alpha+s)} \sqrt{\frac{\sigma^{2}+\sigma_{\xi}^{2}}{\sigma^{2}}} \varphi\left(\sqrt{\frac{\sigma^{2}+\sigma_{\xi}^{2}}{\sigma^{2}}} x_{t}\right) d x_{t} \\
\leq & \int_{0}^{+\infty} \frac{x_{t}}{\alpha-s} \sqrt{\frac{\sigma^{2}+\sigma_{\xi}^{2}}{\sigma^{2}}} \varphi\left(\sqrt{\frac{\sigma^{2}+\sigma_{\xi}^{2}}{\sigma^{2}}} x_{t}\right) d x_{t} .
\end{aligned}
$$

Let $X$ be normally distributed with mean 0 and variance 1 . The RHS of Eq. (0A.9) tends to $\frac{2 \mathbb{E}(X \mid X>0)}{\alpha-s}$ when $\sigma_{\xi} \rightarrow 0$. It follows that

$$
\lim _{\sigma_{\xi} \rightarrow 0} \sigma_{\xi} \int_{0}^{+\infty} \frac{x_{t}}{\alpha-s} \sqrt{\frac{\sigma^{2}+\sigma_{\xi}^{2}}{\sigma^{2}}} \varphi\left(\sqrt{\frac{\sigma^{2}+\sigma_{\xi}^{2}}{\sigma^{2}}} x_{t}\right) d x_{t}=0
$$

and therefore, for any $b>0$, there exists $\hat{\sigma}_{+}$such that, for any $l^{*}$ and any $\sigma_{\xi}<\hat{\sigma}_{+}$,

$$
0<\int_{0}^{+\infty} \frac{x_{t} \sigma_{\xi}}{1-\Phi\left(x_{t}-\frac{\sigma_{\xi}}{\sigma^{2}+\sigma_{\xi}^{2}} l *\right)(1-\alpha+s)} \sqrt{\frac{\sigma^{2}+\sigma_{\xi}^{2}}{\sigma^{2}}} \varphi\left(\sqrt{\frac{\sigma^{2}+\sigma_{\xi}^{2}}{\sigma^{2}}} x_{t}\right) d x_{t}<b
$$

Using

$$
\begin{aligned}
& \int_{-\infty}^{0} \frac{x_{t}}{1-\Phi\left(x_{t}-\frac{\sigma_{\xi}}{\sigma^{2}+\sigma_{\xi}^{2}} l *\right)(1-\alpha+s)} \sqrt{\frac{\sigma^{2}+\sigma_{\xi}^{2}}{\sigma^{2}}} \varphi\left(\sqrt{\frac{\sigma^{2}+\sigma_{\xi}^{2}}{\sigma^{2}}} x_{t}\right) d x_{t} \\
\geq & \int_{0}^{+\infty} \frac{x_{t}}{\alpha-s} \sqrt{\frac{\sigma^{2}+\sigma_{\xi}^{2}}{\sigma^{2}}} \varphi\left(\sqrt{\frac{\sigma^{2}+\sigma_{\xi}^{2}}{\sigma^{2}}} x\right) d x_{t}
\end{aligned}
$$

One similarly shows that, for any $b>0$, there exists $\hat{\sigma}_{-}$such that, for any $l^{*}$ and any 
$\sigma_{\xi}<\hat{\sigma}_{-}$

$$
-b<\int_{-\infty}^{0} \frac{x_{t} \sigma_{\xi}}{1-\Phi\left(x_{t}-\frac{\sigma_{\xi}}{\sigma^{2}+\sigma_{\xi}^{2}} l *\right)(1-\alpha+s)} \sqrt{\frac{\sigma^{2}+\sigma_{\xi}^{2}}{\sigma^{2}}} \varphi\left(\sqrt{\frac{\sigma^{2}+\sigma_{\xi}^{2}}{\sigma^{2}}} x_{t}\right) d x_{t}<0
$$

Combining Eq. (0A.11) and Eq. (0A.14), there exists $\hat{\sigma}$ such that, for any function $l^{*}$ and any $\sigma_{\xi}<\hat{\sigma}$,

$$
-b<\int_{-\infty}^{+\infty} \frac{x_{t} \sigma_{\xi}}{1-\Phi\left(x_{t}-\frac{\sigma_{\xi}}{\sigma^{2}+\sigma_{\xi}^{2}} l *\right)(1-\alpha+s)} \sqrt{\frac{\sigma^{2}+\sigma_{\xi}^{2}}{\sigma^{2}}} \varphi\left(\sqrt{\frac{\sigma^{2}+\sigma_{\xi}^{2}}{\sigma^{2}}} x_{t}\right) d x_{t}<b
$$

Suppose $\frac{\sigma^{2}}{\sigma^{2}+\sigma_{\xi}^{2}} l^{*}>F$, then if $\sigma_{\xi}$ is sufficiently small,

$$
\begin{aligned}
& \int_{-\infty}^{+\infty} \frac{x_{t} \sigma_{\xi}+\frac{\sigma^{2}}{\sigma^{2}+\sigma_{\xi}^{2}} l^{*}-\Phi\left(x_{t}-\frac{\sigma_{\xi}}{\sigma^{2}+\sigma_{\xi}^{2}} l^{*}\right) F}{1-\Phi\left(x_{t}-\frac{\sigma_{\xi}}{\sigma^{2}+\sigma_{\xi}^{2}} l^{*}\right)(1-\alpha+s)} \sqrt{\frac{\sigma^{2}+\sigma_{\xi}^{2}}{\sigma^{2}}} \varphi\left(\sqrt{\frac{\sigma^{2}+\sigma_{\xi}^{2}}{\sigma^{2}}} x_{t}\right) d x_{t} \\
> & \int_{-\infty}^{+\infty}\left(\frac{\sigma^{2}}{\sigma^{2}+\sigma_{\xi}^{2}} l^{*}-F\right) \sqrt{\frac{\sigma^{2}+\sigma_{\xi}^{2}}{\sigma^{2}}} \varphi\left(\sqrt{\frac{\sigma^{2}+\sigma_{\xi}^{2}}{\sigma^{2}} x_{t}}\right) d x_{t}-b \\
= & \frac{\sigma^{2}}{\sigma^{2}+\sigma_{\xi}^{2}} l^{*}-F-b
\end{aligned}
$$

It follows that, if $l^{*}>\max \left\{\frac{\sigma^{2}+\sigma_{\xi}^{2}}{\sigma^{2}} F, \frac{\sigma^{2}+\sigma_{\xi}^{2}}{\sigma^{2}}\left(F+b+\frac{F}{1-\alpha-\beta+s}\right)\right\}$, the LHS of Eq. (0A.7) is strictly greater than $F$. 
Conversely, suppose $l^{*}<\frac{\sigma^{2}+\sigma_{\xi}^{2}}{\sigma^{2}} F$, then if $\sigma_{\xi}$ is sufficiently small,

$$
\begin{aligned}
& \int_{-\infty}^{+\infty} \frac{x_{t} \sigma_{\xi}+\frac{\sigma^{2}}{\sigma^{2}+\sigma_{\xi}^{2}} l^{*}-\Phi\left(x_{t}-\frac{\sigma_{\xi}}{\sigma^{2}+\sigma_{\xi}^{2}} l^{*}\right) F}{1-\Phi\left(x_{t}-\frac{\sigma_{\xi}}{\sigma^{2}+\sigma_{\xi}^{2}} l^{*}\right)(1-\alpha+s)} \sqrt{\frac{\sigma^{2}+\sigma_{\xi}^{2}}{\sigma^{2}}} \varphi\left(\sqrt{\frac{\sigma^{2}+\sigma_{\xi}^{2}}{\sigma^{2}}} x_{t}\right) d x_{t} \\
< & \int_{-\infty}^{+\infty}\left(\frac{\sigma^{2}}{\sigma^{2}+\sigma_{\xi}^{2}} l^{*}-F\right) \sqrt{\frac{\sigma^{2}+\sigma_{\xi}^{2}}{\sigma^{2}}} \varphi\left(\sqrt{\frac{\sigma^{2}+\sigma_{\xi}^{2}}{\sigma^{2}} x_{t}}\right) d x_{t}+b \\
= & \frac{\sigma^{2}}{\sigma^{2}+\sigma_{\xi}^{2}} l^{*}-F+b
\end{aligned}
$$

It follows that if $l^{*}<\min \left\{\frac{\sigma^{2}+\sigma_{\xi}^{2}}{\sigma^{2}} F, \frac{\sigma^{2}+\sigma_{\xi}^{2}}{\sigma^{2}}\left(F-b+\frac{F}{1-\alpha-\beta+s}\right)\right\}$, then the LHS of Eq. (0A.7) is strictly smaller than $F$.

Taken together these two inequalities imply that Eq. (0A.7) has at least one solution, and that there exists an interval $[\underline{l}, \bar{l}]$ such that for any $\sigma_{\xi}$ small enough, all solutions to Eq. (0A.7) belong to $[\underline{l}, \bar{l}]$.

Consider next

$$
\underbrace{\overbrace{\frac{\sigma^{2}}{\sigma^{2}+\sigma_{\xi}^{2}} l^{*}-\Phi\left(x_{t}-\frac{\sigma_{\xi}}{\sigma^{2}+\sigma_{\xi}^{2}} l^{*}\right) F}^{1-\Phi\left(x_{t}-\frac{\sigma_{\xi}}{\sigma^{2}+\sigma_{\xi}^{2}} l^{*}\right)(1-\alpha+s)}}_{\equiv D}
$$

The derivative of Eq. (0A.22) with respect to $l^{*}$ has the sign of

$$
\left[1+\frac{\sigma_{\xi}}{\sigma^{2}} \varphi\left(x_{t}-\frac{\sigma_{\xi}}{\sigma^{2}+\sigma_{\xi}^{2}} l^{*}\right) F\right] D-(1-\alpha+s) \frac{\sigma_{\xi}}{\sigma^{2}} \varphi\left(x_{t}-\frac{\sigma_{\xi}}{\sigma^{2}+\sigma_{\xi}^{2}} l^{*}\right) N
$$

Note that, for any $l^{*}, D>\alpha-s$. Furthermore, $\varphi($.$) is bounded and so is N$ for any $l^{*} \in[\underline{l}, \bar{l}]$. It follows that Eq. (0A.23) is strictly positive if $\frac{\sigma_{\xi}}{\sigma^{2}}$ is small enough. This together with 
Eq. (0A.16) and Eq. (0A.19) imply that the LHS of Eq. (0A.7) is strictly increasing on $l^{*} \in[\underline{l}, \bar{l}]$ if $\frac{\sigma_{\xi}}{\sigma^{2}}$ is small enough. Therefore, since (i) Eq. (0A.7) has at least one solution; (ii) there are no solutions to Eq. (0A.7) outside $[\underline{l}, \bar{l}]$ if $\sigma_{\xi}$ small enough; and (iii) the LHS of Eq. (0A.7) is strictly increasing on $l^{*} \in[\underline{l}, \bar{l}]$ if $\frac{\sigma_{\xi}}{\sigma^{2}}$ is small, then, there is a unique solution to Eq. (0A.7) if $\frac{\sigma_{\xi}}{\sigma^{2}}$ small enough.

Assume from now on that $\frac{\sigma_{\xi}}{\sigma^{2}}$ is small enough. We show next that $\lim _{\sigma_{\xi} \rightarrow 0} \sigma_{\xi} l^{*}=0$. Suppose it was not true, then either $l^{*} \rightarrow+\infty$ and from Eq. (0A.16), the LHS of Eq. (0A.7) tends to $+\infty$, which implies Eq. (0A.7) cannot hold; or $l^{*} \rightarrow-\infty$ and from Eq. (0A.19), the LHS of Eq. (0A.7) tends to $-\infty$, which implies Eq. (0A.7) cannot hold.

Suppose now that $\sigma_{\xi} \rightarrow 0$. Then Eq. (0A.7) has a unique solution defined by

$$
(1-\alpha-\beta+s) \int_{-\infty}^{+\infty} \frac{l^{*}-\Phi\left(x_{t}\right) F}{1-\Phi\left(x_{t}\right)(1-\alpha+s)} \varphi\left(x_{t}\right) d x_{t}=F
$$

Finally, consider the change of variable $z=\Phi\left(x_{t}\right)$, Eq. (0A.24) becomes

$$
(1-\alpha-\beta+s) \int_{0}^{1} \frac{l^{*}-z F}{1-z(1-\alpha+s)} d z=F
$$

From Eq. (0A.25), the proof of Proposition 1 and defining $L^{T}(s)$ as the limit of $l^{*}$ when $\sigma_{\xi} \rightarrow 0:$

$$
L^{T}(s)=\frac{F}{1-\alpha+s}+\frac{\beta F}{(1-\alpha-\beta+s) \ln \left(\frac{1}{\alpha-s}\right)} .
$$

Q.E.D. 
Proof of Proposition OA.2

\section{Part I: Local Necessary Equilibrium Condition.}

Note first, that the proof of Proposition OA.1 does not make use of the specific functional form for $F\left(s_{q}\right)$ and therefore, the operating threshold $L^{T}(s)$ in Proposition OA.1 holds for a generic function $F\left(s_{q}\right)$. Suppose monopolist $q$ chooses $s_{q}$ while all other monopolists choose $s^{*} \in(0, \alpha)$. If $s_{q}=s^{*}$ and $L=L^{T}\left(s^{*}\right)$, monopolist $q$ makes a strictly positive profit at $t=1$ if all other monopolist operate and makes a strictly negative profit if no other monopolist operates. This implies that we can define an interval $\left[s^{*}-\tau, s^{*}+\tau\right]$ for some $\tau>0$ such that if $s_{q} \in\left[s^{*}-\tau, s^{*}+\tau\right]$, monopolist $q$ produces if and only if $L \geq L^{T}\left(s^{*}\right)$. Then, $s^{*}$ being an equilibrium requires that

$$
\begin{array}{r}
s^{*} \in \underset{s_{q} \in\left[s^{*}-\tau, s^{*}+\tau\right]}{\operatorname{argmax}} \mathbf{1}_{\left\{L_{0} \geq L^{T}\left(s^{*}\right)\right\}}\left(\left(1-\alpha-\beta+s_{q}\right) y\left(s^{*}, L_{0}\right)-F\left(s_{q}\right)\right)+ \\
+\theta \int_{L^{T}\left(s^{*}\right)}^{\bar{L}}\left(1-\alpha-\beta+s_{q}\right) y\left(s^{*}, L_{1}\right)-F\left(s_{q}\right) d L_{1},
\end{array}
$$

where $\mathbf{1}_{\left\{L_{0} \geq L^{T}\left(s^{*}\right)\right\}}$ is an indicator function that takes the value of one when $L_{0} \geq L^{T}\left(s^{*}\right)$.

If $L_{0} \geq L^{T}\left(s^{*}\right)$, the local necessary condition for an interior solution to the monopolist optimization problem in Eq. (0A.27) writes:

$$
y\left(s^{*}, L_{0}\right)-F^{\prime}\left(s^{*}\right)+\theta \operatorname{Pr}\left(L_{1} \geq L^{T}\left(s^{*}\right)\right)\left[E\left[y \mid L_{1} \geq L^{T}\left(s^{*}\right)\right]-F^{\prime}\left(s^{*}\right)\right]=0 .
$$

If $L_{0}<L^{T}\left(s^{*}\right)$, the local necessary condition for an interior solution to the monopolist 
optimization problem in Eq. (0A.27) writes:

$$
E\left[y \mid L_{1} \geq L^{T}\left(s^{*}\right)\right]-F^{\prime}\left(s^{*}\right)=0
$$

\section{Part II: Excessive leverage.}

Before analyzing the social planner's optimization problem, we show that the operating threshold, $L^{T}\left(s^{*}\right)$, increases with operating leverage (i.e., $\frac{\partial L^{T}\left(s^{*}\right)}{\partial s}>0$ ) a result that we will later use in the proof.

Lemma 0A.1. $\frac{\partial L^{T}\left(s^{*}\right)}{\partial s}>0$.

Proof of Lemma 0A.1.

Consider first the case in which $L_{0} \geq L^{T}\left(s^{*}\right)$. The local necessary equilibrium condition in Eq. (0A.28) writes

$$
y\left(L_{0}, s^{*}\right)-F^{\prime}\left(s^{*}\right)+\theta \frac{\bar{L}-L^{T}\left(s^{*}\right)}{\bar{L}}\left[\frac{y\left(L^{T}\left(s^{*}\right), s^{*}\right)+y\left(\bar{L}, s^{*}\right)}{2}-F^{\prime}\left(s^{*}\right)\right]=0 .
$$

Since $y\left(L, s^{*}\right)$ is increasing in $L$, and $L^{T}\left(s^{*}\right)<\bar{L}$, then it follows that

$$
y\left(L^{T}\left(s^{*}\right), s^{*}\right)<F^{\prime}\left(s^{*}\right),
$$

as otherwise, the left-hand-side in Eq. (0A.30) would be greater than zero. 
$L_{1}^{T}\left(s^{*}\right)$ is implicitly given by the indifference condition

$$
\int_{0}^{1}\left(1-\alpha-\beta+s^{*}\right) \hat{y}\left(L^{T}\left(s^{*}\right), s^{*}, z\right)-F\left(s^{*}\right) d z=0
$$

where

$$
\hat{y}(L, s, z) \equiv \frac{L-z F(s)}{1-z(1-\alpha+s)}
$$

$\frac{\partial \hat{y}(L, s, z)}{\partial z}\left(L^{T}\left(s^{*}\right), s^{*},.\right)$ has the sign of $\left(1-\alpha+s^{*}\right) L^{T}\left(s^{*}\right)-F\left(s^{*}\right)$ which, from Eq. (13), is strictly positive. It follows that for any $z \in(0,1)$,

$$
\hat{y}\left(L^{T}\left(s^{*}\right), s^{*}, z\right)<\hat{y}\left(L^{T}\left(s^{*}\right), s^{*}, 1\right)=y\left(L^{T}\left(s^{*}\right), s^{*}\right)<F^{\prime}\left(s^{*}\right)
$$

where the last inequality just repeats Eq. (0A.31).

Next, for any $z \in(0,1), \frac{\partial \hat{y}(L, s, z)}{\partial s}\left(L^{T}\left(s^{*}\right), s^{*},.\right)$ has the sign of $y\left(L^{T}\left(s^{*}\right), s^{*}, z\right)-F^{\prime}\left(s^{*}\right)$ which, from Eq. (0A.34), is strictly negative.

Finally, total differentiation of the indifference condition in Eq. (0A.32) with respect to $s^{*}$ yields

$$
\begin{aligned}
& \int_{0}^{1} \hat{y}\left(L^{T}\left(s^{*}\right), s^{*}, z\right)-F^{\prime}\left(s^{*}\right) d z \\
& +\int_{0}^{1}\left(1-\alpha-\beta+s^{*}\right) \frac{\partial \hat{y}(L, s, z)}{\partial s}\left(L^{T}\left(s^{*}\right), s^{*}, .\right) d z \\
& +\int_{0}^{1}\left(1-\alpha-\beta+s^{*}\right) \frac{\partial \hat{y}(L, s, z)}{\partial L}\left(L^{T}\left(s^{*}\right), s^{*}, .\right) \frac{\partial L^{T}\left(s^{*}\right)}{\partial s^{*}} d z=0 .
\end{aligned}
$$

Eq. (0A.34) implies that the first line of this equation is strictly negative. We have shown OA.12 
$\frac{\partial \hat{y}(L, s, z)}{\partial s}\left(L^{T}\left(s^{*}\right), s^{*},.\right)<0$ for any $z \in(0,1)$ which implies that the second line is also negative. Finally $\frac{\partial \hat{y}(L, s, z)}{\partial L}\left(L^{T}\left(s^{*}\right), s^{*},.\right)>0$ for any $z \in(0,1)$. Therefore $\frac{\partial L^{T}\left(s^{*}\right)}{\partial s^{*}}>0$.

Consider now the case in which $L_{0}<L^{T}\left(s^{*}\right)$. The local necessary equilibrium condition in Eq. (0A.29) writes

$$
\frac{\bar{L}-L^{T}\left(s^{*}\right)}{\bar{L}}\left[\frac{y\left(L^{T}\left(s^{*}\right), s^{*}\right)+y\left(\bar{L}, s^{*}\right)}{2}-F^{\prime}\left(s^{*}\right)\right]=0 .
$$

Since $y\left(L, s^{*}\right)$ is increasing in $L$, and $L^{T}\left(s^{*}\right)<\bar{L}$, then it follows that

$$
y\left(L^{T}\left(s^{*}\right), s^{*}\right)<F^{\prime}\left(s^{*}\right),
$$

$L^{T}\left(s^{*}\right)$ is implicitly given by the indifference condition

$$
\int_{0}^{1}\left(1-\alpha-\beta+s^{*}\right) \hat{y}\left(L^{T}\left(s^{*}\right), s^{*}, z\right)-F\left(s^{*}\right) d z=0
$$

and identical derivations to the ones in the first case, shows that $\frac{\partial L^{T}\left(s^{*}\right)}{\partial s^{*}}>0$. This completes the proof of Lemma 0A.1. Q.E.D.

The social planner's objective function for a given $L_{0}$ writes

$$
\begin{aligned}
W\left(s, L_{0}\right)= & 1_{\left\{L_{0} \geq L^{T}(s)\right\}}\left((1-\alpha-\beta+s) \frac{L_{0}-F(s)}{\alpha-s}-F(s)\right)+ \\
& +\theta \int_{\left.\min \left\{L^{T}(s), \bar{L}\right\}\right)}^{\bar{L}}(1-\alpha-\beta+s) \frac{L_{1}-F(s)}{\alpha-s}-F(s) d L_{1},
\end{aligned}
$$


and hence, the optimization problem writes

$$
s^{O p t} \in \arg \max _{S} W\left(s, L_{0}\right)
$$

Since at the optimum $L^{T}(s)<\bar{L}$, the first derivative writes:

- For $L_{0}>L^{T}(s)$ and for $L_{0}=L^{T}(s)$ when $L^{T}(s) \rightarrow L_{0}^{+}$:

$$
\begin{aligned}
& \frac{L_{0}-F(s)}{\alpha-s}-F^{\prime}(s)+(1-\alpha-\beta+s) \frac{\partial}{\partial s}\left(\frac{L_{0}-F(s)}{\alpha-s}\right) \\
& +\theta \int_{L^{T}(s)}^{\bar{L}} \frac{L_{1}-F(s)}{\alpha-s}-F^{\prime}(s) d L_{1}+\theta(1-\alpha-\beta+s) \int_{L^{T}(s)}^{\bar{L}} \frac{\partial}{\partial s}\left(\frac{L_{1}-F(s)}{\alpha-s}\right) d L_{1} \\
& -\theta\left[(1-\alpha-\beta+s) \frac{L^{T}(s)-F(s)}{\alpha-s}-F(s)\right] \frac{\partial L^{T}(s)}{\partial s} .
\end{aligned}
$$

- For $L_{0}<L^{T}(s)$ and for $L_{0}=L^{T}(s)$ when $L^{T}(s) \rightarrow L_{0}^{-}$:

$$
\begin{aligned}
& \theta \int_{L^{T}(s)}^{\bar{L}} \frac{L_{1}-F(s)}{\alpha-s}-F^{\prime}(s) d L_{1}+\theta(1-\alpha-\beta+s) \int_{L^{T}(s)}^{\bar{L}} \frac{\partial}{\partial s}\left(\frac{L_{1}-F(s)}{\alpha-s}\right) d L_{1} \\
& -\theta\left[(1-\alpha-\beta+s) \frac{L^{T}(s)-F(s)}{\alpha-s}-F(s)\right] \frac{\partial L^{T}(s)}{\partial s} .
\end{aligned}
$$

Case 1: $L_{0}>L^{T}\left(s^{*}\right)$. We can write Eq. (0A.41) as 


$$
\begin{aligned}
& \frac{1-\beta}{\alpha-s}\left[\frac{L_{0}-F(s)}{\alpha-s}-F^{\prime}(s)+\theta \int_{L^{T}(s)}^{\bar{L}} \frac{L_{1}-F(s)}{\alpha-s}-F^{\prime}(s) d L_{1}\right] \\
& -\theta\left[(1-\alpha-\beta+s) \frac{L^{T}(s)-F(s)}{\alpha-s}-F(s)\right] \frac{\partial L^{T}(s)}{\partial s}
\end{aligned}
$$

Using Eq. (0A.28), Eq. (0A.43) evaluated at $s^{*}$ writes:

$$
-\theta\left[\left(1-\alpha-\beta+s^{*}\right) \frac{L^{T}\left(s^{*}\right)-F\left(s^{*}\right)}{\alpha-s^{*}}-F\left(s^{*}\right)\right] \frac{\partial L^{T}\left(s^{*}\right)}{\partial s^{*}}
$$

Since at the operating threshold (i.e., at $L=L^{T}(s)$ ) firms make a strictly positive profit,

$$
(1-\alpha-\beta+s) \frac{L^{T}(s)-F(s)}{\alpha-s}-F(s)>0
$$

for any $s$, and using Lemma 0A.1 (i.e., $\frac{\partial L^{T}\left(s^{*}\right)}{\partial s}>0$ ), it follows that the first derivative in Eq. (0A.41) is strictly negative at $s=s^{*}$, that is, a marginal decrease in $s$ around $s^{*}$ increases welfare.

Case 2: $L_{0}<L^{T}\left(s^{*}\right)$. We can write Eq. (0A.42) as

$$
\begin{aligned}
& \theta \frac{1-\beta}{\alpha-s} \int_{L^{T}(s)}^{\bar{L}} \frac{L_{1}-F(s)}{\alpha-s}-F^{\prime}(s) d L_{1} \\
& -\theta\left[(1-\alpha-\beta+s) \frac{L^{T}(s)-F(s)}{\alpha-s}-F(s)\right] \frac{\partial L^{T}(s)}{\partial s} .
\end{aligned}
$$


Using Eq. (0A.29), Eq. (0A.46) evaluated at $s^{*}$ writes,

$$
-\theta\left[\left(1-\alpha-\beta+s^{*}\right) \frac{L^{T}\left(s^{*}\right)-F\left(s^{*}\right)}{\alpha-s^{*}}-F\left(s^{*}\right)\right] \frac{\partial L^{T}\left(s^{*}\right)}{\partial s^{*}}
$$

for any $s$, and using Lemma 0A.1 (i.e., $\frac{\partial L^{T}\left(s^{*}\right)}{\partial s}>0$ ), it follows that the first derivative in Eq. (0A.42) is strictly negative at $s=s^{*}$, that is, a marginal decrease in $s$ around $s^{*}$ increases welfare.

Case 3: $L_{0}=L^{T}\left(s^{*}\right)$. The social welfare function is not continuos at $L_{0}=L^{T}\left(s^{*}\right)$ as an increase in $s$ beyond $s^{*}$ leads monopolists not to produce at $t=0$. Consider first the case in which $L_{0} \rightarrow L^{T}(s)^{+}$. Using Eq. (0A.28), Eq. (0A.41) evaluated at $s^{*}$ writes as in Eq. (0A.44):

$$
-\theta\left[\left(1-\alpha-\beta+s^{*}\right) \frac{L^{T}\left(s^{*}\right)-F\left(s^{*}\right)}{\alpha-s^{*}}-F\left(s^{*}\right)\right] \frac{\partial L^{T}\left(s^{*}\right)}{\partial s}
$$

Since at the operating threshold (i.e., at $L=L^{T}(s)$ ) firms make a strictly positive profit,

$$
(1-\alpha-\beta+s) \frac{L^{T}(s)-F(s)}{\alpha-s}-F(s)>0
$$

for any $s$, and using Lemma 0A.1 (i.e., $\frac{\partial L^{T}\left(s^{*}\right)}{\partial s}>0$ ), it follows the first derivative for $L_{0}=L^{T}\left(s^{*}\right)$ when $L^{T}(s) \rightarrow L^{T}\left(s^{*}\right)^{+}$(that is, when $s \rightarrow s^{*-}$ since $\left.\frac{\partial L^{T}\left(s^{*}\right)}{\partial s}>0\right)$ is negative, that is, a marginal decrease in $s$ around $s^{*}$ from below increases welfare.

Consider now the case in which $L_{0} \rightarrow L^{T}(s)^{-}$(that is, in which $s \rightarrow s^{*+}$ ). Since $L^{T}\left(s^{*}\right)$ is increasing in $s^{*}$ (Lemma 0A.1) and since monopolists make strictly positive profits at the 
threshold, $L=L^{T}\left(s^{*}\right)$, it follows there is a discrete increase in the welfare function at $s^{*}$ when $s$ approaches $s^{*}$ from above and monopolists start producing at $t=0$, that is,

$$
\lim _{s \rightarrow s^{*+}} W\left(s, L^{T}(s)\right)<W\left(s^{*}, L^{T}\left(s^{*}\right)\right)
$$

Therefore, an increase in operating leverage beyond $s^{*}$ decreases welfare in an interval $\left(s^{*}, s^{*}+\delta\right)$ for some $\delta>0$. In summary, at $L_{0}=L^{T}\left(s^{*}\right)$, a decrease in $s^{*}$ increases welfare and an increase in $s^{*}$ decreases welfare. Q.E.D. 